Portland State University

PDXScholar

Dissertations and Theses

Dissertations and Theses

Winter 3-15-2013

\title{
War's Visual Discourse: A Content Analysis of Iraq War Imagery
}

Mary Elizabeth Major

Portland State University

Follow this and additional works at: https://pdxscholar.library.pdx.edu/open_access_etds

Part of the Critical and Cultural Studies Commons, Journalism Studies Commons, Mass Communication Commons, and the Social Influence and Political Communication Commons Let us know how access to this document benefits you.

\section{Recommended Citation}

Major, Mary Elizabeth, "War's Visual Discourse: A Content Analysis of Iraq War Imagery" (2013).

Dissertations and Theses. Paper 572.

https://doi.org/10.15760/etd.572

This Thesis is brought to you for free and open access. It has been accepted for inclusion in Dissertations and Theses by an authorized administrator of PDXScholar. Please contact us if we can make this document more accessible: pdxscholar@pdx.edu. 
War's Visual Discourse: A Content Analysis of Iraq War Imagery

\author{
by \\ Mary Elizabeth Major
}

A thesis submitted in partial fulfillment of the requirements for the degree of

\title{
Master of Science \\ in \\ Communication
}

\section{Thesis Committee:}

L. David Ritchie, Chair

Cynthia-Lou Coleman

Leslie Rill

\section{Portland State University}

2013 
(C) 2012 Mary Elizabeth Major 


\begin{abstract}
This study reports the findings of a systematic visual content analysis of 356 randomly sampled images published about the Iraq War in Time, Newsweek, and U.S. News and World Report from 2003-2009. In comparison to a 1995 Gulf War study, published images in all three newsmagazines continued to be U.S.-centric, with the highest content frequencies reflected in the categories U.S. troops on combat patrol, Iraqi civilians, and U.S. political leaders respectively. These content categories do not resemble the results of the Gulf War study in which armaments garnered the largest share of the images with $23 \%$.

This study concludes that embedding photojournalists, in addition to media economics, governance, and the media-organizational culture, restricted an accurate representation of the Iraq War and its consequences. Embedding allowed more access to both troops and civilians than the journalistic pool system of the Gulf War, which stationed the majority of journalists in Saudi Arabia and allowed only a few journalists into Iraq with the understanding they would share information. However, the perceived opportunity by journalists to more thoroughly cover the war through the policy of embedding was not realized to the extent they had hoped for. The embed protocols acted more as an indirect form of censorship.
\end{abstract}




\section{Dedication}

This project is dedicated to my parents Tom and Joy Major, who instilled in me an intense curiosity about the world and without whose support my education would have been much more difficult—and long. It is also dedicated to my brother, Dr. Peter F.

Major, who thankfully returned from Vietnam, and whose help and guidance in understanding the complexities of serving in the military were very much appreciated. 


\section{Acknowledgements}

Thank you to my professors in the communication and philosophy departments of Portland State University for their help during this research. Of particular note are Dr. L. David Ritchie and Dr. Cynthia Coleman of the Communication Department who helped with theoretical and methodological questions and from whom I have had the fortune to take a majority of my coursework at Portland State University. I would also like to thank Dr. Tom Seppalainen of the Portland State University Philosophy Department whose discussion of my philosophical treatment of photography and objectivity ultimately led to the selection of this topic for my thesis.

I appreciate the time commitment from Valrie Dyhouse, M.S., and Molly Swisher who both offered to code my data, a process that was interesting to them, but also more time consuming than any of us anticipated. Thank you also to my nephew, Dr. Ken Major, and my friend, Gary Rogowski, for proof-reading sections of the final draft despite their own very busy schedules. 


\section{Table of Contents}

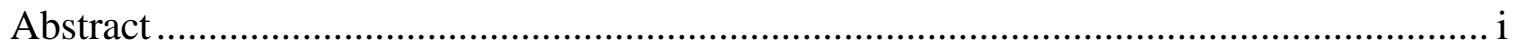

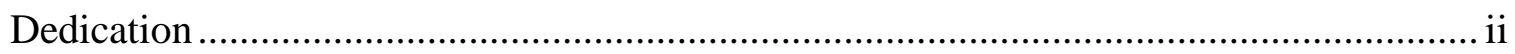

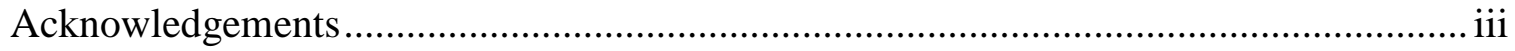

List of Tables ................................................................................................. vii

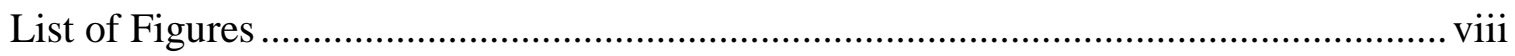

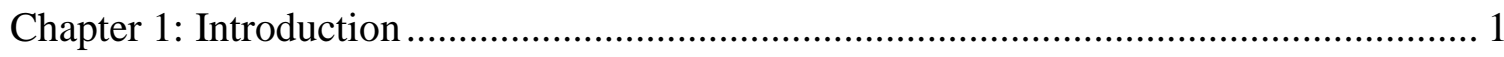

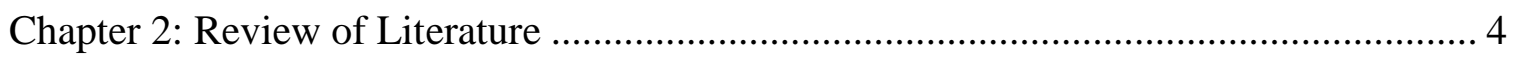

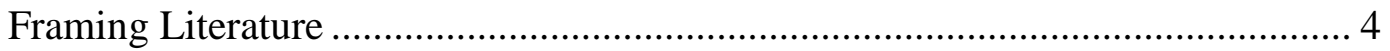

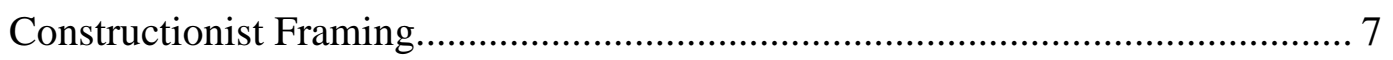

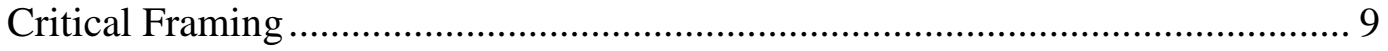

War and the Media................................................................................ 10

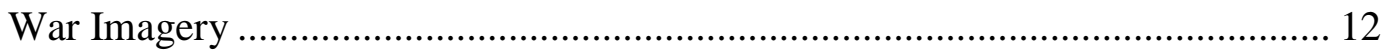

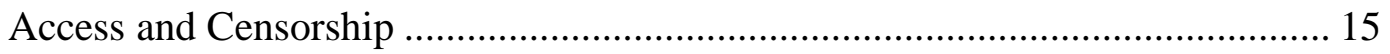

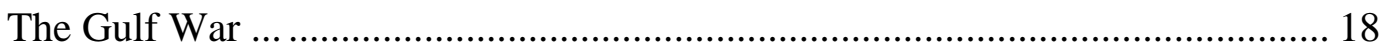

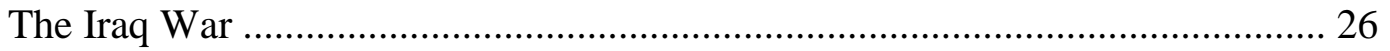

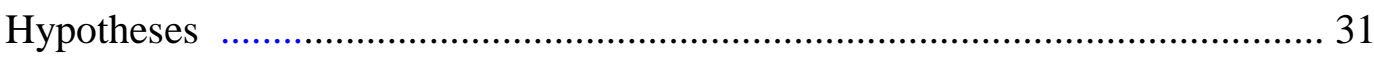

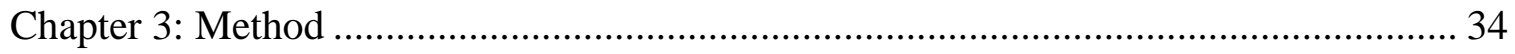

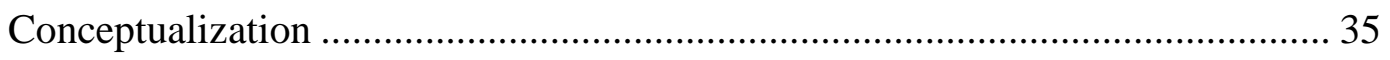

Coding Scheme, Codebook, and Coding Sheet ........................................... 38

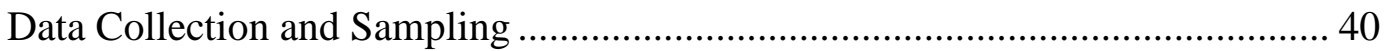




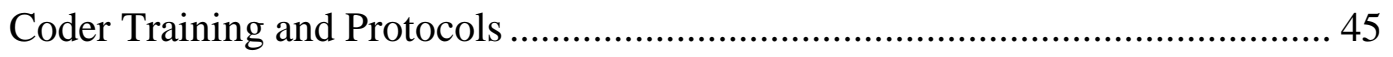

Emergent Categories .......................................................................... 47

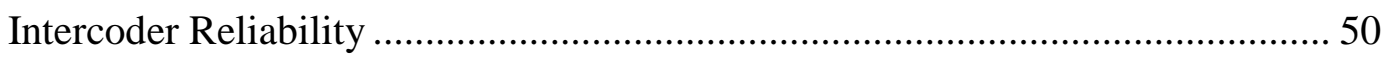

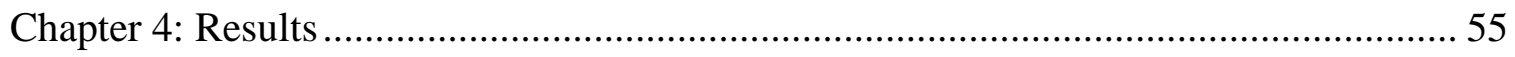

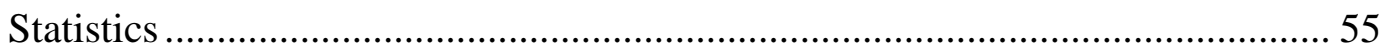

High Frequency Categories...................................................................... 56

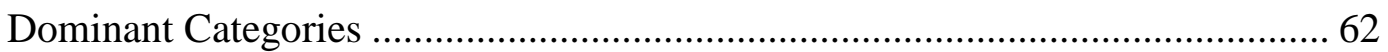

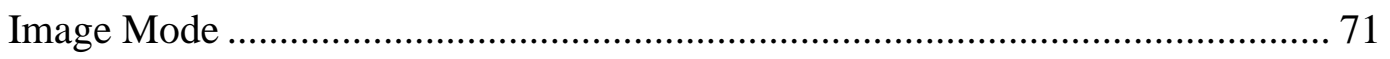

Archival images.. ....................................................................... 71

Staged and posed images......................................................... 72

Grisly images...................................................................... 73

Infographics. ....................................................................... 74

Weighting Images by Size ................................................................. 74

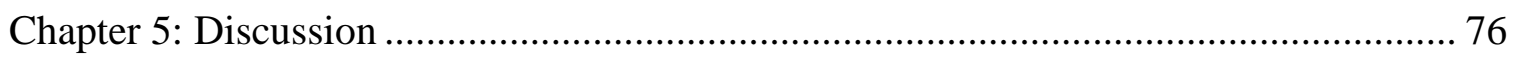

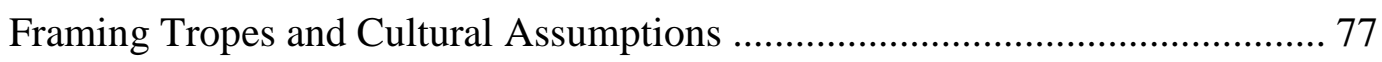

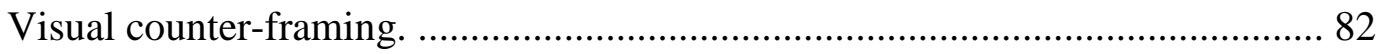

Visual counter-framing of text. .................................................. 82

Visual counter-framing of cultural commitments.............................. 85

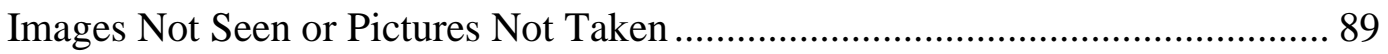

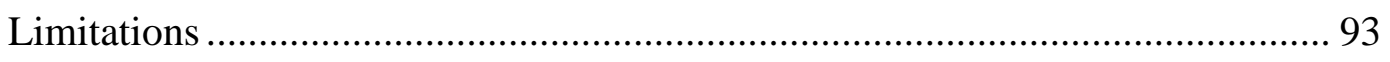

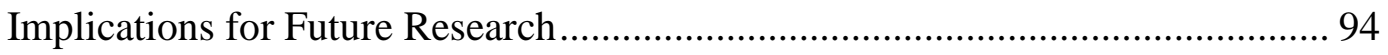




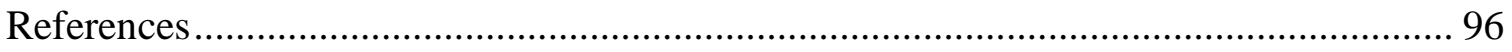

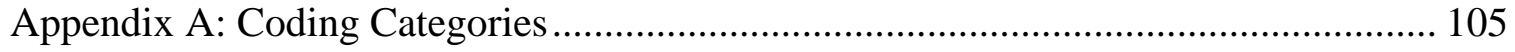

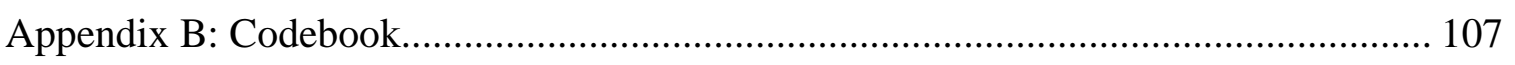

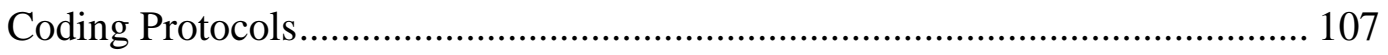

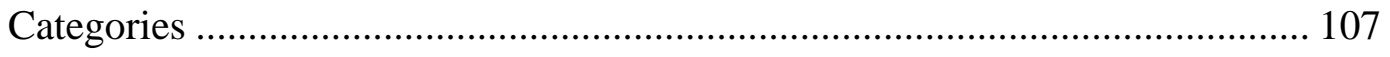

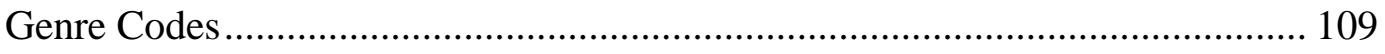

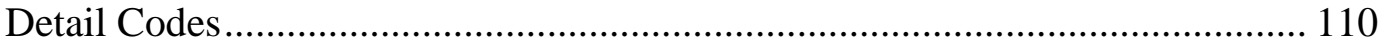

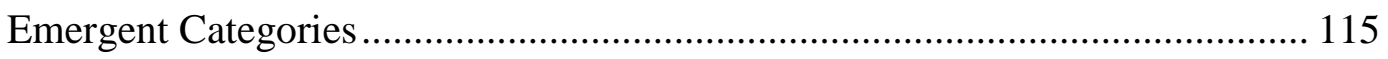

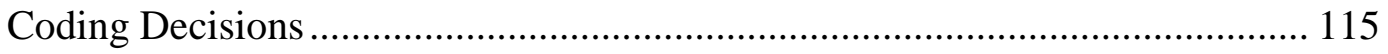

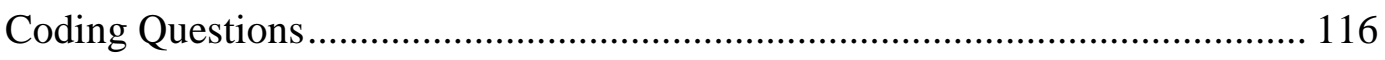

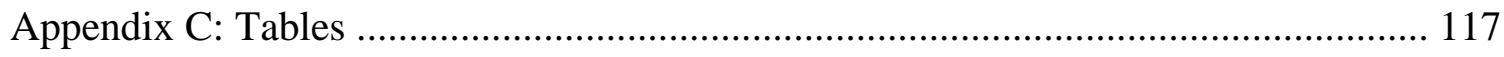

Table 3 - Intercoder Agreement per Category using Cohen's Kappa ............... 117

Table 4 - Statistical Significance of Iraq War Categories ............................. 119

Table 5 - High Frequency Categories in Gulf War Pictures ........................... 126

Table 6 - Low Frequency Categories in Gulf War Pictures ........................... 127 


\section{List of Tables}

Table

$1 \quad$ High Frequency Categories in Iraq War Pictures................................57

2 Low Frequency Categories in Iraq War Pictures................................71 


\section{List of Figures}

Figure

Page

1 Samuel Aranda (photographer), The New York Times, World Press

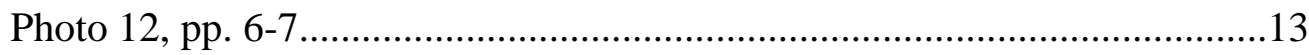

2 Yuri Kozyrev (photographer), in Time 161(16), 4.21.03, pp. 38-39. ............13

3 Yuri Kozyrev (photographer), in Time 168(21), 11.20.06, p. 45. .................52

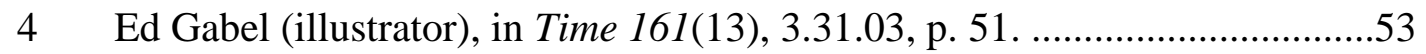

$5 \quad$ Yuri Kozyrev (photographer), in Time 161(15), 4.14.03, pp. 52-53. ............61

6 Wathig Khusaie (photographer), Getty Images, in Newsweek 144(13), 9.27.04, pp. 32-33.

7 Robert Nickelsberg (photographer), Getty Images, in Time 162(25), 12.22.03, pp. 80-81.

8 James Nachtwey (photographer), VII in Time 162(26), 12.29.03, pp. 44-45.

9 Photographer unknown, U.S. News and World Report 135(4), 8.11.03, p. 18.

10 Gary Knight (photographer), in Newsweek 143(1), 1.5.04, pp. 34-35.

11 Todd Heisler (photographer), Rocky Mountain News in Time 166(21), 11.21.05, pp. 42-43.

12 Northrup Grumman-Landor, in Newsweek 151(23), 6.9.08, pp. 24-25. .66

13 Photographer unknown, AP in Washington Post, in U.S. News \& World Report 136(17), 5.17.04, p. 28. 
14 Lucian Read (photographer), WPN in Newsweek 147(24), 6.12.06, pp. 22-23.

15 Wathiq Khuzaie (photographer), Getty Images, in Newsweek 148(23), 12.4.06, p. 29 .

16 Mike Segar (photographer), Reuters, in Time 161(7), 3.17.03, p. 26.

17 Damir Sagofj (photographer), Reuters, in U.S. News \& World Report 135(23), 1.5.04, pp. 28-29.

18 Gary Knight (photographer), Newsweek 143/1, 1.5.04, p. 37. .84

19 Yuri Kozyrev (photographer), in Time 169(16), 4.16.07, p. 28. .86 


\section{Chapter 1: Introduction}

A critique is not a matter of saying that things are not right as they are. It is a matter of pointing out on what kinds of assumptions, what kinds of familiar, unchallenged, unconsidered modes of thought the practices that we accept rest.

Michel Foucault (1981)

It seems almost perverse to have a personal fascination with war photography. I have a certain guilt associated with viewing images of humans in extremis. Even the Latin is a way to distance myself from what I do, which is actually to look at photographs of the maimed and dead, the displaced, the abandoned as well as the rubble and human cost of war. There is something about the representations of war and what I feel is missing, that must be there beyond the camera's view that draws me in. It might simply be the question of how we continue to believe that war can be an honorable endeavor, particularly when we see and are aware of our own culpability in the perpetration of its life-altering pain and suffering. My brother served during the Vietnam War and I was distraught at the thought he might be killed and I would never see him again. There are many families that have experienced the heartache and fear and also the pride of having a family member enlist or be drafted. Stories of war, movies about war, and photographs of war depict acts of heroism as a defining war experience, yet soldiers themselves claim they do not feel like "heroes." Stories of the special camaraderie of fellow servicemen and women that is never surpassed outside the military are common. Over the years I have come to understand that conflating war and heroism is a mistake. Heroism, acts of courage, and bravery are certainly present during wartime, but they are not only 
experiences of war. Heroism is part of a narrative surrounding war that serves a purpose for a stakeholder. Much more realistic, or holistic, is a representation of war as a cost to the environment and all beings_-and heroism is a spandrel, or byproduct, of a desperate situation. I suspect there are other cultural narratives in our depictions of war for which the photograph acts as proof or evidence. In this sense photographs do not represent "war" per se, but rather are selected to represent our myths about war or our narrative interests. The term "war" has become an indexical attribution of meaning, a process of bracketing an event and separating it from its context so that in future references to the event, the "meaning" that was originally derived from the event "becomes" the event instead of a part of a complex series of interrelated events. This points to a practice of contemporary journalism to report episodically without a broader causal anchoring (Iyengar, 1991). In this way, the indexicalization of events become evidence of the meaning of war, thus conflating causal and indexing processes (Tuchman, 1978).

It is all the more important to recognize and deepen the understanding of the human cost of war when what is represented in the media does not frame it as a human endeavor, but focuses instead on the technological innovations and means of war or textual and visual tropes about war that have been culturally anchored in the war narrative. In a study of the 1991 Gulf War, Griffin and Lee (1995) found that $23 \%$ of pictorial coverage focused on weapons systems and technology. This was a significant change from previous wars, and one that literally replaced the percentage of imagery traditionally dedicated to warfare with images of "American military technology and 
power" (Griffin \& Lee, 1995, p. 817). I replicated and extended Griffin and Lee's content analysis of Gulf War images by performing a content analysis of images representing the Iraq War. The study was conducted in two stages. First, the content analysis of manifest content of media images was coded, and the results of the coding were compared with the original study to see whether the predominance of armament coverage discovered by Griffin and Lee continued for the Iraq War. Second, the content frequencies that emerged from the content analysis were interpreted as a discursive archive of a journalistic institution (Rose, 2001, p. 164), a visual culture particular to that institution's structure and procedures with implications for our contemporary understanding of war.

First, I review the literature on framing, and war and the media in particular, situating my study as an empirical study replicating and extending the 1995 Gulf War study conducted by Griffin and Lee. I detail the methodology and results of Griffin and Lee's study, and the implications suggested by the resultant findings. I then discuss how I collected and coded the images of the Iraq War, how I analyzed the resultant data set, and discuss the implications of the results. 


\section{Chapter 2: Review of Literature}

The first things we see when we read an article are the images related to the story. Eye-tracking studies suggest that the most dominant photograph on a page is the point at which attention is directed first, with visually salient and larger photographs leading a reader into a story (Olk \& Kappas, 2011; Smith, 2005). Images have the power to draw us into the story and in conjunction with the headlines and captions help to frame how we interpret and make meaning of the subject matter. Because photographs lack formal propositional syntax, that anchors an image to only one particular meaning (Borah, 2009), images can be persuasive rhetorical tools in support of many different texts and in activating cultural schemata (Newton, 2001; Perlmutter, 1998). Therefore war photography is not a transparent medium, it is a moment in time onto which meaning is constructed or vested. Framing is a practice through which meaning can be assigned to a photograph through text, and also a methodology through which photography can be analyzed for meaning construction.

\section{Framing Literature}

Framing theory and framing research have developed over the past decade by reflexively defining and refining what framing is as a communication theory and methodological approach (Tannen, 1993). Researchers have yet to agree on how to define and research framing. Some confusion stems from the inability to agree on a consistent vocabulary and the resultant ambiguity in a term's meaning, and part of the confusion seems to stem from a shift in level of analysis—-from meta-analyses to individual case 
studies. Framing as a research theory is also conflated with framing as a methodology. It seems clear from the multiple models proposed that it is a concept that is still being defined. According to Entman (1993), to "frame" is to:

Select some aspects of a perceived reality and make [it] more salient in a communicating test, in such a way as to promote a particular problem definition, causal interpretation, moral evaluation, and/or treatment recommendation for the item described. (p. 52)

As a general definition upon which to expand, a frame includes structures, processes, intentions, and goals that contribute to the construction of a frame. Framing research attempts to make those elements and mechanisms transparent by examining: how frames are sponsored by political actors (Andsager, 2000; Coleman, Hartley \& Kennamer, 2006; Snow, Rochford, Worden, \& Benford, 1986); how media processes construct and constrain media frames (Cook, 1983; Iyengar, 1991; Mintz \& Redd, 2004; Molotch \& Lester, 1975); and how publics are affected by a frame in their interpretation and decision-making (Entman, 1993; Gamson, 1992; Price, Tewksbury \& Powers, 1997; Scheufele, 2004; Tversky \& Kahneman, 1981).

D'Angelo (2002) suggests that there are some general assumptions about framing that most media scholars accept: (a) that media frames amalgamate text and image with a framing device of contextualization that is either episodic or thematic (Iyengar, 1991); or (b) that a mass media frame involves conflict, human interest, or consequences. Framing is a term used to describe the processes of meaning-making by media and other social and political organizations through the selection, omission, and construction of 
communicating messages for the purpose of influencing an individual's perception of an event or issue. Whether a particular frame is consciously constructed for rhetorical purposes, or emerges unconsciously as a reflection of cultural values, framing operates in complex ways. Framing research seeks to make the structure and processes of frame construction transparent, because much of the power of a frame is in its ability to escape detection by the public it influences. A useful way to think about framing is in the manner that D'Angelo (2002) outlines in his meta-analysis of framing research. D'Angelo (2002) classified types of framing research into three paradigms that reflect specific researchers' attitudes and beliefs toward how frames are constructed and how the effects are exhibited. These distinct research paradigms examine evidence in text and images in specific ways, which he names the constructionist, the critical, and the cognitive framing paradigms (D’Angelo, 2002, pp. 876-878). Scholars agree on four basic goals for framing research, but may disagree on how and why a frame is generated and what constitutes measurable effects. The four primary goals are: (a) to identify thematic units called frames which are based on the content of the text or image being investigated; (b) to investigate the antecedent conditions that produce frames which may exist as unquestioned cultural assumptions; (c) to examine the effects of news frames by analyzing how news frames interact with established schemata on an individual and social level; and (d) to examine how news frames shape public debate and social processes (D’Angelo, 2002, p. 873). 


\section{Constructionist Framing}

Gamson and Modigliani (1989) claim that journalists process information by creating "interpretive packages" that reflect the interests of different sources invested in the message. Further, they conceptualize process and structure as distinct from content and its effects on publics. They place framing with a constructionist framework, which generates a frame's interpretive package through "the use of metaphor, catchphrases, visual images, moral appeals and other symbolic devices that characterize the discourse" (Gamson \& Modigliani, 1989, p. 2). An interpretive package makes sense of events and gives meaning to them by indicating what is at stake.

Fundamental to the production of interpretive packages is whether the theme is deeply embedded within the culture as an organizing theme, how interest-bearers (Molotch \& Lester, 1975) or sponsors (Gamson \& Modigliani, 1989) promote the interpretive package, and how media practices influence the dissemination through frequency of coverage, news values such as conflict, human interest and consequence reporting (Neuman, Just, \& Crigler, 1992). Gamson and Modigliani (1989) suggest that the most successful interpretive packages over time are those that can assimilate new events into schemata or constructs already operating within the culture-something that resonates within the cultural psyche of a nation and is then used as an organizing theme. Many organizing constructs are embedded in the American cultural discourse, some of which are modeled as two opposing sides of a dialectic such as the technological progress versus nature construct, or the personal freedom versus social dependence construct. This 
"shared public vocabulary" (Andsager, 2000, p. 578) enables a frame and occasionally a plurality of frames to compete for dominance on an issue (Coleman, Hartley, \&

Kennamer, 2006). In addition, part of the framing process involves ascribing causal consequences to the frame or the opposing frames (Snow et al., 1986).

Constructionist researchers believe that journalistic frames are of practical use to a public needing to form opinions and make decisions about issues of the day (D'Angelo, 2002, p. 877). However, researchers using this interpretive model also assume that journalists limit the range of information due to a journalistic convention that privileges official sources, such as the government, as the most knowledgeable. The dominance of a frame in the media is therefore influenced by a stakeholder's access to media (Carragee \& Roefs, 2004), frequency of coverage, emotional valence of the message, and the absence of contextualization through additional stakeholders' frames (Andsager, 2000; Coleman et al., 2006; Cook et al., 1983; Molotch \& Lester, 1975). This study assumes a constructionist theoretical perspective influenced by news routines and processing so that the reality constructed by the media is weighted in favor of certain meaning constructions and not others. For example, framing has a boundary setting function. One instance related to the first Gulf War showed that spokespersons for U.S. policy were successful in limiting the choice of frame options to a retributive frame necessitating punishment despite antiwar protester's attempts to expand the available frames to other forms of redress, namely reparation or negotiation (Lakoff, 1996; Pan \& Kosicki, 2001). The defining or framing function serves to activate journalistic norms and conventions of 
interpretation that are both shared and recognizable by readers (Pan \& Kosicki, 2001; Zelizer, 2004). It sets up a shared "discursive community by differentiating actors, actions and action settings to 'act out' its discursive and sociological binding" (Pan \& Kosicki, 2001, p. 42).

\section{Critical Framing}

The critical paradigm as defined by D'Angelo (2002) also has some theoretical insight when considering news frame creation. Carragee and Roefs (2004) examine what components of a frame influence public attitudes. It is their contention that it is not only frame content, but also in whose interests content is constructed that bears examination. Stakeholder processes that get reported in the media tend to be dominated by those entities with the most access to the media. This process is separate from the construction of the frame, yet greatly influences what is reported. In general, stakeholders-whether from political elites or grass-roots social movements (Snow et al., 1980)—attempt to claim an ideological perspective through a process of deflecting resistance to a frame. The process includes strategies to incorporate or weaken alternate perspectives, and a constant delimiting, defending, and modification of, a frame (Carragee \& Roefs, 2004).

Likewise, scholars who work within the critical and constructionist paradigms "claim that frames are the outcome of newsgathering routines by which journalists convey information about issues and events from the perspective of values held by politician and economic elites" (D'Angelo, 2002, p. 876). Framing practices that omit other information in order to support a narrow description of what is at issue bypass 
alternative frames and possibly alternative stakeholders (Coleman et al., 2006). A frame constructs a particular meaning and specific way of analyzing possible entailments while ignoring others. It seeks to gain adherents through aligning certain values and beliefs within a particular frame's definition. Very often these values and beliefs represent the most powerful stakeholders because they are the ones that have survived and succeeded in developing a shared public vocabulary. In studying the framing process as a result of a "meaning war" (Carragee \& Roefs, 2004, p. 222) between stakeholders, researchers can trace and make transparent the "relationship between news and the distribution of power in American society" (p. 222). Carragee and Roefs (2004) insist that studies on framing have neglected political power as a sponsoring source for frames, leading to an absence of transparency regarding the influence of powerful sources. Thus, contrary to other framing paradigms, the authors do not believe that frames can be simply explored as a "content feature" (Carragee \& Roefs, 2004, p. 225) that produce media effects, but must also question in whose interests those effects are to be produced.

\section{War and the Media}

Culler (1997) suggests that meaning is created through a wide variety of discursive practices within a culture (p. 5), practices that include textual and symbolic language, historical assumptions and practices, and discourse through which meaning is continually negotiated. In this study therefore, with the topic of war, images are part of a series of cultural discursive practices that extend beyond a simple definition of war as a state of armed conflict between different nations or states, but include social and cultural 
practices, war mythologies, and conceptual assumptions about war that have persisted over time and define the boundaries of war as a narrative (Culler, 1997). Particularly in media depictions of war, where photographs are primarily used to illustrate text, and occasionally provide the story themselves, a study of visual imagery, usually thought to document and provide information about war might echo a representational social discourse about war rather than photojournalistic evidence of the particular war itself (Culler, 1997; Zelizer, 2004).

Because the nature of photography is to frame and frames exclude, the manifest content of a photograph, and its reproduction and proliferation, becomes important evidence of how this discourse is shaped (Griffin \& Lee, 1995; Sontag, 2002; Tankard, 2001). Frames can be manifest in visual documents such as films, political posters, recruiting materials, and photographic representations of war. The study of war imagery can reveal how the media pictures war and can also reveal gaps in manifest content that historically were part of the war discourse and may have disappeared, thus making visual studies of war an important component to the study of how war is represented overall, and how war coverage changes over time (Reese \& Lewis, 2009).

The scholarly literature studying war and how the media have contributed to a war discourse consists of two types of investigation: (a) commentary and criticism with deep assumptions of institutional mechanisms and processes from both a political and media perspective; and (b) empirical research studying how recent wars are framed both textually and visually in comparison to past wars and conflicts. As exemplified by studies 
on the Gulf War by Hallin and Gitlin (1993) and the Iraq War by King and Lester (2005), and Fahmy and Johnson (2005), studies are performed on a limited period of time or important isolated events of a war (Fahmy \& Kim, 2008). Few, if any, studies bridge the textual/visual divide, offering an analysis that covers both image and text over an extended period of time.

Many of the empirical studies compare media coverage of current wars to those of previous wars, noting changes in information technology as well as media production values and processes that influence, in the case of imagery, what is made visible to the public. Factors affecting production values could include decisions regarding the amount of time and money to dedicate to a certain issue and the prominence it holds for the public. Within this literature, media scholars examine how media coverage of war is framed and through what processes that framing is accomplished (Gowing, 2003; Thussu, 2003; Weber, 2003). My study aligns itself within the tradition of war studies focusing on a comparison of pictorial coverage during the Gulf War to subsequent changes in coverage during the war in Iraq and how the imagery helped to frame the Iraq War in 2003.

\section{War Imagery}

War imagery is intimately connected to war photographers. As Tim Page, a war photographer, says in an interview, "Every good war picture becomes an anti-war picture. You are not making anti-war statements, but the fact that you have made a good war picture means that it becomes an anti-war statement" (Tee, 2011). War photography, like 
all great news photography, captures a moment in time that is symbolic, surprising, memorable, dramatic, and aesthetically appealing (Nöth, 2011; Zelizer, 2004).

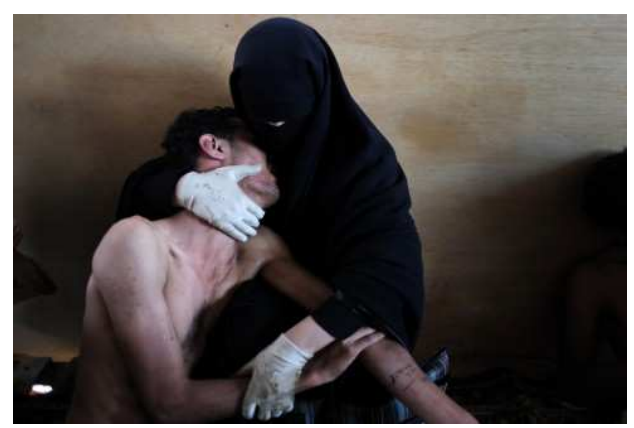

Figure 1. Samuel Aranda (photographer), The New York Times, World Press Photo 12, pp. 6-7.

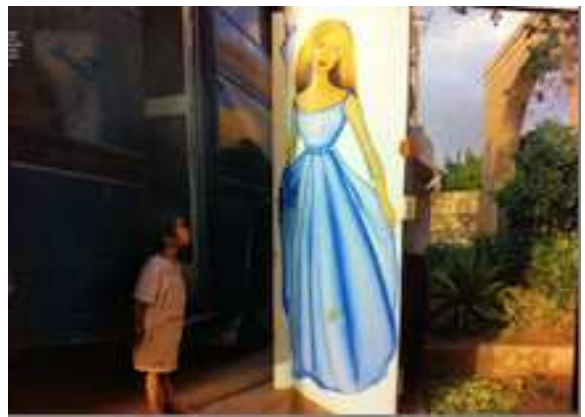

Figure 2. Yuri Kozyrev (photographer), in Time 161(16) 4.21.03, pp. 38-39.

The above prize-winning photographs exhibit many of the qualities of great news photography. The photograph on the left by photojournalist Samuel Aranda pictures Fatima al-Qaws cradling her son, Zayed, in Yemen after he succumbed to tear gas during a protest against the Saleh government. The posture is reminiscent of Christian representations of the pieta. The use of the posture emphasizes a symbolic cultural theme to dramatically illustrate the universality of a grieving mother whether Christian or Muslim. Through this conjunction it becomes a great photograph (Figure 1). The photograph on the right, was a 2003 World Press Photo winner by photographer, Yuri Kozyrev. The juxtaposition of the little boy looking at the image of an American Barbie painted on a wardrobe door symbolizes the military and cultural invasion taking place at the time of the photo (Figure 2). At first glance the photo is charming, while expressing a 
memorable and cynical perspective of the war. However, inclusion of war images into news coverage is not only about memorable and prize-winning photographs. Particularly in newsmagazines that now include access to online compendiums of photographs attached to an article, coverage is aggregated, with a series of photographs grouped to complete a story, or offer aspects of a particular event, such as a battle, or multiple details concerning an issue such as the legal and moral arguments surrounding the use of torture.

The reason that images can be the subject matter of social science is that they can reveal basic underlying, and very often unconscious, assumptions or paradigms from which we operate (Wagner, 2011). Those assumptions will leak out into our symbolic forms, such as photography, to create meaning (Thompson, 1990). The power and robust nature of photography to appeal to the emotions is the result of parallel features of photography as both a denotative and connotative vehicle of meaning. Within journalism, its denotative function seems to take precedence with its ability to depict the world "realistically" and the requisite association to truth-values, representation, and indexicality. However, it is impossible to disentangle connotative functions from denotative functions of photography, as photographs simultaneously tap into symbolic language associated with universality and generalizability (Hall, 1974; Sekula, 1984 in Zelizer, 2004, p. 117).

Media use of imagery increases significantly during wartime, and, after September 11, 2001, sometimes doubled in newspapers and newsmagazines. This trend continued with the Gulf War in 1991, the war in Afghanistan in 2002, and the Iraq War in 
2003 (Zelizer, 2004). This trend toward the visual is enhanced by online repositories of images to expand what is available in the printed versions of newspapers and newsmagazines. However, this does not necessarily indicate that more topical information about a war is being made available to publics, because many of the photographs represent familiar tropes without specific information that would contextualize the photographs to thematic reference points of the war (Zelizer, 2004, p. 121).

\section{Access and Censorship}

The military has required and the media has complied with censorship protocols regarding publication of photographs of American dead during most wars in which the U.S. has been involved. The U.S. had been at war for 21 months in WWII before images of dead soldiers appeared in print. The strict censorship of WWI was relaxed during WWII and photographers were allowed onto the battlefield. They could photograph what, when, and how they wanted. However, those photographs were censored both in the field and again in Washington before release. At the beginning of the war, the delays in publication could be as long as 4 months, but after the invasion of Normandy, the Allies were winning and publication was swift despite military censorship (Kobré, 2008, p. 447). Photographs of dead or mutilated soldiers were placed in a secret Pentagon file called the "Chamber of Horrors" (Kobré, 2008, p. 446). Censors were worried that if Americans saw pictures of the dead, that they would press for compromise settlements with Germany and Japan. However, later in the war, when the government felt that the 
American public had become too complacent due to all the reporting of Allied victories, they did release some of these photographs.

There were opposing viewpoints to censorship—-that withholding photographs was treating the public like children, or the view that too much photography of war was unhealthy for the viewer. Interestingly, "the censors held back any pictures showing racial conflicts at American bases, and other visual evidence of disunity or disorder" (Kobré, 2008, p. 446). Following the surrender of Hitler, photographers were present with the troops at the opening of concentration camps throughout Europe. Many members of the public did not believe the written reports of the scenes of mass graves and emaciated corpses encountered in the camps. Once the photographs were published however, the public was shocked at the extent of the annihilation of targeted groups such as Jews, homosexuals, and gypsies (Kobré, 2008, p. 447).

During the Korean War, General MacArthur allowed photographers to selfcensor, until American forces began to retreat. At that point he imposed full and absolute military censorship. However, even before full censorship, only $5 \%$ of the self-censored photographs included combat photos. This percentage is far lower that the $22 \%$ combat photos that were published during the war in Vietnam, and the $24 \%$ that showed brief glimpses of American dead and wounded (Hallin, 1986, p. 129). A more developed system of accreditation of journalists combined with no military censorship was a new development during Vietnam. Correspondents and photojournalists were given the freedom to report, photograph, and transmit anything they wanted aside from sensitive 
strategic military operations, troop movements, and body counts. The press exercised self-censorship more often than the military enforced it by withdrawing accreditation. A more subtle form of censorship was exercised through the dependence of reporters for transportation by military helicopters through the jungle (Moeller, 1989, p. 361).

Although photographs of the dead and wounded on both sides were taken, relatively little reached the American public despite lack of military censorship at the time. Exceptions did occur as in a critical and shocking report by Morley Safer in 1965 that filmed the destruction of the Vietnamese village Cam Ne by American marines. But this was by no means the rule. To the consternation of reporters and photojournalists, a substantial amount of "news management" (Moeller, 1989, p. 363) was attempted by the government and practiced by media organizations alike.

It has been claimed that the relative freedom of photojournalists during the Vietnam War and the subsequent negative response by American audiences to graphic images of war was responsible for the American pullout from Vietnam. Media scholars deny that claim (Griffin, 1995, 2004, 2010; Hallin, 1986), and suggest that visual images may have an impact of their own, but it is more likely that publics were explicitly told what they were seeing (Hallin, 1986; Sontag, 1973, 2003). Although many other wars have occurred during the Cold War era (1945-1991), and post Cold War (1991-2001) era, the First Gulf War and subsequent post 9/11 wars in Afghanistan and Iraq garner the most interest from mass media scholars. 


\section{The Gulf War}

During the Gulf War (August 1990-February 1991) media coverage of the conflict was heavily censored by the military. Most coverage was reported based on briefings organized by the military. A small group of journalists was allowed access to individual soldiers, but only if they were accompanied by an officer and subject to prior approval and subsequent editing. General coverage was accomplished through the pool system, with a small number of journalists allowed into Iraq, sharing photographs and reports while the majority of journalists were stationed in Saudi Arabia. This level of censorship was a significant change from coverage during the Vietnam War when U.S. military censorship was practically nonexistent (Moeller, 1989, p. 363). Despite this censorship, coverage during the commencement of coalition hostilities recurred in a twenty-four hour per day, seven days a week news cycle of the Cable News Network (CNN). CNN broadcast uninterrupted visuals related to the war repeating the same images over and over again, and later referred to as "techno-imagery" (Griffin \& Lee, 1995, p. 83).

The Gulf War differentiates itself in another way from previous wars in that it was the first war following the Vietnam War to have been fought with a professional U.S. military as opposed to one comprised of both professional soldiers and draftees, as were WWI, WWII, Korea, and Vietnam wars. The death count of coalition troops during the Gulf War in 1991 was relatively low compared to other wars, including the later Iraq War of 2003. The low body count was most probably due to the short period of conflict in 
which the coalition troops were involved in the Gulf War (January 17, 1991- February 28, 1991). Civilian deaths are notably higher than military deaths in all wars. The Project on Defense Alternatives estimates that the ratio of Iraqi combatant and noncombatant deaths during the first three months of the Gulf War compared to the first three months of the Iraq War were almost indistinguishable despite being fought with completely different goals in mind. The proximate goal of the Gulf War was to expel the invading Iraqi military from Kuwait, and that of the Iraq War was to effect regime change (Conetta, 2003). U.S. Department of Defense statistics for total U.S. military deaths attributed to the Iraq War is 4,409, with 31,924 wounded as of May 4, 2012 (U.S. Dept. of Defense, 2012). The U.S. Department of Defense does not provide casualty figures for Iraqi combatants or noncombatants. Tentative figures of violent deaths of noncombatants compiled from verifiable death records by a nonprofit U.K./U.S. organization is estimated to be about 116,000 as of January 2012 . These figures are significantly lower than previous wars such as World War II (CBS, 2005) and Vietnam (Hirschman, Preston, \& Loi, 1995) that had civilian fatalities in the millions.

Particularly with military wounded, the survival rate increases as medical technologies enable medical personnel to save lives that earlier would have certainly been added to the lists of the deceased. This leads to military personnel with enduring traumas such as amputations or traumatic brain injuries. Still, the statistics for the U.S. military wounded in action does not approach the statistics from the previous wars, with U.S. 
wounded in Vietnam reaching above 153,000 compared to the 32,000 of the Iraq War (U.S. Department of Defense, 2012).

Griffin and Lee (1995) questioned whether the perception of the Gulf War as a war witnessed first-hand was indeed reflected in the images used to represent the war. They were spurred by earlier studies of the Vietnam War that belied popular perceptions of the Vietnam War as a "living room war," during which combat was covered in the field, documenting the human cost of war. Those studies, including the later comprehensive study by Hallin (1986) showed that contrary to popular opinion, the coverage was remarkably restrained given the lack of censorship (p. 131). The same question motivated Griffin and Lee to ask a similar question about the Gulf War, namely, whether what was popularly considered to be a war that the public witnessed first-hand on television, was reflected in the images the public saw. Their content analysis of three news magazines revealed that contrary to popular opinion and claims by $\mathrm{CNN}$ that the coverage was "live," only the initial days of the war provided "live" coverage after which coverage "reproduced traditional patterns of war imagery much like those ... in high school history textbooks" (Griffin \& Lee, 1995, p. 821). Griffin and Lee (1995) quote Perlmutter's visual study of high school textbooks in which photographs are described as predominantly U.S. centered and focused on action. Perlmutter also found that the action shots were either staged or inauthentic and that editors avoided images depicting death, injury, or implied death such as funerals (Griffin \& Lee, 1995; Perlmutter, 1992). 
One of the concerns expressed by Griffin and Lee (1995) was whether the public was seeing images taken in the field. Were the published photographs depictions of actual events as they were happening, or did they tend to be symbolic representations of nations, cultural attitudes, and military power? If the photos depicted on-the-scene events of specific places and events occurring in the Gulf, then Griffin and Lee (1995) believed that the media were doing their job. However, if the images were symbolic representations of war, then media were not providing timely information, and coverage could not be thought of as a reliable record of the war. Symbolic representations are typically thought to support enduring symbolic concepts—in this case those related to the Middle East, Arab culture, military power, and the presidency (Griffin \& Lee, 1995; Pan, Ostman, Moy, \& Reynolds, 1994). Likewise, assessing the frequencies of on-site combat photographs could confirm complaints from journalists about "military censorship and limited access to war zones" (Griffin \& Lee, 1995, p. 815) by comparing it to journalistic access and censorship during other wars.

Another concern of Griffin and Lee's was to respond to complaints the media promoted the Gulf War. Therefore, in some of their categories they tried to capture how often Allied troops were depicted, and whether and in what ways Iraq's forces were depicted. Finally, with the example of the Vietnam War, Griffin and Lee wanted to see if coverage would include evidence of the discourse surrounding a war such as images of civilian casualties, damage and destruction, and depictions of antiwar demonstrations (Griffin \& Lee, 1995). 
The content analysis results showed that 6 out of the final 36 categories accounted for more than half of the 1,104 images coded. The largest image genre in each individual news magazine consisted of images of military hardware, such as photographs or illustrations of planes, ships, tanks, missiles, and weapon guidance systems. These images were stand-alone photographs, illustrations, and schematics—some reproduced from arms catalogues or provided by the Department of Defense or arms manufacturers. They did not include images in which the armaments were part of the image content for a combat photograph, which were coded as the combat genre. For every photograph of direct combat ( $3 \%$ of the total), there were nine images of the American military arsenal. The original category included subdivisions that would include armaments from all Allied countries and the opposition. However, the coverage focused overwhelmingly on American armaments and military capability (Griffin \& Lee, 1995).

The second most frequent category consisted of photographs of troops, and included American, Allied, and Iraqi troops in noncombat situations. Griffin and Lee (1995) made an assumption that the public would be seeing images from both American and Allied troops, because President George H.W. Bush's response to Iraq's invasion of Kuwait was based on U.N. resolutions and a multinational coalition of troops. The complete category comprised $14 \%$ of the total photographs coded. However, within that $14 \%$, U.S. troops were pictured $95 \%$ of the time, Allied (Saudi, Kuwait) soldiers and pilots comprised $2 \%$ of the total, and 3\% pictured Iraqi soldiers. Two aspects of this coverage are noteworthy. First, that the second most frequent category is comprised of 
behind the scene photographs of troops, many taken before the war in preparation for combat and virtually replacing coverage of soldiers in combat, typical of previous war coverage. Second, reportage shows an overwhelming dominance of coverage of U.S. troops to the exclusion of Allied troops and with a total of five photographs of Iraqi troops.

The third most frequent category of coverage included Western political (7\%) and military leaders (5\%) comprising $12 \%$ of the total coverage. Again, the coverage was predominantly U.S. centered. Photographs of Iraqi political leaders (4\%) were comprised almost exclusively of photographs of Saddam Hussein in an equal amount to photographs of George H.W. Bush. Photographs of Bush and Hussein were often positioned opposite one another on one page or a double page spread facing each other as if the conflict was a personal confrontation between two leaders (Griffin \& Lee, 1995; Hallin \& Gitlin, 1993). Coverage of American political and military leaders was more varied, including congressional leaders and various military commanders. However, Saddam Hussein was the exclusive representative of Iraqi political and military leaders except for one picture of Tariq Aziz, Iraq's Prime Minister. There were no Iraqi military leaders pictured at all (Griffin \& Lee, 1995, p. 118).

The categories "military armaments," "unengaged troops," and "political and military leaders" comprised 57\% of the image genres in Time, Newsweek and US News and World Report. They were the top three image genres across news magazines and within each news magazine. According to Griffin and Lee (1995), this coverage 
emphasized U.S. firepower by cataloging the arsenal with an overwhelming 249 images compared to 40 images of Iraqi weaponry. This coverage also focused predominantly on noncombat troops (158 images) with 38 pictures of U.S. troops in combat. In contrast, there are only five pictures of Iraqi soldiers, which leave them literally and metaphorically unseen. When the enemy is reduced to a stereotype, they are metaphorically unseen because the images "reinforce prevailing news narratives rather than contribute independent or unique visual information" (Griffin, 2005, p. 399). Photographs that present a more nuanced image of the "enemy" are available of course, but they are not used within the discourse about war. The predominance of images of U.S. political and military leaders, contrasted with a visually ill-defined enemy, or visually defined through one image of Saddam Hussein, sets up a conceptual juxtaposition of a plural U.S. society fighting against a monolithic state with one single dictatorial enemy (Griffin \& Lee, 1995, p. 818).

Griffin and Lee (1995) argue that the content analysis identified elements of the Gulf War that remained invisible and therefore did not become part of the discourse of war. Much of that information is revealed in the gaps between coverage of previous wars and coverage of the Gulf War. The most obvious gap is the replacement of images of combat with images related to U.S. armaments. Equally, the lack of portrayals of the human cost of war, whether it is casualties, deaths, or damage and destruction has the effect of distancing the viewer from the consequences of war. This is in no way unusual in the Western tradition of war iconography (Perlmutter, 1992). However, this distancing 
has political and cultural consequences, promoting an inaccurate and sanitized version of war's reality. Scholars, journalists, and philosophers have commented about the implications of an inaccurate understanding of war and its consequences. Hallin and Gitlin (1993) point out that war typically has a "narrative logic full of suspense, crescendos, and collective emotion" (p. 422), which lends itself to myth making. The idealized and romantic mythologies associated with World War II gave way to a more ambiguous and controversial set of mythologies after the war in Vietnam and those myths are reflected in movies made about those conflicts (Hallin \& Gitlin, 1993). Ott, Aoki and Dickinson (2011) suggest that framing weapons as "mechanical innovations—as objects of scientific inquiry whose history can ... be chronicled in a detached and disinterested way" (p. 219) distances the viewer from the consequences and purpose of a weapon. This corresponds with the types of images Griffin and Lee (1995) found catalogued in their content analysis: photographs, illustrations, and schematics, some reproduced from arms catalogues (p. 816).

Zelizer (2010) offers another way to view the preponderance of armaments in the news magazine as images that presume death, such as pictures of the bombing of Hiroshima and Nagasaki on August 6th and 9th, 1945, which only show a mushroom cloud, but no death. The public saw the first images of Hiroshima and Nagasaki on August 11th. At the time, the connection between the image of a mushroom cloud and the loss of human life was unclear to a public for whom this was a new experience. Death was presumed, but there was no previous reference point to serve as an example of the 
possible level of death and destruction. Therefore, during a period when the discourse about nuclear armaments was developing, ambiguous images of a mushroom cloud “disconnected the event from its impact" (Zelizer, 2010, p. 88). Likewise, images of technological warfare, and armaments such as electronic targeting devices, imply death without having to show actual images or assign agency to the destruction. It is left to the imagination of the viewer to create a visual narrative. In this way, "images of presumed death ... provide multiple levels of distancing from the depiction of death itself" (Zelizer, 2010, p. 77).

\section{The Iraq War}

Data from a content analysis cannot definitively assign meaning to the numbers, but they can point out differences or gaps in coverage over time, and thus the changing discourse and its possible implications. Griffin and Lee's (1995) content analysis data empirically demonstrate what other visual communication scholars mean when they refer to the potential of images and the power of their repetition or absence to shape a discourse of war.

According to several media scholars, one of the most prevalent factors defining U.S. media coverage of war in the post $9 / 11$ period is the policy of embedding journalists with the military (Fahmy \& Johnson, 2005; King \& Lester, 2005; Kuypers \& Cooper, 2005). Following complaints about access to combat zones during the Gulf War, the military developed a policy of embedding journalists with the troops. With the new policy of embedding during the Iraq War, the sheer scale of embedded journalists was 
unprecedented, with numbers above 600 at the onset of hostilities (Pfau, Haigh, Gettle, Donnelly, Scott, Warr, \& Wittenberg, 2005).

Embedding is defined by the military as "a media representative remaining with a unit on an extended basis" to "facilitate in-depth coverage of U.S. forces in combat and related operations" (Pfau et al., 2005, p. 74). According to empirical studies of media coverage of the Iraq War by Pfau et al. (2005) and Fahmy and Johnson (2005), the embed policy produced reporting that showed deep, rich coverage of individual combat units, but was limited in its ability to contextualize to the broader goals or effectiveness of the war. Journalists received the same training as the soldiers with whom they were being embedded, and then were embedded for long periods of time, sometimes up to 6 months, with a particular unit. The authors believe that the dependence on the military for food, shelter, and protection, as well as the inevitable identification with the military forces, tended to weight the reporting to a promilitary perspective (Pfau et al., 2005). Journalists also occasionally used the first-person in narratives about developments of combat units, placing themselves into the frame of the conflict, writing, "we took some casualties," or "we won that battle" (Gardner, 2008, p. 113). Fahmy and Johnson (2005) interviewed journalists about the purported promilitary perspective. The journalists interviewed reported that they balanced their awareness of a possible promilitary perspective with a belief that the unprecedented access and detail afforded by embedding overrode any concerns that their coverage jeopardized their ability to submit "accurate, trustworthy, and fair" (Fahmy \& Johnson, 2005, p. 311) stories. In fact, the journalists believed that 
non-embedded journalists could editorially offset any such subjectivity with a different "slice" (Fahmy \& Johnson, 2005, p. 307) of the conflict, such as reports on refugees, civilians, or perceptions not favorable to the U.S. military. Although the policy of embedding did not exist during the Gulf War (Griffin, personal communication, July 15, 2011), analysis offering different accounts of the war did not materialize in the visual material published of the Gulf War. Less than .5\% of the total photographs pictured civilians in any context (Griffin \& Lee, 1995).

Embedding provides access to troops and military commanders, without a formal censorship apparatus that would release photographs only after they had been viewed and approved by military censors. However, the embed policy itself functioned as a loose censorship apparatus restricting what could and could not be reported and punishing violations by withdrawing permission to embed. The embedding contract restricted photographing identifiable servicemen/women on all sides of the conflict that had been killed or wounded, and also restricted photographing landscape and urban markers, that would identify zones of military preparation. From the military point of view, the embed policy safeguarded against "disinformation and distortion" (Public Affairs Guidance, document unclassified, SECDEF MSG, DTG 172200Z JAN 03) and tried to balance media access with operational security. From a journalistic standpoint, embedding was a reprieve from the pool system of the Gulf War, but provided challenges to traditional journalistic values for war reporting. In a conflict zone, journalists are typically required to be responsive to immediate events as they occur, yet remain safe, to contribute reliable 
and sound information while remaining open to gaps in truth-claims from varying sources, to be dispassionate about conflicts with more than one side and the strategies that motivate them while remaining passionate about the erosion of human dignity, and to be compassionate about human suffering (Allen \& Zelizer, 2004). Not only does the military want to balance access and operational security, but journalists want to balance their ideal values with access and a minimum of censorship when covering war. When those interests do not align, a struggle to control what gets pictured ensues. The result of the struggle between the embed rules and control of the military message with traditional journalistic values to inform the public converge in the media product that reaches the public.

If we talk about images as cultural artifacts and readable like a text, or subtext as Culler (2004) does, we can posit that images have discursive effects just as conventional texts do because images live in our memory in a way that text does not (Newton, 2001; Sontag, 2002). Images have added symbolic value when they become iconic representations and are utilized to culturally define a war (Perlmutter, 1998). Therefore, not only can images be analyzed by their manifest content and pictorial genre, but also by the cumulative and priming effects of repeated exposure to the same type of image (Newton, 2001). Early evaluations of the Gulf War as "nintendo warfare" or "technoimagery" seem to be confirmed by Griffin and Lee's (1995) study. However, the question remains whether the Gulf War discourse represents an accurate depiction of the war itself or simply a symbolic representation of U.S. military power. Cultural attitudes about 
photographs that equate them with knowledge, truth, and evidence (Neuman, Just, \& Crigler, 1992; Sontag, 2002) still pervade the literature despite proof to the contrary, or whether photographs warrant the assumption of evidence granted them. When Saddam Hussein's statue was toppled during the Iraq War, Griffin (2005) found that the photographs served as a priming motif for news narratives. The news magazines carried numerous shots of the toppling, which served as "visible symbols of Baathist collapse and American success" (Griffin, 2005, p. 398). Griffin (2005) argues that in the end it doesn't matter that later evidence from Reuters and AFP revealed that these events had been staged because "the mythic story served by these photos in American newsmagazines and on American television, had already become the accepted symbol of 'liberation' and 'victory”' (p. 398). Major and Perlmutter (2005) argue that news organizations are expected to contextualize what is being reported and pictured. In this particular example, the media showed cropped, close up frames of the event. However, only wide-angled shots would have been able to inform the audience of what was actually taking place in Firdos Square. This example illustrates the ability of a photograph to be used both to symbolize and to provide evidence, while lacking the warrant to do either. In the literature, few comprehensive empirical studies have been completed on visual materials of the Iraq war to date. Keith, Schwalbe, and Silcock (2010) suggest that a multimodal content analysis of visual material would involve methodological difficulties due to the variety of media platforms involved in bringing images to the public: television, film, print newspapers, magazines, and electronic media. Consumers 
read each mode of presentation in ways particular to the medium, requiring a complex cross-modality methodology. Thus, single mode media analyses provide the most effective way of accumulating data on the use of visual materials in media coverage. As such, a replication of an empirical content analysis of Gulf War imagery extended to the Iraq War makes a vital contribution to the overall analysis of war as a constructed discursive media practice and process.

\section{Hypotheses}

Griffin and Lee (1995) showed that the discourse surrounding war had changed markedly from previous wars. It might only indicate that modern warfare itself has changed-that war is now irrevocably tied to technology. It might reflect the effective public relations efforts of the Pentagon and The White House, or it might be a reflection of the level of censorship and the pool system of war coverage. Given the differences in external circumstances of the Gulf War and the Iraq War-access to troops, degree of censorship, and length of the wars-four hypotheses can be stated. First, the media have claimed to have unprecedented access to the theater of war through the policy of embedding journalists with the troops, which was not the case during the Gulf War. If media has had unprecedented access to the troops, then a conflict frame should include a higher frequency of combat photographs as part of the construction of the interpretive package (Entman, 1993) than the images utilized during the Gulf War. The photographic coverage should provide a more complex representation of war in general, and how this particular war was conducted. Therefore the first hypothesis states: 
$\mathrm{H}_{1}$ : The inclusion of visual images in coverage of the Iraq War will feature more photos of combat compared to the amount of combat depicted during the Gulf War.

Similarly, embedding journalists with the troops should provide proximity to civilian populations and therefore an opportunity to cover the effects of the war on civilian populations as stakeholders in the cessation of hostilities. For example, one might expect more images that address the human cost of war not only to combatants on all sides, but also civilian populations affected by the hostilities. The restoration of services disrupted by the war such as basic physical and organizational infrastructures needed for the peaceful operation of the society should be pictured as well as the cost of war on civilian populations. Therefore, the second research hypotheses is:

$\mathrm{H}_{2}$ The inclusion of visual images in coverage of the Iraq War will feature more photos of Iraqi civilians than coverage during the Gulf War.

Likewise, embedding journalists with the troops should provide proximity to the effects of the war on the environment, whether it is an urban or a rural environment. Such damage and destruction could include damage to important cultural and social edifices as well as the destruction of necessary resources for the functioning of the society such as water and oil. Such a framing would strengthen the journalistic value of objectivity and frame the war in a way that included more stakeholders. Therefore the third hypothesis is:

$\mathrm{H}_{3} \quad$ The inclusion of visual images in coverage of the Iraq War will feature more photographic coverage of damage and destruction than coverage during the Gulf War. 
In contrast to the Gulf War study in which catalog-style armament images were used to frame the war, embedding with the troops should either provide images of the results of this increased tendency to use highly technological warfare, instead of the armaments themselves, or decrease the stand-alone armament imagery featured in the Gulf War study. Thus, the fourth hypothesis is:

$\mathrm{H}_{4} \quad$ The visual images in coverage of the Iraq War will feature less coverage of armaments captured in the "cataloging the armaments" category than coverage during the Gulf War.

The results of this study clarify what effect, if any, embedding journalists with the troops had on the subject matter of published war photography. The comparison with the results of Griffin and Lee's study of the Gulf War clarifies the similarities and differences of war coverage between these two wars. 


\section{Chapter 3: Method}

This study replicates and extends a methodology utilized by Griffin and Lee (1995) in their visual content analysis of the Gulf War. Quantitative content analysis is the systematic account and summary of key categories within a particular message set (Neuendorf, 2002). In this study, the message set is war photography. The strength of quantitative content analysis lies in its ability to reduce, simplify, and explicate large amounts of complex media content. It can also track historical changes in modes of representation using frequency analysis (Bock, Isermann, \& Knieper, 2011). Typically mass media content analyses do not provide details of individual images, but measure their general manifest content. More detailed visual content analyses point to specific aspects of a media representation, such as how women or cultural minorities are depicted through clothing or body positioning in communicating texts. Griffin and Lee (1995) used a content analysis to gather data regarding the inclusion or omission of manifest content associated with war generally and the Gulf War specifically. For instance instead of coding for how the president was pictured, behind a podium, a portrait, or at work, Griffin and Lee (1995) simply coded for the presence of a picture of the President regardless of his positioning in relation to other elements within the photograph. In this study, I replicated and ultimately extended their categorization style to analyze representations of the Iraq War. 


\section{Conceptualization}

Griffin and Lee's (1995) categorization criteria were based upon a survey of war coverage from three previous wars: World War II, the Korean War, and the Vietnam War. They employed coding categories distilled using a constant comparative method to include manifest photographic content published during those wars (Griffin \& Lee, 1995, pp. 814-15). Manifest content in a quantitative content analysis is considered content that is visible and quantifiable in the photograph (Neuendorf, 2002). For example, a photograph of a person within the context of the war such as George W. Bush or Saddam Hussein would be coded as present in a political category, while U.S. or Iraq generals would be coded in a military category based on Griffin and Lee's categorization scheme.

Griffin and Lee (1995) defined their unit of measurement as a single photograph or image. Each visual document was supported with reference to the texts accompanying the image as headers or captions. Griffin and Lee (1995) found that an overwhelming majority of the images had a clear focus of content, so that coding for multiple genre categories in one image, and therefore weighting content, was not necessary (Griffin, personal communication, July 15, 2011). The content of the image was considered to be the overriding manifest theme or focal point of the image. As one of the original scholars noted, “. . . we found that the overwhelming majority of pictures had a "clear main focus of content' so that this procedure [coding for prominent manifest content] did not prove problematic" (Griffin, personal communication, July 15, 2011). Additionally, structural aspects of images such as color versus black and white photography and the size of the 
image were tracked for each image. Images were also coded for the degree to which they were contemporaneous with current events, as opposed to those that were posed or staged. Posed photographs usually occurred with portraits of individuals such as the president or major political actors in the Gulf War. These photographs were relatively easy to spot by references to the source of the photo, such as the White House photographer in the case of political actors, or portrait photography taken by a professional photographer before a soldier deployed and used to represent soldiers who had died in combat. In the context of war, staged photographs were considered to be those that captured a sense of a battle through photographs of its reenactment. Historically these photos were accompanied by text indicating that the scene is staged for clarification purposes. There were also some photographs that were originally published and have since been revealed as "fakes" that were originally intended to deceive or give a false impression. One such example is the toppling of a statue of Saddam Hussein in Baghdad's Firdos Square (Fahmy, 2007). The presence of an archival photo was usually indicated in the caption, was obviously taken during a previous war, or was the result of lack of access to the pictured individual, such as Saddam Hussein or Osama bin Laden and was therefore pulled from archival photographs or a screen shot from television.

A photograph or image was eligible for inclusion in this study if it accompanied any article covering the Iraq War from January 1, 2003 through December 31, 2011. These dates were selected to include images used to frame the necessity of the war before the war began, the onset of hostilities, and the proposed end of hostilities and pullout of 
troops in December 2011. There were no exclusions to this rule unless a photograph was duplicated in a cover or title page and then reproduced again within the article itself. If there were duplications, preference was given to the photograph included in the article, which was usually the larger photograph. A protocol for counting the images when multiple images appeared on the same page was to number them in order from top left to right and from top to bottom of the page. If a photograph spanned the fold in the middle of two pages (which happened often), the page number assigned to that photograph was the left-hand page.

I based my coding categories on the original codes identified by Griffin and Lee (1995) in their content analysis of the Gulf War. Their findings during a pilot coding session found that some categories were not useful in detecting prominent content, or that very few pictures related to those categories. Therefore, in their final analysis they collapsed the number of categories, and combined a number of very low count categories into "other." They did retain those low count categories that they thought might be measures of important absences in the pictorial coverage (Griffin, personal communication, July 15, 2011). I base my categories on Griffin and Lee's (1995) original codes allowing the full spectrum of possible coding choices.

Weighting of content was only accounted for through the size of the image, with a cover or two-page spread counting more than a full-page image (or a front cover) counting more than a half page image, which counted more than a quarter page image, and so forth. In visual communication studies, it has been found that the larger the image 
size, the more salience is accorded to the visual content (Bock et al., 2011). Likewise, positioning an image on the front cover of the magazine accords that image relevant status as a defining image of the war. Coding for color or black and white images can inform us about the types of image shown in black and white, perhaps a particularly grisly or archival photograph.

\section{Coding Scheme, Codebook, and Coding Sheet}

The coding scheme included five general categories under which multiple details were possible. The most general category was the genre category, which captured the focal interest of the photograph. Each possible genre had four options which allowed coding for four participating combatants of the Iraq War: the U.S., Allies of the U.S., Iraq, or Other, which might include images associated with non-Allied nations or the U.N. The general genre categories included: political, military, civilian life, damage and destruction, and the emergent category of terrorism.

The genre categories were followed by detail categories that included: people, types of warfare such as combat or behind the lines representations, casualties, and types of damage and destruction. The category of people included political leaders, military leaders, soldiers/troops, POWs, civilians, protesters, and women and children. Armaments, which Griffin and Lee (1995) called "cataloging the arsenal" (p. 816), were divided into separate categories for each type of armament such as jets, helicopters, tanks or Humvees, naval vessels, missiles, and drones. One of the major findings of Griffin and Lee's 1995 study was the prevalence "cataloging the arsenal" images which constituted 
$23 \%$ of the total published. Each type of armament was originally listed separately and only later collapsed into one category called "cataloging the arsenal." Following Griffin and Lee's categorization, my original categorization design maintained their initial category distinctions in order to document the prevalence of certain types of weaponry.

Casualties were also coded to specify wounded or dead individuals who were political, military, or civilian in nature across the four sub-categories of war combatants. Included in this category were representations of death—pictures in which coffins or portraits of fallen soldiers or civilians represented the dead individual. The genre of damage and destruction had detail categories that included general damage to infrastructure—buildings, governmental agencies, housing, mosques, and roads. Other kinds of damage such as sabotage to oil fields or reserves and/or environmental damage such as contamination of water or the destruction of agriculture or animals were also coded for as subcategories of the general genre of damage and destruction.

The codes in the codebook accounted for demographic information about each photograph, which were identified by an identifying number, the name of the publication in which it was published, the volume and issue number, the date of publication, the name of the photographer, the source of the photo (e.g., from the government/military or news agency), whether the photo was black and white or color, the size of the image, and the heading, subhead, and caption accompanying the article and image. The above information is considered the "media context" in visual content analysis and was 
documented by the primary investigator on each individual coding sheet before the coders came into contact with the images.

Each broad coding category, or genre, included smaller subcategories that gave more detail. A photograph was coded for its genre as well as the dominant detail category as the focal point of the photograph. If the photograph or image mode was archival, grisly, posed, or staged, that information was also coded. Most of the possible categories were not abstract concepts that required complex judgments by the coders. They simply required a judgment as to the presence of the category within the manifest content of the image. Most of the categories were nominally coded for the most prominent subject or content of the image, by which prominence was measured by the centrality of the main subject matter within the image, or identification by a reference in the caption.

The coding form provided to the coders was a two-sided single sheet of $8-1 / 2$ " $\mathrm{x}$ 11" paper with the possible codes for each image. The full codebook is included in Appendix A, and an example of the coding form after the emergent codes were included is shown in Appendix B.

\section{Data Collection and Sampling}

I obtained images related to the Iraq War by accessing the physical copies of the three weekly news publications that were utilized by Griffin and Lee (1995). Time Magazine, Newsweek Magazine, and U.S. News and World Report supply weekly compilations of coverage of the Iraq War that "compress, recapitulate, elaborate upon and critique television and newspaper reports of the previous week" (Griffin \& Lee, 1995, p. 
814). At the same time, these newsmagazines had large readerships and subscription bases as well as an online presence with additional visual material available through a website listed at the bottom of the page of an article. As of August 2010, the three top newsmagazines in the U.S. were Time Magazine with a circulation of 3,312,484; Newsweek Magazine with a circulation of 1,610,632; and U.S. News and World Report with a circulation of $1,129,618$. All circulation figures are as reported by the Audit Bureau of Circulation (Huff Post Media, 2011). In addition to circulation numbers, newsmagazines offer the advantage of a "populations of images" (Griffin, 1995, p. 814) to analyze on a weekly basis establishing an historical paradigm of meaning for individual wars.

Portland State University library had physical copies of each periodical for the years in question except 2010 and 2011, which were available at the Multnomah County Library in Portland, Oregon. I documented each photograph that was included in an article about the Iraq War by making a list and numbering each photograph in the order dictated by the numbering protocol, noting the date of publication, and the page number on which the photograph appeared. Because each magazine is published at the end of each week and on the same day, the publication dates for all three news magazines coincided with each other. I decided to use a stratified sampling method because such a sampling "recognizes distinct subpopulations (strata) within a population" (Krippendorff, 2004, p. 115). Each sampling unit belongs to only one stratum, such as the decreasing population of images per year of war coverage, so that sampling for each stratum can be 
conducted separately and can be sampled in their proportion to the census population of images (Krippendorff, 2004). Listing the census of images, which would later determine the stratified sample, was done in repetitive order of Time, then Newsweek, and then U.S. News and World Report so that the images in each of the three news magazines would reflect the same range of dates. The only time this order changed was in 2008 and 2009, when U.S. News and World Report reduced its frequency of publication to twice monthly. The subsequent bimonthly issues of U.S. News and World Report covered 2 weeks of news on Iraq. The original design to number the photographs with the date of publication was maintained through 2008 and 2009.

A stratified sampling method is also sensitive to changes in coverage due to major political and military events or shifts in policy. A sample that is sensitive to the war's trajectory from 2003-2009, including major political and military events, is important to an analysis of war images due to a viewer's ability to withdraw images from any contextual and representational anchoring (Anderson, 1989). Likewise, tracking not just the overall frequencies of manifest content, but also connecting image content frequencies to an historical timeline provided patterns of usage and omission not provided by simple overall frequencies. Included in the sample were images and photographs on the magazine covers as well as the smaller photographs in the content section of the newsmagazine, provided they were not duplicates of images reproduced in the article itself. Further, the decision was made to physically go through each magazine 
after an online search using Communication and Mass Media Complete and the search criteria "Iraq" occasionally yielded articles on Iran.

The photographs and images related to the Iraq War from January 1, 2001 through December 31, 2009 generated a population of $N=4,754$ images. In order to generate a sample size that would give me a 95\% confidence level that a random selection of images would reflect the content of the full population of images with only a 5\% margin of error, I used Creative Research System's online sample size calculator. With a census size of $N=4,754$ as the population of images, the calculator generated a suggested sample size of $n=356$ images. I then used the percentage of photographs per year to generate a random sample for each year of publication using Urbaniak and Pious' (2008) Research Randomizer. Of those images, 1,950 photographs were published about the war in 2003, constituting $41 \%$ of the total population of images; 843 photographs were published in 2004 constituting $17.7 \%$ of the total; 622 photographs were published in 2005 constituting 13\% of the total; 556 photographs were published in 2006 constituting 12\% of the total; 557 were published in 2007 constituting 11.7\% of the total; 144 photographs were published in 2008 constituting $3 \%$ of the total; and 78 photographs were published in 2009 constituting $1.6 \%$ of the total. These percentages indicated that I needed 146 images from 2003, 63 images from 2004, 46 images from 2005, 42 images from 2006, another 42 images from 2007, 11 images from 2008, and 6 images from 2009. These amounts were then used to generate random samples in each year of publication using the 
sequential numbering system I had established when documenting the full population of images.

The numbers generated referred to the number of the photograph to be included in the sample as listed in the complete population of images. I then went to the Portland State University library and looked up each photograph according to the list, which included the publication name, date of publication, issue number, and page number. Using both my iPhone and iPad, I photographed each image that the randomizer had selected in order to digitize the image for the coders to code.

My study includes both photographs and images, such as infographics and maps, from the preparation of troops before the onset of the war, including the dates January 1 , 2003 to the commencement of hostilities on March 20, 2003, and continuing until December 21, 2009. The images published a few months before the Allied invasion of Iraq are considered crucial to how the war was visually framed. Additionally, my intent was to include coverage of the Iraq War until December 2011, when it was announced by President Barack Obama that U.S. troops were returning to the United States. A search for the missing information in 2010 and 2011 revealed that there were approximately 109 additional photographs covering the war during that time period. As a percentage of the full census, this would have included only an additional 8 images, 4 in each year. The Portland State University library had stopped carrying hard copies of the three newsmagazines and other regional university libraries only had the data on microfiche, which would only provide me with a negative photographic image. The one source that 
did carry the physical copies of the magazines, Multnomah County Library, had had the copies concerning the Iraq War stolen. Therefore, out of necessity, the break off date of the study was December 2009.

\section{Coder Training and Protocols}

Two coders volunteered to code the randomly selected sample of $n=110$ images. One coder was a former graduate from Portland State University's Department of Communication with an M.S. in Communication Studies, and the other is an established artist and former graphic designer with The Oregonian newspaper in Portland, Oregon. The coding protocol and codebook gave the coders specific parameters for the operationalization of each category (Appendix A), as well as an overview of the whole project. Thirty-five photographs not included in the codebook examples or in the final thesis sample were selected from the full census for an intercoder reliability pilot test. Intercoder reliability from the first pilot test generated $78 \%$ simple percent agreement across categories. With such a low percent of agreement, further coder training was necessary and I conducted a 4-hour training session with the coders. We reviewed the codebook parameters and systematically went through the previous coding attempt and discussed how the first test sample was coded, refining everyone's understanding of the coding and category definitions, as well as adopting additional codes that clarified and distinguished one category from another. For instance, it became clear that it was difficult to know whether to code pictured veterans as military or civilian. A coding rule was 
agreed upon to create a category for veterans to alleviate this uncertainty and account for the amount of coverage veterans received in the media.

After the second training session, a further test of intercoder reliability was conducted by coding another sample randomly selected from the full population of images. The intercoder reliability on this second test sample generated a $94 \%$ simple percentage agreement and the decision was made to start the final coding of the sample photographs. Reliability coefficients of .90 or greater are acceptable to all, and .80 or greater are acceptable to report. Cohen's Kappa, the method used to calculate the final intercoder reliability in this study, allows more liberal parameters (Neuendorf, 2002, p. 143). During the pilot coding process, coders were instructed to place any manifest content that did not fit the established codes into an "emergent" category and to jot down suggestions for how they would code those photographs. The use of emergent categories to capture content not anticipated, particularly in a content analysis duplicating and extending the methodology of previous research, is a necessity. These emergent category codes were discussed during the second pilot training session and 11 emergent codes were agreed upon and added to a revised codebook and addendum to the coding sheet. The final intercoder reliability coding sample of 110 new images was subsequently coded using the additional emergent categories.

Griffin and Lee (1995) decided to combine some categories during their coding process because maintaining separate categories did not reveal significant information. This process was also justifiable in the current content analysis. Thus, 24 categories were 
collapsed into 5 categories. The category "Cataloging the Arsenal" originally distinguished between different types of armaments for four participating combatants, the U.S., Allied troops, Iraq, and Other. This did not prove to be productive for the study, because the images associated with armaments included many different armaments within one, usually illustrated, infographic. An infographic was counted as one instance of the category instead of counting each illustration of a weapon within the infographic as an instance. This compression of the category still allowed for subsequent individual images of weapons to be counted for each participating combatant provided it was a stand-alone photograph or graphic image. Drones were maintained as a separate category due to the prominence they have received in the press related to ethical, policy, and budget considerations. This is justified by the increased use of drones as a war technology and particularly in as much as the 2013 defense budget proposed an increase in the budget for unmanned aerial vehicles (UAV) or drones (McGreal, 2012).

The coders were given access to the full sample of images they were to code when I placed the randomly selected coding sample of 110 images into Dropbox, an online sharing platform for documents and images. The random sample of 110 images amounted to $30 \%$ of the full sample of $n=356$ images coded for the study. A sample of $20 \%$ would suffice to guarantee reliability and generalizability to a larger population, however, $30 \%$ seemed a more appropriate size for this study in order to capture photographs that included the large set of variables. 


\section{Emergent Categories}

During the two coding pilot tests, 11 additional coding categories were agreed upon and added to both the codebook and the coding sheet. The emergent categories captured content that was either not present in the coverage of previous wars, or were created to clarify existing categories. One category was created to differentiate between photographs of combat in which actual fighting was pictured, and combat patrol.

Patrolling is a form of combat because of the diffuse nature of conflict in modern warfare tending more to smaller patrols, skirmishes, and sniping rather than battle lines and troops facing each other. The anxiety associated with constant vigilance necessary during a patrol justifies coding "patrolling" as a form of combat, but also its differentiation from battles in which direct combat is pictured. The new category, "C-patrol," was included with four dimensions for U.S., Allies, Iraq, and Other combatants.

The original decision to omit "terrorism" as a category was made during the process of documenting the census data. Issues of terrorism were almost exclusively tied in coverage to the war in Afghanistan or to the events of September 11, 2001. However, terrorists and terrorism were tied to Iraq in a few articles justifying additional emergent codes. Consequently, "Terrorism-Iraq" and "Terrorism-Other" were added to the genre category and "Terrorist-Iraq" and "Terrorist-Other" were added as a subcategory of "people." The categories "Terrorism-Other," and "Terrorist-Other" typically depicted terrorists from other countries operating in Iraq and considered to be influencing the fighting. Categories to account for wounded and dead terrorists were also created as 
"Terrorist-Wounded," and “Terrorist-Dead." Likewise, coding Iraqi civilians as terrorists because of their use of terrorist tactics like suicide bombings was decided against in favor of categorizing them as "Civilian Insurgents." This category only appeared during the coding process after the beginning of sectarian violence between Shi'ite and Sunni Muslim factions. A differentiation between Shi'ite insurgents and Sunni insurgents was not made. In a similar vein, two additional codes, "Military Misconduct-U.S." and "Military Misconduct-Iraq," emerged when photographs associated with the Abu Ghraib prisoner abuse, and the beheading of the American journalist, Nicholas Berg could not be accounted for with the original codes. The code "Political Misconduct-U.S." emerged to account for photographs and images related to the outing of Valerie Plame as a CIA operative, and the congressional hearings and grand jury testimony of highly placed U.S. political insiders. The subsequent indictment of Scooter Libby for his part in the disclosure of classified information and the connection to the suppression of evidence that there were no weapons of mass destruction as claimed by the administration was also included in the articles related to the war in Iraq.

When coders questioned whether to code U.S. veterans as military or civilian, the photos were examined and instances of either coding decision could be justified. The decision was made to clarify those decisions with the category of "Veteran-U.S." under the larger military genre category. Similarly, categories of "political dead" and "political wounded" were added after a symbolic photo representing the assassination of an Iraqi politician was part of the sample and could not be meaningfully coded as military or 
civilian dead. The new codes were created to resemble the predetermined codes accounting for all four combatant categories involved in the war.

\section{Intercoder Reliability}

Two coders and myself coded the sample of $n=110$ photographs and images after which each code sheet, for all three coders, was entered into an SPSS spreadsheet with the number " 1 " indicating the presence of a category and the number " 0 " indicating the absence of the category. There were no missing values. Each individual category was entered into an Excel spreadsheet with the coders on the $x$-axis and each case on the $y$ axis. These data were copied and pasted into the online reliability calculator, ReCal3, developed by Deen Freelon (2012). ReCal3 calculates Cohen's Kappa, $\kappa=\left[\left(\underline{A}_{\underline{0}} \underline{P}_{c} \underline{L}-/(1-\right.\right.$ $P_{\mathrm{c}}$ " "where $A_{\mathrm{o}}$ is a proportion of units with matching categories (\% agreement), and $P_{\mathrm{c}}$ is the agreement that can be expected when the two observers' proclivity to use their categories differently is assumed and taken for granted" (Krippendorff, 2008, p. 246). ReCal3 can calculate Cohen's Kappa between three coders, establishing averaged intercoder reliability for each category as well as pairwise agreement between coders. To calculate overall agreement for all categories, I added the agreement for each code and averaged them for a final intercoder reliability of $86 \%$. There were 64 categories that were not included in calculating Cohen's Kappa because they were designated "undefined" by ReCal3. These categories reached 100\% simple percent agreement because the categories were not represented in the coding sample and zeros indicating "absent" were recorded on the code sheets. Expected disagreement on such categories 
cannot be calculated according to Krippendorff (2008) and were therefore omitted from the intercoder reliability calculation.

The categories included in calculating intercoder reliability consisted of 61 categories and yielded an intercoder reliability of 0.856 , with maximum agreement reached in the "Military-Allied," "Behind the lines-Allied" and "Destruction-Other" categories all with 1.0 agreement. The lowest percent agreement occurred in the category of "Political-Allied" probably due to coder uncertainty regarding the status of the U.N. as a neutral party versus an ally of the United States. Systematic divergent coding was evident in the category of "Grisly-U.S." with an overall reliability coefficient of .66. The "grisly" category, as an abstract concept, was used to capture photographs in which soldiers or civilians were shown distressed, wounded, or near death. Any visible evidence of blood also implied a categorization as grisly. However, there were systematic differences between the coders regarding what constituted a grisly photograph, suggesting that the coders coded for latent content instead of manifest content. For example, a photograph of Iraqi women prisoners as shown in Figure 3 was coded by coder \#2 and coder \#3 as grisly, an obvious coding of latent content because the caption indicated that at least one of these women was scheduled to be executed. However, the manifest content of the photograph is not grisly and requires interpretation to be coded thus. 


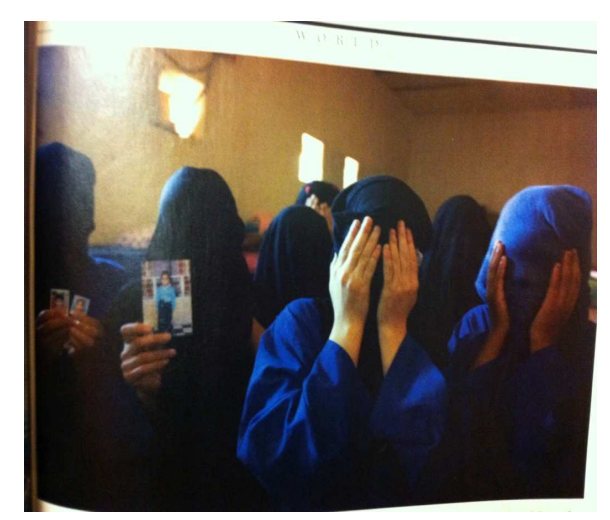

Figure 3. Yuri Kozyrev (photographer), in Time 168(21), 11.20.06, p. 45.

Overall, pairwise intercoder reliability in the genre category showed 0.78 agreement between coder \#1 and coder \#3; 0.82 agreement between coders \#1 and \#2; and 0.72 agreement between coders \#2 and \#3.

The category of media context or mode of an image-whether it was pulled from an archive, was posed by the photographer or event organizer, or was an infographic explaining the political or military terrain-had a low level of intercoder agreement. The overall agreement for the "Mode" category was 0.67 , with pairwise agreement between coder \#1 and coder \#3 at 0.60 ; between coder \#1 and \#2 at 0.71 ; and between coder \#2 and \#3 at .72. Indications of archival images were usually aided by the caption; however, disagreements were usually due to omission, rather than disagreements about the mode.

The category of "People" as a detail category generated a total agreement of 0.87 , with the highest percent agreement occurring in the categories "Political Leader-U.S.," “Military Leader-U.S.," "Soldiers/Troops-Allied," and "Soldiers/Troops-Other," "Veterans-U.S.," "Protesters-Iraq," and "Protesters-Other." These seven categories 
generated $100 \%$ agreement. These all tended to be categories in which the caption identified the individuals within the photograph. Pairwise agreement for the overall category resulted in coder \#1 and \#3 reaching 0.86 agreement, coder \#1 and \#2 with .92 agreement, and coder \#2 and \#3 with 0.82 agreement. The detail codes with the lowest percent agreement were "Civilians-U.S.," and "Political leader-Other." This could be due to failure to code for U.S. civilians if it was felt they were not the focus of the photograph, or in the case of other political leaders, simply not knowing the status of a pictured political leader.

The categories that had the highest percentage of agreement were "Cataloging the Arsenal-U.S.," with an overall agreement of .95, and "Damage and Destruction-U.S.," "Damage and Destruction-Iraq," and "Damage and Destruction-Other" all with 100\% agreement. The mode through which "Cataloging the Arsenal" was represented was almost exclusively in the style of infographics. Each infographic was considered one instance of the category despite having multiple images of armaments within the borders of the infographic as seen in Figure 4.

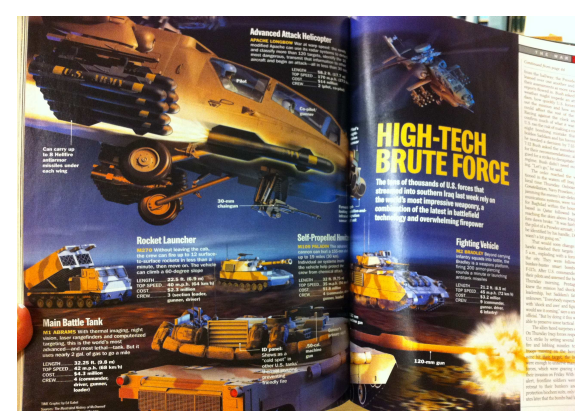

Figure 4. Ed Gabel (illustrator), in Time 161(13), 3.31.03, p. 51. 
The "casualty" category had high agreement in some detail categories and low agreement in others. High agreement was reached in "Political Dead-Iraq," with 1.0 agreement, "Military Dead-U.S.," with .94 agreement, "Military Dead-Iraq" with 1.0 agreement, and "Civilian wounded-Iraq" with .90 agreement. The lowest agreement was with the categories "Civilian Wounded-Other," and "Coffins-Iraq," both with an overall intercoder reliability of .333. For a full comparison and individual tabulations of overall and pairwise intercoder reliabilities see Table 3 in the Appendices.

The emergent category "Military Misconduct-U.S." also had a high level of intercoder reliability with an overall coefficient of .94. Pairwise agreement between coder $\# 1$ and \#3 was .91, between \#1 and \#2 was 1.0, and between \#2 and \#3 was .91. Many of these images were also included in the "Grisly-Iraq" category, which also generated high overall agreement of .94 .

A post hoc review of the categorization scheme of Griffin and Lee's (1995) Gulf War study in which I applied my coding scheme to the census of images used, revealed virtually identical coding with one exception, primarily in the "cataloging the armaments" category. The results of this parallel coding are discussed in the results section. 


\section{Chapter 4: Results}

According to the literature on visual methodologies, "there is no stable point that can provide an entrance into the meaning-making process; all meanings are relational not only within the image, but also in relation to other images and to broader dominant codes, referent systems and mythologies" (Rose, 2006, p. 91). The predominance of one code over another could be said to have "weight" in that its preponderance will act as a cue to cognitive relevance. In this sense categories with high frequencies will become more relevant to the meaning-making functions of news images for a particular war.

\section{Statistics}

The coded data were entered into Statistical Package for Social Sciences (SPSS), a software program that manages large sets of data and facilitates the emergence of patterns through text analytics and statistical analysis. The coded visual content was calculated using simple statistical frequency counts and proportions to see if the hypotheses about changes in the visual categories in Iraq War images were supported by the data and differentiated from the data that predominated in Griffin and Lee's (1995) study of the Gulf War. Typically the relationship between sets of numerical data and their significance cannot be determined simply by counting, therefore percentages and proportions of the sample were added to give more meaning to the numbers. A proportion "reflects the degree to which a particular category dominates the whole" (Riffe, Lacey, \& Fico, 2005, p. 179). The results of the frequency counts have also been compared to those of the Gulf War to see if the changes, if any, are statistically significant in that the 
probability of getting the quantifiable categorization result reflects a pattern beyond chance, or are simply substantively significant, in that the real world effects the results have on the meaning of the findings are considered substantive.

\section{High Frequency Categories}

Six categories captured $90 \%$ of the images. The largest category of photographs and images were of the "Soldiers/Troops-U.S." and constituted 30\% of the sample images with 108 images. This individual category was part of the larger inclusive military category, which captured another $10 \%$ of the images including military leaders, the U.S. arsenal, military misconduct, veterans, and military infographics for an overall genre category capturing $40 \%$ of the image share. Naturally one expects images of combat, troops, military leaders, and weaponry and technology to dominate war imagery. However, the prevalence of images of U.S. military troops to the exclusion of Allied troops, or any Allied involvement is reflected in the low or nonexistent percentages of photographs showing Allied troops or politicians. Particularly America's closest ally, Britain, is noticeably absent in any representations, with only one photograph of Tony Blair in the political category, one of British troops on patrol, and the balance of Allied images consisting of the Peshmerga, a Kurdish allied militia. The second most frequent category was "Civilian Life-Iraq" with 55 images constituting 15\% of the sample images. The third most frequent category was "Political-U.S." with 48 images constituting $13.4 \%$ of the sample images. The top three categories accounted for $68 \%$ of the sample images. The next two most frequent categories, the category "Political-Iraq" 
$(10.7 \%)$, and "Military-Iraq" (7\%) raise the overall percentage to $86 \%$ with a count of 38 images and 24 images respectively. The sixth most frequent category, "Damage \& Destruction-Iraq" accounted for $3.65 \%$ of the sample with 13 images.

\section{Table 1}

High Frequency Categories in Iraq War Pictures

\begin{tabular}{|c|c|c|c|}
\hline Category & Subcategory & Photos & $\%$ of total \\
\hline $\begin{array}{l}\text { Military-U.S. } \\
\text { Troops }\end{array}$ & $\begin{array}{l}\text { Soldiers/Troops } \\
\text { Behind-lines (25) } \\
\text { Combat (10) } \\
\text { C-patrol (35) } \\
\text { Wounded (13) } \\
\text { Dead (15) } \\
\text { General (10) }\end{array}$ & 108 & $30 \%$ \\
\hline Military-U.S. & $\begin{array}{l}\text { Military leaders (5) } \\
\text { Armaments (13) } \\
\text { Misconduct (14) } \\
\text { Veterans (2) } \\
\text { Infographics (1) }\end{array}$ & 35 & $10 \%$ \\
\hline Civilian Life-Iraq & $\begin{array}{l}\text { Civilians } \\
\text { Women/Children (25) } \\
\text { Civilian Men (16) } \\
\text { Civilian wounded (7) } \\
\text { Civilian dead (7) }\end{array}$ & 55 & $15 \%$ \\
\hline Political-U.S. & $\begin{array}{l}\text { Political leaders (33) } \\
\text { Protesters (4) } \\
\text { Political dead (1) } \\
\text { Guantanamo (6) } \\
\text { Infographics (4) }\end{array}$ & 48 & $13 \%$ \\
\hline Political-Iraq & $\begin{array}{l}\text { Political leaders (19) } \\
\text { Protesters (2) } \\
\text { Political misconduct (2) } \\
\text { Political civilians (10) } \\
\text { Infographics (5) }\end{array}$ & 38 & $11 \%$ \\
\hline
\end{tabular}


Table 1

High Frequency Categories in Iraq War Pictures

\begin{tabular}{lllc}
\hline Category & Subcategory & Photos & $\%$ of total \\
\hline Military-Iraq & Military leaders (1) & 24 & $7 \%$ \\
& Arsenal (2) & & \\
& Troops (1) & & \\
& Insurgents (11) & & \\
& Military misconduct (3) & & $4 \%$ \\
Destruction-Iraq & Infrastructure (12) & 13 & \\
& Oil \& Energy (1) & & \\
\hline
\end{tabular}

Totals

321

$90 \%^{1}$

Four hypotheses were proposed for this research. As a response to Griffin and Lee's (1995) Gulf War study and the replacement of combat images with a predominance of images devoted to armaments (23\%), it was hypothesized that journalists embedding with the troops would reverse this photographic trend. The first hypothesis, $\mathrm{H}_{1}$, predicted that the amount of images of troops in combat would increase compared to the amount pictured during the Gulf War. The second hypothesis, $\mathrm{H}_{2}$, hypothesized that more Iraqi civilians would be pictured in coverage of the Iraq War due to the urban nature of the war and access to civilians through the embed policy. The third hypothesis, $\mathrm{H}_{3}$, hypothesized that coverage would feature more images of overall damage and destruction than previous coverage during the Gulf War. And the fourth hypothesis, $\mathrm{H}_{4}$, hypothesized that coverage concentrating on "cataloging the armaments" would decrease as a result of having more immediate access to troops.

\footnotetext{
${ }^{1}$ Percentages have been rounded up to a full percentage point if the decimal place was above .5 , and rounded down to a full percentage point if the decimal place was below .5 .
} 
As hypothesized in $\mathrm{H}_{1}$, the incidence of combat photography increased during the Iraq War and accounted for 13\% of the photographs in the sample. It is, however, important to distinguish between traditional combat photography in which combat action (3\%) was pictured, and the category of C-patrol (10\%), which was an emergent combat category. These images pictured troops within an urban environment and showed troops performing specific tactical tasks such as gathering information, reconnaissance, surveillance, and providing security. Such images do not impart the action, danger, and/or anguish that are typically considered to comprise combat photography. Patrolling nevertheless requires a type of vigilance consistent with combat and not required by troops behind the lines. Comparing traditional combat photography with the Gulf War study, which aggregated combat images for all nations, the percentage of combat images to the total remained at approximately $3 \%$, with the qualitative difference being that the traditional combat photography in this Iraq War study only pictured U.S. troops and not allied or enemy troops. Also in the post hoc review of the Gulf War images, photographs that could have been coded as "C-patrol," were not included in the population of photographs Griffin and Lee (1995) coded. This is likely due to the nature of the war itself, which was to expel Iraq's military from Kuwait and not nation building which required a continued presence in Iraq. Chi Square calculated between categories related to images representing traditional U.S. combat, and patrol, as well as images related to the Iraq military categories in the Iraq War data with, $n=356, \mathrm{df}=1$, showed no 
statistical significance, n.s. (Table 4). Therefore, the first hypothesis was not supported by the data.

The second hypothesis, $\mathrm{H}_{2}$, proposed that more images of Iraqi civilians would be published during the Iraq War. Indeed, images of Iraqi civilians constituted $15 \%$ of the sample, a dramatic increase from the $1 \%$ pictured during the Gulf War and the second largest category of images included in the study. An Iraqi civilian was typically pictorially differentiated by dress, gender, and age. Categorization decisions were also assisted by captions identifying whether the person pictured was a civilian, a militiaman, or an insurgent. Chi Square calculated between categories related to images representing the Iraq military and images related to picturing civilians in the Iraq War data with, $n=$ $356, \mathrm{df}=1$, showed statistical significance in one category — "Iraqi insurgents" and "Iraqi civilians" - with .041 p value (Table 4). This single statistically significant value however, does not support the second hypothesis.

The third hypothesis, $\mathrm{H}_{3}$, proposed that images of damage and destruction would increase in frequency compared to Griffin and Lee's (1995) Gulf War study. This study showed an overall frequency of $5.62 \%$ of the sample picturing damage and destruction to all parties engaged in the war, compared to the $3 \%$ pictured during the Gulf War. However, the percentage of damage and destruction to Iraq alone was $3.65 \%$, compared to the $3 \%$ in Griffin and Lee's $(1995$, p. 817) study. Most of the images of damage and destruction in this Iraq War study were long-distance shots of Baghdad as pictured in Figure 5, or close up shots as the result of a specific incident as shown in Figure 6. 


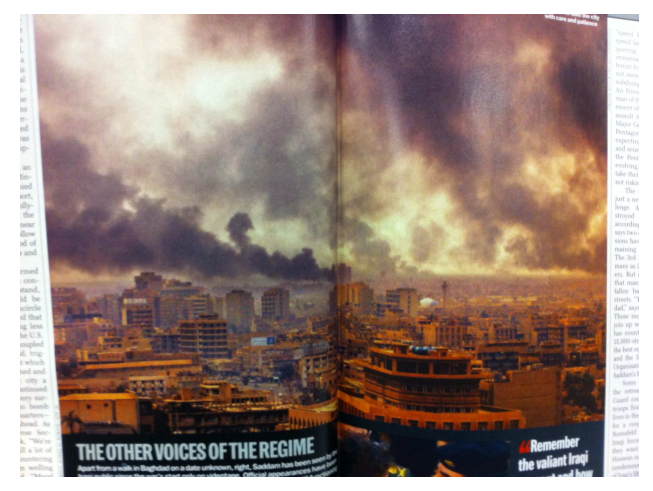

Figure 5. Yuri Kozyrev (photographer), in Time 161(15), 4.14.03, pp. 52-53.

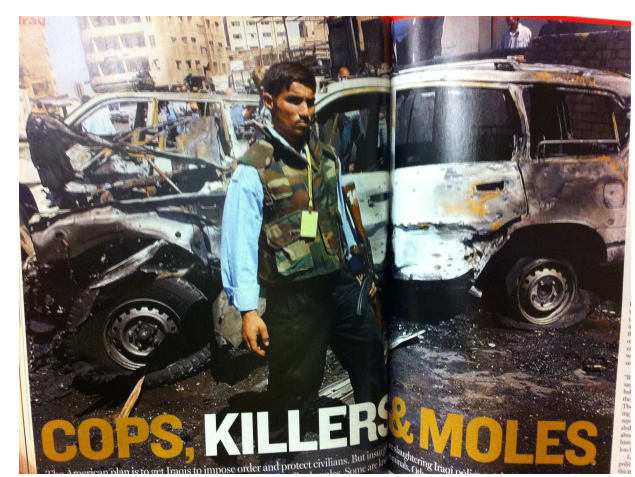

Figure 6. Wathig Khusaie (photographer), Getty Images, in Newsweek 144(13), 9.27.04, pp. 32-33.

There was damage and destruction in many photographs, but the focal point of the image was usually not the damage and destruction, rather other elements of the photograph and were therefore coded to other categories. The damage and destruction to Iraq alone accounted for $3.65 \%$ of the sample, with 13 photographs, and included one photo, that documented damage to the oil industry through oil smuggling. This may be an artifact of the sample, but the scarcity of oil-related images is curious given the essential nature of oil exports to Iraq's economy. The other $1.8 \%$ of the photos in the damage and destruction categories pictured damage to U.S. materiel, and damage due to the bombing of the U.N. headquarters in August, 2003, categorized as "Destruction-Other." Chi Square calculated between categories related to "U.S. Damage and Destruction", "Other Damage and Destruction," "Iraq Damage and Destruction," and "Oil" in the Iraq War data with, $n=356$, df $=1$, showed no statistical significance, n.s. in any content categories (Table 4). Therefore, the third hypothesis was not supported by the data. 
The total number of images in the sample slightly favored both Time (36.5\%) and Newsweek (38.2\%) with U.S. News and World Report (25.3\%) accounting for 10\%+ less of the images selected during the random sampling. U.S. News and World Report reduced publication frequency in 2008 , which alone did not contribute to the overall smaller percentage of contribution. U.S. News and World Report covered 2 weeks of events within one issue, the consequence of which was reduced publication space available to illustrate events on the ground, and thus fewer photographs. Despite this reduction of contribution, the top three categories: "Military-U.S.," "Civilian Life-Iraq," and "Political-U.S.," accounted for $68 \%$ of the images and were the top three categories across all three magazines.

\section{Dominant Categories}

Within the most prevalent genre of "Military-U.S.," the category "C-patrol-U.S." generated the most photographs with 35 photos and $10 \%$ of the total sample, this combined with the category "Combat-U.S." and 10 photos (3\%) constituted $32 \%$ of the U.S. military genre, and $13 \%$ of the overall sample. Typical combat photographs are shown in Figures 7 and 8. 


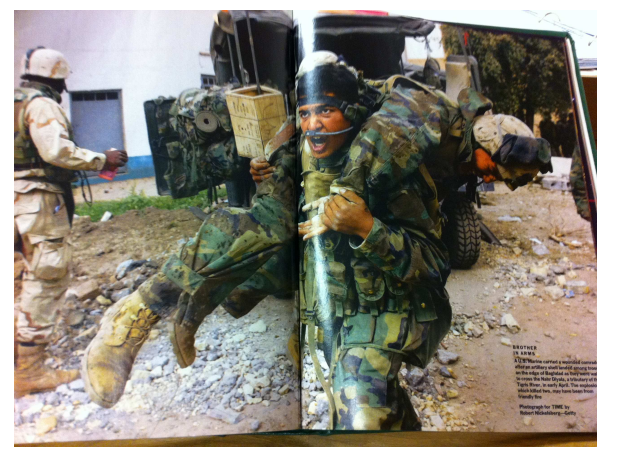

Figure 7. Robert Nickelsberg (photographer), Getty Images, in Time 162(25), 12.22.03, pp. 80-81

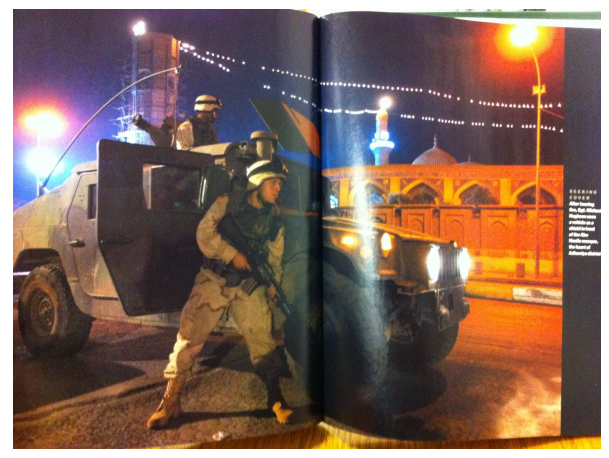

Figure 8. James Nachtwey (photographer), VII, in Time 162(26), 12.29.03, pp.45-45.

Photographs coded as "C-patrol" pictured U.S. troops patrolling the streets, guarding POWs, house-to-house searches, and interfacing with civilians while on patrol (Figures 9 and 10).

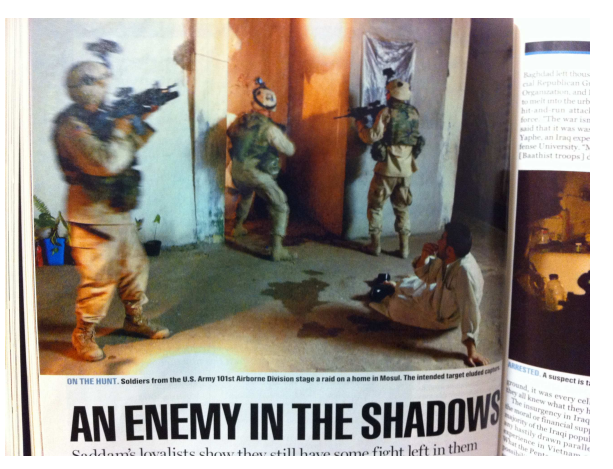

Figure 9. Photographer unknown, U.S. News and World Report 135(4), 8.11.03, p. 18.

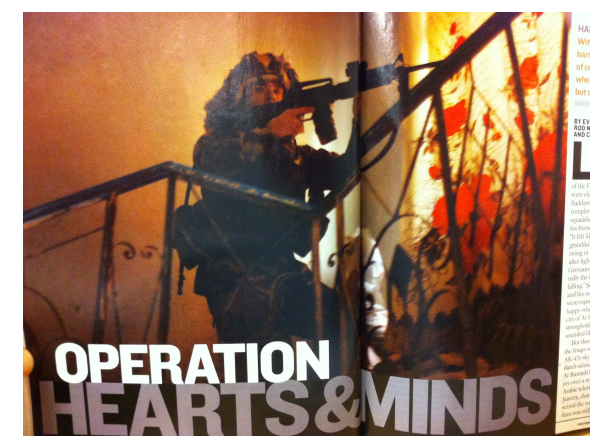

Figure 10. Gary Knight (photographer), in Newsweek 143(1), 1.5.04, pp. 34-35.

In the post hoc review of the photographs coded for the Gulf War study, the " $\mathrm{C}$ patrol - U.S." category was not represented in the census of photographs coded by Griffin and Lee (1995). This result is likely due to the nature of the conflict and not a reflection of differing coding protocols. Patrolling and reconnaissance was simply 
integral to a strategy requiring a continued presence in Iraq's urban settings. Because of this, statistical significance cannot be calculated. However, substantive significance suggests that inclusion of this emergent category has meaning for the overall differences in category dominance during the Iraq War.

Images of U.S. troops behind the lines constituted $18 \%$ of the military genre with 25 photos. Behind the lines images usually pictured troops training in Kuwait for combat in Iraq, training Iraqi militias to take over combat duties from coalition forces, practicing, and Peshmerga guards in Kurdistan, a northern region of Iraq. They also portrayed training at West Point for the next generation of U.S. officers. Some of the behind the lines images were visually indistinguishable from real combat photos and therefore, as Hallin (1986) and Sontag $(1973,2003)$ suggest, were dependent on captions to tell the coders what they were seeing.

The "Troops-U.S." category dominated the U.S. military genre with a larger percentage of inclusion than "Military Leaders-U.S." There were only 5 images of military leaders included in the sample, a low frequency category of $1.4 \%$. Images of U.S. military leaders replaced images of political leaders in 2003 and were primarily of U.S. generals that had taken over control of the U.S. troops throughout the conflict. Images of their counterparts in the Iraqi Army were practically nonexistent, with one image of Saddam Hussein posing with military leaders in February 2003, before the hostilities began. No further images of Iraqi military leaders were included in the sample, 
which might be due to issues of access, but more likely is due to the contested U.S. administration's order to disband the Iraqi Army in 2003 (Kaplan, 2007).

The casualty category "Military Wounded-U.S." garnered 13 images (4\%) and "Military Dead-U.S." with 15 images (4\%), had a combined percentage of $8 \%$ of the total sample. While the images of the military wounded did occasionally show the results of their wounds, including bloody and mangled body parts, the military dead were exclusively represented by photographs taken before the soldiers were deployed to Iraq, and were largely posed portraits in uniform. Occasionally a memorial tableaux arranged in a parent's or loved one's home, or typical military symbolism of a helmet on the soldier's rifle were used to represent dead troops. There were four pictures of flag-draped coffins included in the representations of dead U.S. troops, one of which received a journalistic award (Figure 11).

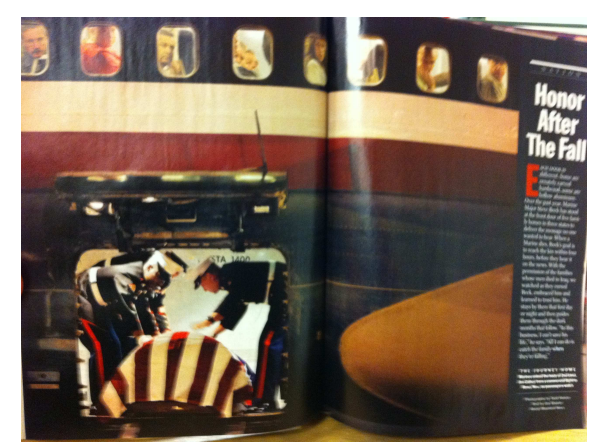

Figure 11. Todd Heisler (photographer), Rocky Mountain News in Time 166(21), 11.21.05, pp. 42-43.

The category "Cataloging the Arsenal" that predominated coverage in Griffin and Lee's (1995) Gulf War study with 23\% of the total coverage and 249 images, constituted only $4 \%$ of the overall total coverage in this sample with 13 images overall. Drones 
comprised half of those images and were stand-alone images or infographics of U.S. firepower. As in Griffin and Lee's (1995) study, none of these images portrayed this technology in action, rather they were portrayed as another member of the coalition force with one a glossy portrait from the drone manufacturer (Figure 12) taken with the sky lighted in a manner reminiscent of religious paintings, showing streams of light emerging from the clouds, which in visual aesthetics theory is thought to impart more spiritual than material concerns to the subject (Dake, 2005, p. 11).

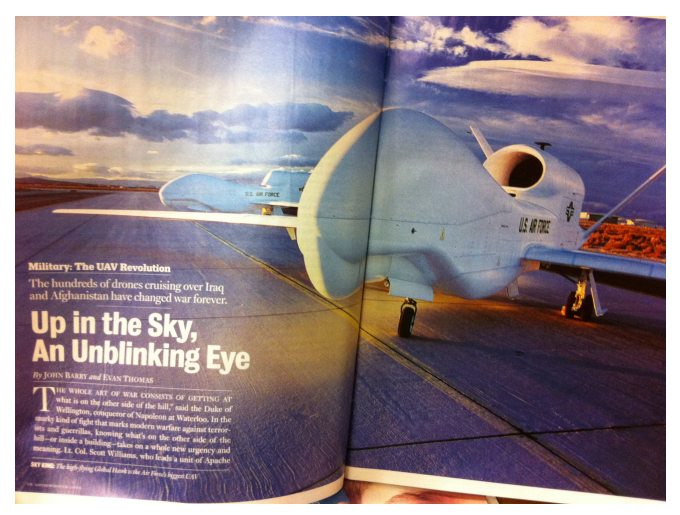

Figure 12. Northrup Grumman-Landor, in Newsweek 151(23), 6.9.08, pp. 24-25. In the post hoc review of images included in the Gulf War study, I coded the Gulf War images according to my own coding guidelines. My coding generated fewer “cataloging the arsenal" images than Griffin and Lee's (1995) coding of the same images. Despite differences in coding protocols, the conclusion that "cataloging the arsenal" was a dominant category still seems justified given that coding during the Iraq War showed fewer of the same qualitative type of images as those coded by Griffin and Lee. 
The estimated mean of the Gulf War study categories based on those reported in Griffin and Lee's (1995) study and adjusted for aggregation of some categories, was approximately 25 . The estimated mean for the Iraq War study, aggregating those categories that overlapped in the same manner as was reported in the Gulf War study, revealed a mean of 9. An F-test for the significance of the difference between the variances of the two independent samples revealed $p=<.0001$. A $t$-Test of the two different populations of images assuming unequal sample variances and a 95\% C.I. has a $S E=10.69$. As the sample means get larger, the more confident we can be that these two populations of images reflect different populations of images, that there are genuine differences between the populations of images, and that the respective samples are representative of their particular parent populations. The null hypothesis can therefore probably be rejected.

Of note is that images of American firepower (13) outstripped the number of images of actual combat (10). Although the comparison does not approach the one to nine ratio of combat to arsenal images published during the Gulf War study, images of weaponry still slightly exceeded that of combat in coverage of the Iraq War. Due to differences in coding protocols, statistical significance cannot be calculated between the Gulf War and Iraq War studies. However, substantive increases in pictorial coverage of troops and civilians suggest, that given access to troops and civilians through embedding, journalists do not rely on representations of power to construct and frame the meaning of war. 
One of the emergent categories, "Military Misconduct-U.S." contained images related to the Abu Ghraib scandal of U.S. Army prisoner abuse in 2003, as well as the killing of 24 civilians by U.S. Marines in 2005, known as the Haditha Incident (McGirk, 2006, p. 34). Of the fourteen (14) images related to both incidents, eight (8) of them were also categorized as "grisly." One image connected to Abu Ghraib has become iconic and was included in all three publications, although the image in the sample came from U.S. News \& World Report (Figure 13). The images were taken by the perpetrators of the abuse and the quality of the images are less than adequate, but show a detainee in Abu Ghraib attached to electrical wires that would deliver shocks during interrogation, or if he fell off the pedestal.

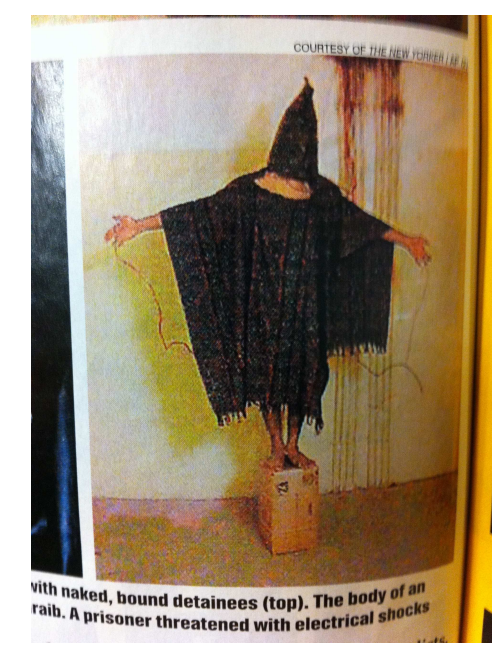

Figure 13. Photographer unknown, AP in Washington Post, in U.S. News \& World Report 136(17), 5.17.04, p. 28. 
Most of the images documenting the Haditha killings showed the victims in shrouds (Figure 14).

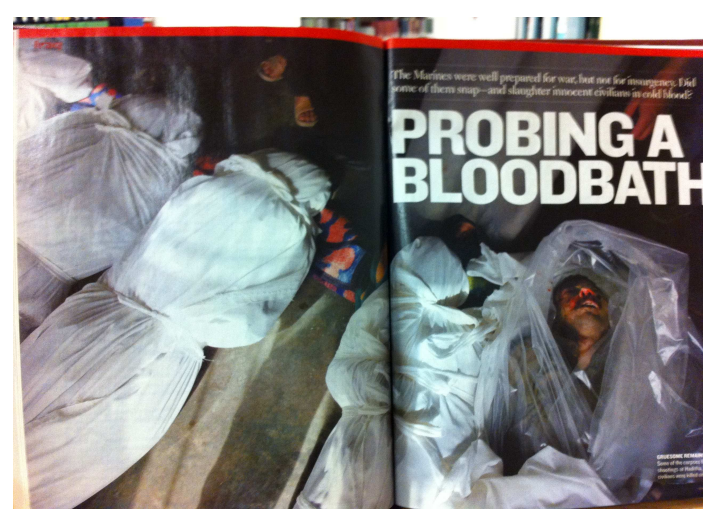

Figure 14. Lucian Read (photographer), WPN in Newsweek 147(24), 6.12.06, pp. 22-23.

The second largest genre pictured, "Civilian Life-Iraq," had a 15\% share of the images published in the sample with 55 images. Of those images 25 were of women and/or children, comprising $45 \%$ of the overall genre. The largest components of the genre were the categories: "Women Civilians-Iraq," "Civilian Wounded-Iraq," and "Civilian Dead-Iraq."

The fourth, fifth, sixth, and seventh largest genres were "Political-Iraq," constituting 11\% with 38 images, "Military-U.S. (leaders)," constituting 9\% with 33 images, "Military-Iraq," constituting 7\% with 24 images, and "Damage \& DestructionIraq" constituting 4\% with 13 images. In the political category, the category "Political Leaders-Iraq" constituted 50\% of the category. At the beginning of the war in 2003, Saddam Hussein dominated the political leader category until a provisional council was established shortly after the invasion in April 2003, and speculation over future leaders of 
a parliamentary system of democracy included images of other possible leaders. Of the 19 images showing political leaders, 8 images were of Saddam Hussein, 2 of which showed him after his capture in December 2003. Contrary to coverage during the Gulf War and Griffin and Lee's (1995) observation that images of Saddam Hussein were juxtaposed across from images of George H.W. Bush as if they were confronting each other (p. 818), coverage during the Iraq War had few such images. Images of Saddam Hussein were used to depict him as a target and not necessarily as a legitimate political leader. Particularly during the beginning of the war, Newsweek magazine used a graphic element in the upper left border of articles that headed the section "Target: Iraq."

The top six categories constituted $90 \%$ of the coverage, with U.S. military and political categories amounting to $53 \%$ of the coverage with a total of 191 images, and Iraqi civilian, political, military, and damage and destruction categories amounting to $37 \%$ of the coverage with 130 images. The balance of the images belonged to low frequency categories with percentage values of $2.2 \%$ or less and amounting to $10 \%$ of the overall coverage as shown in Table 2. 
Table 2

Low Frequency Categories in Iraq War Pictures

\begin{tabular}{|c|c|c|c|}
\hline$\overline{\text { Category }}$ & Subcategory & Photos & $\%$ of total \\
\hline \multirow[t]{2}{*}{ Political-Allied } & Leaders & 2 & 0.60 \\
\hline & Protesters & 1 & 0.30 \\
\hline Political-Other & Protesters & 2 & 0.60 \\
\hline \multirow[t]{2}{*}{ Military-Allied } & Behind the lines & 1 & 0.30 \\
\hline & C-Patrol & 3 & 0.80 \\
\hline Military-Other & Troops-Iran & 1 & 0.30 \\
\hline \multirow[t]{4}{*}{ Civilians-U. S. } & Civilians & 5 & 1.40 \\
\hline & Journalist wound & 1 & 0.30 \\
\hline & Infographic & 1 & 0.30 \\
\hline & Civilians & 2 & 0.60 \\
\hline Civilians-Other & Damage & 3 & 0.80 \\
\hline Destruction-U.S. & Damage & 4 & 1.00 \\
\hline Destruction-Other & Terrorist leader & 2 & 0.60 \\
\hline \multirow[t]{4}{*}{ Terrorism-Iraq } & Infographic & 3 & 0.80 \\
\hline & Terrorists & 2 & 0.60 \\
\hline & Damage & 1 & 0.30 \\
\hline & Terrorist-Dead & 1 & 0.30 \\
\hline \multicolumn{4}{|l|}{ Terrorism-Other } \\
\hline & Total & $\overline{35}$ & 10.00 \\
\hline
\end{tabular}

\section{Image Mode}

Archival images. Archival images were defined as images used to illustrate something in the article, but not depicting action on the ground in Iraq. It could be from a previous war, or a photograph of training going on in the U.S., or a photograph of a person involved in the war that was not taken recently, but drawn from the sources archives for whatever reason. The main point is that the photo was not taken close to the time it was published.

Archival images comprised $6.7 \%$ of the total images under study. Many of these photographs were images of Saddam Hussein, Osama bin Laden, and other political 
actors such as Muqtada al-Sadr, access to whom was not possible at the time. These images appeared over and over again anchoring one image as the representative image of these individuals. One image of Muqtada al-Sadr (Figure 15) shows him in a menacing posture and a black cloak, which to American audiences, with little experience of Islamic leaders or attire, might remind them of depictions of villains in film. The photograph is similar to many other images of Muqtada al-Sadr in which he is pictured with a menacing

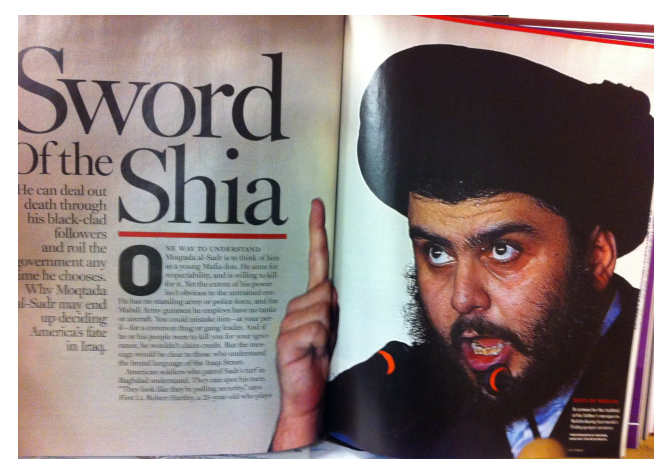

Figure 15. Wathiq Khuzaie (photographer), Getty Images, in Newsweek 148(23), 12.4.06, p. 29.

posture. The repeated use of this type of archival image develops an iconic and metonymic reference for this individual and Islam in general (Nöth, 2011) to create a stereotype.

Staged and posed images. There were not many photographs that seemed to be staged at first glance during the coding process. Most of the photographs that were staged were discovered to be staged through further inquiry by journalists or scholars. Two particular instances in the sample, the toppling of the Saddam statue in Firdos Square, and the rescue of Private Jessica Lynch are the examples in the study. In the case of the 
toppling of the Saddam statue, it would have been obvious to photographers that the tight framing of the photographs omitted the paucity of civilian participation and framed the image as a victory and punctuation for the end of the war (Fahmy, 2007). The image of Jessica Lynch being transported to a German hospital after her rescue from an Iraqi hospital was not a staged image, although the "story" of the Jessica Lynch rescue and the details surrounding her capture misled the public. There were only two staged photographs in the sample, one of which was the toppling of the Saddam statue, and the second was an image promoting new "sci-fi" battle gear. It is not clear whether the soldier photographed is indeed a soldier, or a model used to promote what is termed a "future warrior" (Newsweek, 141/8, E2).

A distinction was made between staged photographs, in which there was an intention to deceive on the part of the initiators and has been termed a "pseudo-event," (Baudrillard, 2012; Boorstin, 1992) and posed photographs such as those of troops killed in action, or portraits of political and military leaders taken for the covers of magazines and considered to be legitimate albeit conventional use of posed images. Posed images were coded, and accounted for $10 \%$ of the total images with 36 photographs in the sample. Most of these images were portraits of U.S. political or military leaders, photographs of deceased U.S. troops taken before they were deployed, or pictures of U.S. family members of the deceased.

Grisly images. Grisly images were defined as a type of image that shows human(s) in extremis: distressed, wounded, or dead soldiers or civilians, or even the 
presence of blood suggesting a grisly incident. Grisly images were captured in three main categories: "Military Misconduct-U.S.," "Civilian Wounded-Iraq," and "Civilian DeadIraq." As a percent of the total sample images, grisly images accounted for $9 \%$ of the total images evenly divided between the U.S. category and the Iraq categories with approximately 12 images each. Some of the grisly images were of U.S. wounded troops, but qualitatively they were not as grisly as those of the wounded and dead Iraqi civilians or of the Abu Ghraib prisoners of war and Haditha incident victims.

Infographics. Infographics including maps constituted a large percentage of the sample images. Total images in the information graphic mode had content detailing American firepower, maps of Iraq, traditional areas of Muslim religious denominations, battles, and political support for the war in America. There were a total of 36 infographic images, constituting $10 \%$ of the sample. Particularly in a war in which Western audiences are unfamiliar with the culture and terrain of the Middle East, this is not surprising and can be helpful to publics trying to make sense of the conflict.

\section{Weighting Images by Size}

In the original study, Griffin and Lee (1995) counted the number of images falling into each category and then weighted the images according to size to see if the prominence of a category was also reflected by the size of the image. They argued, "a smaller number of pictures appearing in larger scale could have greater prominence than a larger number of small pictures" (Griffin \& Lee, 1995, p. 823). However, they found that weighting for picture size made no appreciable difference to the frequency ranks of 
each category. The same top 18 categories of picture weight constituted $90 \%$ of the total, with combat images being raised to $6 \%$ versus $3 \%$ of the total count because of a larger and more prominent photograph size.

Weighting due to picture size did not change the ranking order of the top three genres in this Iraq War study, yet the percentage share did shift downward without exception. Contrary to Griffin and Lee's (1995) Gulf War study in which weighting due to picture size increased the combat category, the larger genre, "Military-U.S." dropped to $33.07 \%$ from the original $40 \%$, "Civilian Life-Iraq" shifted to $10.6 \%$ of the sample, down from the original 15\%, and the category "Political-U.S." also dropped slightly from its original $13.4 \%$ to $8.13 \%$. There could be many reasons for this, however, most likely is the length of the conflict and the tendency of the news magazines to publish smaller images toward the end of the conflict than at the beginning. Taking only the first 3 months of the war into account and weighting the sample images for that time only, which would match the timeline of the Gulf War coverage, the genre "Military-U.S." garnered $69 \%$ of the images in contrast to $40 \%$ spread over the 9 years studied. 


\section{Chapter 5: Discussion}

The Iraq War was visually framed with a succession of frames diverging slightly from Perlmutter's (1992) contention that images used to represent war follow conventional visual tropes about war, with a tendency toward action and U.S.-centric images. While the visual representations of the Iraq War were primarily U.S.-centric, photographs of action were rare, with photographs of traditional combat replaced by the qualitatively disparate "combat patrol," imagery. The emerging category "combat patrol" could only be coded as combat as a latent content distinction, but manifestly resembled a distinction made by Griffin and Lee (1995) of "unengaged troops" (p.819). On the whole, the majority of the photography representing the Iraq War in Time, Newsweek, and U.S. News \& World Report, were mundane, or tropes at best. The imagery did not reflect written accounts of the war, whether journalistic or published personal accounts (Hoyt \& Palattella, 2007). Given U.S. military embed protocols that allowed journalists access to troops and civilians, the scant quantity of traditional combat photography (10\%) is surprising, suggesting that either the embed protocols did not allow access to the degree necessary to gather combat images, or combat photography was edited out at the level of the news organization. The military journalist, Colonel William Daley, reporting for the Military Review, suggests that embedding only allowed you to "[see] the war through a straw" (Hoyt \& Palattella, 2007, p. 97). The lack of an exhaustive visual record of the Iraq War in Time, Newsweek and U.S. News and World Report, has been influenced not only by the embed policy acting as an indirect form of censorship, but also by editorial 
decisions and the tendency for the media to primarily use political and military entities as information sources. It was also influenced by journalistic standards that require a second source to verify reports. In the case of the Abu Ghraib scandal in 2003, journalists interviewed after they returned reported that they were getting reports of abuse, but could not publish due to their inability to verify personal accounts of torture, or were skeptical of the reports due to what seemed like fantastical accounts of humiliation and abuse (Hoyt \& Palattella, 2007, p. 67). The Abu Ghraib photographs, in part taken by U.S. Army specialist, Lynndie England, and the subsequent exposé in the New Yorker by Seymour Hersch in April 2004 were the first time the abuse was confirmed by a journalistic source (Hoyt \& Palattella, 2007, p. 66).

\section{Framing tropes and cultural assumptions}

The U.S.-centric visual coverage conforms to an observed tendency by the media to favor official sources for content thus reflecting the issues that those official sources want to emphasize (Shoemaker, 1996). Images such as the individual archival portraits of Iraqi politicians and military leaders as U.S. targets, or graphics of armaments intended to accomplish that goal epitomized the U.S.-centric coverage and constructed a conventional visual history of the "enemy." Photographs of practicing troops, combat, prisoners of war, and maps of the territory involved in the conflict all establish the hurdles and barriers to the U.S. interest in a regime change, while assuming that there were no other stakeholders that might have alternative plausible objectives. 
The increase in the combat category can be attributed to the coding of " $\mathrm{C}-$ patrolU.S." as a combat category, with its emphasis on reconnaissance, surveillance, and security operations, capturing the majority of the images, and can very probably be attributed to embedding journalists with the troops. The rarity of traditional combat photos in the study, however, is puzzling given the access to the troops, but is consistent with recent war coverage (Griffin, 2010).

The U.S. embedding policy also acted as a mild form of censorship. Journalists were not allowed to roam unaccompanied in Iraq or Baghdad to photograph anything they pleased, which limited access to civilians unless troops were somehow engaged with them. Only unembedded journalists who worked in Iraq outside the embed policy had the freedom to photograph unimpeded, and usually at great risk to themselves and without protection from U.S. or coalition troops. According to some unembedded photographers, any attempt to walk away, even briefly, from the assigned military unit to cover some action nearby could lead to that journalist losing his or her embed privileges (AbdulAhad, Alford, Anderson, \& Leistner, 2005).

While a majority of the visual images documented U.S. interests and policies, according to a PEW Research Center study (2007), just more than half of the textual coverage was negative (56\%), focusing more skeptically on the ability of the new Iraqi government to attain stability in Iraq than negative assessments about U.S. policies or overall success in U.S. goals in Iraq (PEW, December 19, 2007). This negative textual wash would also influence how publics read the images. 
Photographs that perpetuated and supported U.S. cultural beliefs and assumptions of U.S. goals were further supported by images of Iraqi civilians in the process of fulfilling U.S. political and military objectives and policies in Iraq. For instance there were many photographs of civilians voting — a representation of the sought for democratization of Iraq. Images of civilian casualties that appeared were usually attributed to the insurgents or not attributed to an agent at all. One 2003 Time photograph showed a wounded 4-year-old girl being helped by U.S. marines and identified as "a victim of crossfire" between locals and Saddam loyalists (Time, 141/14, 22-23). Another 2004 U.S. News photograph of an injured woman was described as "collateral damage" of insurgent clashes with U.S. forces in Sadr City (U.S. News, 136/13, 32). Captions tended to skirt any attribution of involvement on the part of the U.S. and allied forces in the rising body count of opposing Iraqi forces or civilians. According to one journalist, the military would decide when it was in their best interests to give an attribution or body count of the opposing side and that did not happen very often (Hoyt \& Palattella, 2007, p. 71). One image in the sample showed future Iraqi soldiers being trained by American troops (U.S. News, 134/16, 20). Interestingly, the photograph pictured Iraqi troops sitting in the dirt and listening, while U.S. troops were standing and demonstrating how to restrain a captive. The caption reads, "Skull session: Instructing new Iraqi militiamen," and a headline, "The Men in the Shadows" referring to U.S. Special Forces as a model for a new type of war. Another image shows an Iraqi and American soldier patrolling together, with the Iraqi soldier taking point (U.S. News, 145/1, 28). While these images 
represent the transition to an Iraqi based presence, U.S. forces are still pictured in a dominant position visually, usually standing while Iraqis are pictured sitting and looking up.

There were few pictures of individuals working, going to school, or in their homes. A pictorial essay of family life in the sample photographed by Farah Nosh, an Iraqi/Canadian photojournalist, and published in Time magazine was an exception. The black and white images were taken of Nosh's family members and are in a subdued mood with one showing a young boy smiling as he "dance[ed] to the beat of Eastern and Western music" (Time, 167/21, 44-45). More than 50\% of the photographs devoted to civilians were of women and/or children. Although this might suggest that civilian life was being represented, it is predominantly those aspects of civilian life that intersect with U.S. military goals that were pictured—goals such as the establishment of democratic practices or "roadblocks" to democracy in the form of insurgent fighting and their use of "terrorist" tactics. Images of civilian Iraqi men were routinely older men, prisoners of war, men in subjugating positions such as on their knees, or with their hands tied.

A Pew Research Center study on how the press covered events in Iraq in 2007 , confirmed journalists' opinions that the subject matter they felt was "under covered" in Iraq War coverage was ordinary Iraqi civilian life (PEW, December 19, 2007). The same study found that $46.7 \%$ of the textual reporting covered daily violence. This number was reflected to a slightly lower degree $(43 \%)$ in the visual reporting. Images reflecting violence showed: the results of bombings, armed insurgents and militiamen, the killings 
of the Blackwater contractors, and injured or dead civilians. Other photographs with less violent themes (57\%) showed grieving U.S. families, Iraqi refugees, veterans in the U.S., military and political leaders, and one "mixed" Muslim wedding between a Shi' ite and Sunni.

These visual tropes were echoed in headlines and captions that tried to usher in a conclusion to the war. Examples of such attempts in the sample included a 2003 photograph of the toppling of the statue of Saddam with the headline "Tyranny Tumbles: Iraqis topple symbols of oppression as allied troops clash with Saddam holdouts," and a caption that reads, "Iraqis bring down a statue of Saddam in Baghdad with U.S. help" (Time, 161/16, 5). The later realization that this was an action orchestrated by the C.I.A. did little to dampen the symbolic value of the image as visual punctuation to the war (Fahmy, 2007), giving a false sense of success with the symbolic value of the image outweighing its value as a document of reality.

The PEW Research Center's Project for Excellence in Journalism in conjunction with the Poynter Institute surveyed the American public in 2005 about its confidence in the believability of U.S. print journalism. A shift took place in 2004 with only $50 \%$ of the readership rating their primary print news source as believable, down 9\% points from 2002 and 13\% points from 1998 — with no difference between national and local news sources. There was also an increase in readership preferring pictures over words at 55\% indicating that television was the preferred source of news with only $40 \%$ preferring written news or hearing about the news on the radio (PEW, March, 15, 2005). 


\section{Visual counter-framing}

Counter framing is defined as a frame that "opposes an earlier effective frame" (Chong \& Druckman, 2011) in that it appears later in time than an earlier effective frame, creates a meaning in opposition to the previously accepted frame and also affects opinions about the previously accepted frame. In the context of this study, the visual counter-framing appears in two distinct respects. First, counter-framing appears as a visual counterpoint to the textual headline or caption accompanying the photograph; and second, as a visual counter-frame to deeply held social and cultural beliefs and commitments.

\section{Visual counter-framing of text}

There were many instances in the sample of visual counter-framing of headlines. While the caption might have accurately described what was taking place in the photograph, the photograph's representative task was in opposition to the headline it was purported to represent. An early example in the study's sample was a picture of Secretary of State Colin Powell addressing the U.N. to assert the presence of weapons of mass destruction in Iraq. There are many photographs of Secretary Powell holding a model vial of Anthrax, but the photograph chosen to accompany the article, was one in which he was pursing his lips as if inhaling cannabis (Time, 161/7,26), perhaps a visual commentary on the likelihood of weapons of mass destruction the U.S. administration was using to justify the invasion of Iraq. 


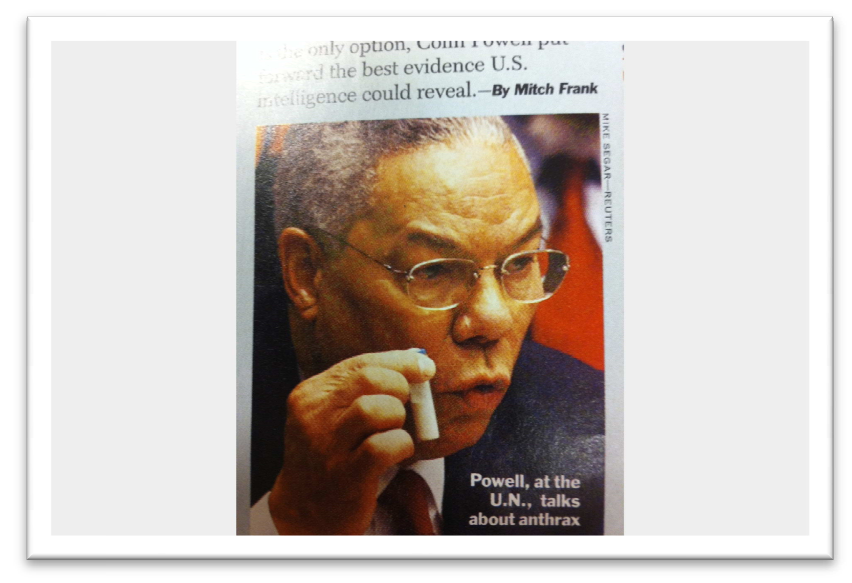

Figure 16. Mike Segar (photographer). Reuters in Time 161(7), 3.17.03, p.26.

Similarly, a 2004 story entitled "Finishing the Job," (U.S. News, 135/23, 28-29) with a subtitle indicating that the U.S. was facing the challenge of "winning the peace" is belied by the photograph used to illustrate it by showing a lone soldier seemingly lost amidst tall grasses (Figure 17), a metaphorical treatment suggesting that winning the peace was a lost cause.

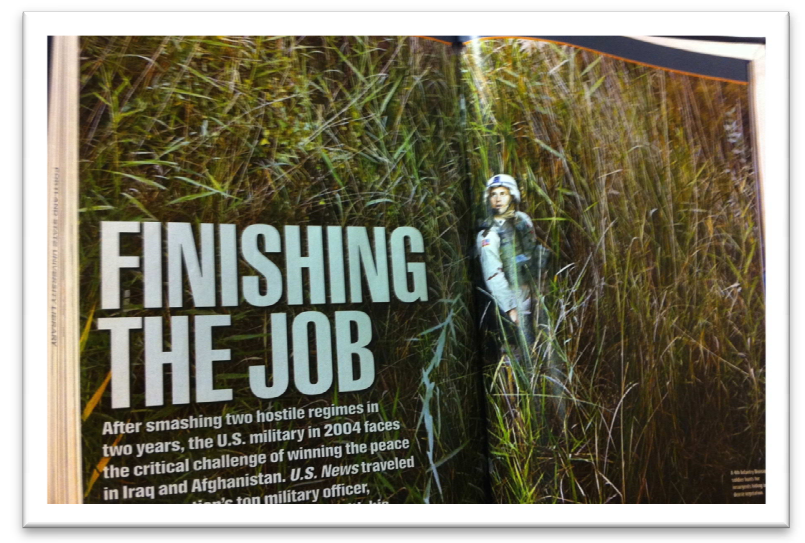

Figure 17. Damir Sagofj (photographer), Reuters in U.S. News \& World Report 135(23), 1.5.04, pp. 28-29. 
A similar use of visual counter-framing was used in one photograph picturing a man in his home during a U.S. house-to-house search. He is pictured on his knees, holding up both hands with a water pistol in his right hand (Newsweek, 143/1, 37). With the headline of "Operation Hearts \& Minds," the photograph seems either to mock U.S. search tactics by portraying Iraqis as defenseless, or to mock the strength of the subject using him as a metonym for Iraq, by the inclusion of a water pistol. As Nancy Youssef, a journalist for Knight Ridder reported civilians saying, "Well, how can they win our hearts and minds? They're killing us. They're killing us in at checkpoints; they're killing us in our houses. What hearts and minds are they talking about?" (Hoyt \& Palattella, 2007, p. 72).

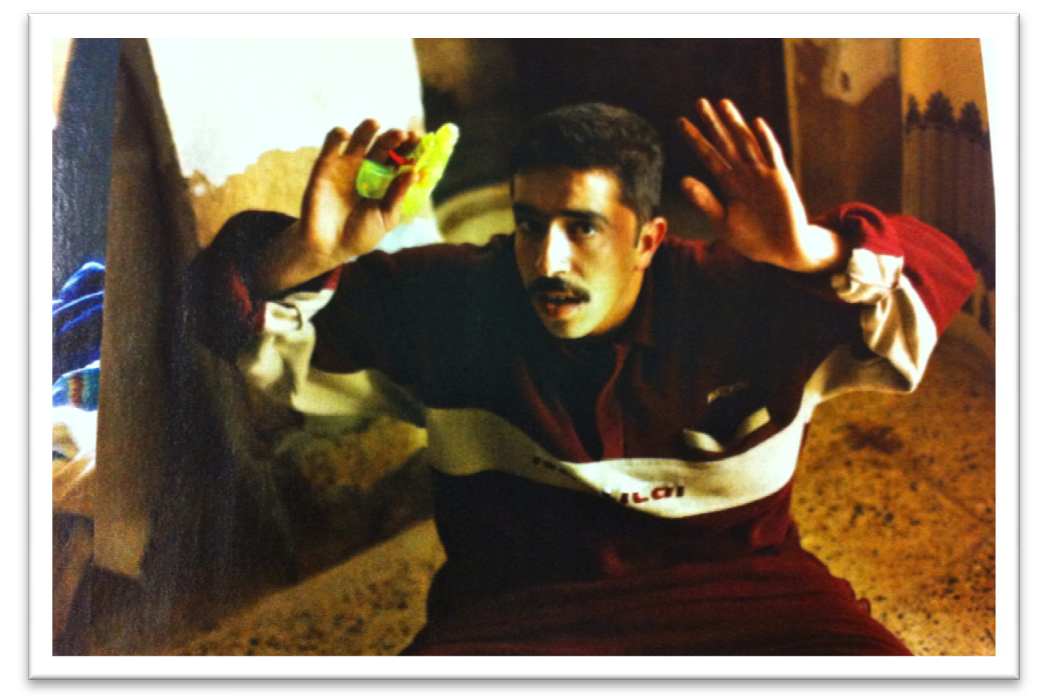

Figure 18. Gary Knight (photographer). Newsweek 143/1, 1.5.04, p. 37. 


\section{Visual counter-framing of cultural commitments}

One way to maintain a cultural commitment to the superiority of your armed forces is to shift responsibility for outcomes to a different responsible party. In the case of the Iraq War, the proximate goal of the war was regime change. The new Iraqi parliament and newly trained armed forces were textually and visually framed as the new responsible party, while U.S. involvement was portrayed as ancillary and supportive of the new regime. A 2007 photograph by Guassem Zein is accompanied by text referring to Iraqi forces in the third person and the problems "they" are facing. The headline reads, “Apocalypse Now" (Newsweek, 149/7, 36-37), a reference to Francis Ford Coppola's epic Vietnam film of the same name. Responsibility for the future of the war is editorially associated solely with Iraqi forces. Another shift of responsibility is suggested by the photograph of a U.S. army officer as an advisor to Iraqi officers describing his job as "armed social work" (Time, 148/25, 43). The dissonance between the two concepts of social work and carrying a weapon suggests a cautious withdrawal and distancing from the former position of armed soldier to one of social work and a cessation of active warfare despite an increase in fatalities at the time of publication. Similarly, the headline

"On duty at the Alamo," is accompanied by a photograph of a lone bespectacled soldier patrolling along what appears to be a street of adult men watching him. The photograph bridges the magazine fold to take up one third of the double page spread and is a composite of two photographs visually joined at the fold. It is unknown if the two photographs were taken at two different time periods, or is a cropped panoramic photo 
depicting actual events. The headline leaves no doubt that the defense of the area pictured is a doomed enterprise, just as the battle for the Alamo was doomed by overwhelming forces (Newsweek, 148/18, 46-47). While the photograph and headline are in accord with one another, both the photograph and article counter-frame a deep cultural belief and accepted frame of the U.S. as an overwhelming and effective force of change in the Middle East.

Images used metaphorically to illustrate the text also counter-framed the psychological commitment to a U.S. military superiority as exemplified by the image of an armored personnel carrier that was hit by a roadside bomb in Ramadi killing five U.S. troops and juxtaposed with a palm tree in the background. The headline, "Broken Down" not only refers to the personnel carrier, but obliquely also to the American Army in general as the subheading indicates with: "What the war in Iraq had done to America's Army - and how to fix it" (Figure 19).

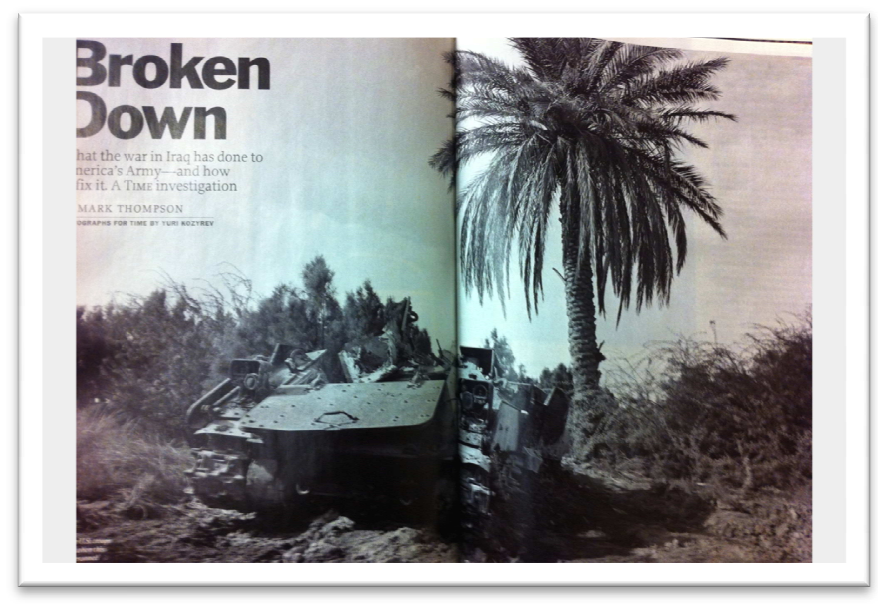

Figure 19. Yuri Kozyrev (photographer), in Time 169(16), 4.16.07, pp. 28-29. 
American discursive practices construct a war mythology weighted toward an assumption of the just war and our troops as fair and principled individuals led by trained and disciplined officers. Those cultural commitments are reinforced by film enactments of past wars, in which average servicemen and women are portrayed as unambiguous bearers of that mythology. Perhaps the most damaging photographs associated with the Iraq War were the Abu Ghraib photographs that counter-framed the American mythology with images of torture and abuse by American servicemen and -women. The Abu Ghraib photographs in U.S. News \& World Report used a textual variation of "shock and awe," a reference to the U.S. military strategy for rapid dominance, by headlining the article with "Shocking and Awful" (U.S. News \& World Report 136/17, 28-31). Another Newsweek article examining how torture came to define the U.S. military engagement in Iraq headlined the article with "The Roots of Torture" with a photograph of President George W. Bush and Alberto Gonzalez, White House Attorney General (Newsweek 143 /21, 29). This juxtaposition of the president and the headline suggested a causal relationship between torture and President Bush, thus counter-framing a cultural commitment toward America as the architect of democracy and fair play.

The publication of images of prisoner torture and abuse by U.S. military personnel frames the Iraq War as a war coming apart at the seams and conducted in a way contrary to deeply held cultural beliefs about America's fairness and honor. Not only public opinion in America was affected, but the photographs became evidence for American allies, Iraqi combatants, and Iraqi civilians alike that considered the 
photographs evidence of practices, about which they had only heard rumors (Hoyt \& Palattella, 2007, p. 70).

According to a PEW study, the Abu Ghraib photographs influenced American attitudes about the war by lowering public satisfaction with the war's trajectory to $46 \%$ from its stable 70\% approval rating in January 2004 (PEW, May, 2004). However, on the heels of the Abu Ghraib scandal and the early 2004 killing and desecration of four U.S. Blackwater contractors, support for keeping troops in Iraq was still above average at $53 \%$, with evaluations of the Bush presidency dropping to 44\% (PEW, May, 2004). The survey first primed the subjects by asking about Abu Ghraib images, which significantly lowered approval ratings of President Bush. When asked further for opinions about remaining in Iraq, the respondents favored remaining in Iraq until a stable democratic government could be established. Priming and framing effects in how the questions were asked by prefacing the question with questions about whether the respondents had seen images of the Abu Ghraib prisoner abuses influenced the responses, after which questions about staying to complete the mission reverted to other decision-making values (Chong \& Druckman, 2007).

In contrast, the political misconduct by U.S. administration insiders that leaked classified information in retaliation for a report suggesting that they had knowledge before the war began that no WMDs existed, was hardly registered or tracked by the American public. The one photograph of Valerie Plame included in the sample pictured her with a coy and flirtatious mien, framing Plame in a stereotyped negative gendered 
style, thus supporting the Bush Administration's contention that she was not a CIA operative. Only $23 \%$ of the American public said they paid close attention to the scandal. Despite slightly partisan opinions from the Democrat and Independent parties favoring resignation of Carl Rove for his suspected role in the scandal and the indictment of Scooter Libby, Vice President Cheney's Chief of Staff, the political scandal did not affect attitudes about the war, according to a July 2005 survey (PEW, July 2005).

The visual framing of the Iraq War tended to follow the lead of the textual framing, most of which contextualized the war in an episodic and conventional U.S.centric manner. However, textual and visual counter-framing was a subtle way to undermine these conventions. Whether this counter-framing was exercised with editorial intent or not, it could be construed as a clever device to reveal uncertainty with official accounts of the war.

\section{Images Not Seen or Pictures Not Taken}

While a war is traditionally tied to a "conflict frame" (Neuman et al., 1992) or as a "military conflict frame," as Carpenter (2007) labels it in his analysis of newspaper coverage of the Iraq War, a conflict frame would suggest that at least two stakeholders with opposing objectives should be pictured. In this study not only was the coverage U.S. -centric, but also devoid of representations of allies or other stakeholders with alternative objectives, views, and solutions. An assumption of a conflict frame, however conventional, can be informative by revealing what is absent in a war's representation, with the result that the photographs are not simply a type of visual communication; they 
are "the power to make visible" (Frosh, 2001, p. 43). As such, that which is not made visible does not count in the meaning making equation of war.

In an empirical study it is difficult to talk about images or photographs that are missing from the documentation of the war. We assume that if something is not part of the documentation that it did not exist. However, it is incumbent on media scholars to question what is missing, either because we want to see some aspect of coverage that has not been included or should see some aspect of coverage that is glaringly missing. In this sense it is legitimate to ask what is not being shown.

The lack of photographs of civilians going about their daily lives or civilians in professional capacities is noteworthy. Civilian casualties are historically the highest during war. If we think of civilians as stakeholders in the outcome of war, then they are stakeholders that are not being pictured to the same extent that they are impacted by war. The embed system allowed for closer coverage of the military, but according to personal accounts by journalists, this did not necessarily translate into increased coverage of, or proximity to, civilians. At the start of the war, civilians felt safe talking to journalists, but because of embedding, journalists started to be considered part of the military and it became dangerous for civilians to talk to journalists for fear of being targeted by insurgents as sympathizers (Hoyt \& Palattella, 2007, pp. 19-20). This suggests that aside from structural media processes and editorial pressures, what got pictured was also influenced by events on the ground and Iraqi cultural assumptions about journalists in 
general, who, during the Saddam Hussein regime, were thought to work for Iraqi intelligence and were therefore avoided (Hoyt \& Palattella, 2007, p. 37).

Also noteworthy is the lack of photographs of American civilian contractors to whom the rebuilding of Iraq was outsourced. These multinational corporations, such as Bechtel and Halliburton received very little coverage and, with the exception of Blackwater security forces protecting Paul Bremer in his role as Administrator of the Coalition Provisional Authority of Iraq, and the killing of Blackwater employees in 2004, there were no images of employees providing services that were formerly provided by the armed services itself, such as provisioning of water, food stuffs, and mess services, to the U.S. military. Given complaints about the effectiveness of these profit-motivated enterprises, it is noteworthy that coverage of these services was not included in visual representations of the war. Nor were reconstruction efforts by these corporations to restore water, sewer, and communication services to the Iraqi people visually represented. As mentioned before, particularly images of efforts to restore oil production were not pictured despite the Iraqi Oil Ministry in Baghdad being the only structure that was protected and guarded by U.S. and coalition troops at the beginning of the war (Hoyt \& Palattella, 2007, p. 31). In order to interview officials of these international corporations, journalists had to get permission to enter the Green Zone, a highly fortified zone in central Baghdad. The Green Zone was the former site of the Republican Palace and during the Iraq War was the site of the Coalition Provisional Authority. It was also the base for international contractors such as Halliburton and Bechtel. The paperwork 
required for journalists to get into the Green Zone was extensive, sometimes taking two months to complete. According to some journalists, they were bureaucratically locked out of the Green Zone, and the Green Zone was isolated from the realities of what was happening in Iraq (Hoyt \& Palattella, 2007, p. 52).

Political rhetoric at the beginning of the war in Afghanistan (2001) and the Iraq war (2003) connected these wars with the Crusades suggesting the wars were also religious in nature. While there were some photographs of troops and civilians praying in primarily Christian and Muslim traditions, religious imagery did not dominate any of the categories. Of the 356 photographs in the sample, only 7 included religious overtones through the inclusion of praying postures, or religious iconography. However, articles devoted to explicating Islam, the differences between different Muslim sects, or articles on Christianity were placed in close proximity to articles on the wars in Iraq and Afghanistan in all three publications.

As discussed in the literature review, the visual framing of the Iraq War has implications for historical, cultural, and journalistic ways of constructing a dialogue about war's meaning. It is historical in the sense that an accurate visual depiction of war does not get recorded at the time it is occurring. It is cultural in the sense that an understanding of the causes and complexity of a particular war are not distinguished from war tropes and mythologies that stand in for the realities of war (Hallin \& Gitlin, 1993). Finally, it is journalistic in the sense that constraints on coverage during war should not interfere with the social responsibility of the journalist to inform the public (Allan \& 
Zelizer, 2003). Embedding influenced what was covered, and sometimes acted as a form of indirect censorship. Embedding also influenced the perceptions of Iraqi civilians toward journalists, cutting off access to civilians as stakeholders in the picturing of the war, and eventually positioning journalists as targets themselves rather than third party objective observers. This had consequences for how the war was framed and counterframed.

\section{Limitations}

The main internal limitation to the study, particularly as it concerns comparisons to the previous Gulf War study, is the possibility of different parameters for category inclusion. Particularly for the category "cataloging the arsenal," the high count of Griffin and Lee's (1995) study and the relatively low category count in this Iraq War study reflected a marked difference. In my post hoc review of the population of images used in the Gulf War study, and my lower count of "cataloging the arsenal" photographs using my categorization protocols makes the comparison of this particular category impossible. This study considered one graphic image containing many separate illustrations of armaments as one instance of the category. It is unknown if the same protocol was used in the Gulf War study. Similarly, this study considered "C-patrol" a combat category, and not "unengaged troops" as I suspect the Griffin and Lee (1995) study did. Again, this is a possible difference in coding protocol that affects comparisons between studies.

As a sample of a larger census of photographs, this study captured the main events and themes of the Iraq War and is largely generalizable to the larger population of 
photographs in these news magazines. Despite this generalizability, there were gaps in coverage of particular events such as the U.S. and allied phosphorus bombing of Fallujah in 2004. Concurrently, the results cannot be generalized to media coverage on different platforms such as television, extended coverage in online news magazines, blogs, or constructed pictorial accounts in books about the Iraq War.

\section{Implications for Future Research}

Censorship protocols of the military will undoubtedly change in the future to control the use of smart phones by military personnel to document their experiences and possible publication to social media. In the future, framing research will have to account for the effect that a lack of censorship exerts when individuals can disseminate information and transmit photographs immediately in some type of "direct-to-consumer" social networking process. By bypassing the traditional mass media discursive monopoly, the mechanisms of a mass media frame generation will be affected or become irrelevant (Bennett \& Iyengar, 2008). Visual information may also have unintended consequences when the audience is a global audience with access to the Internet and conflicting interests. Because photographs have no propositional syntax and can be contextually isolated, they can become meaning-making vehicles for opposing interests.

As the visual turn of news generation continues, more studies and surveys of the effects of visual materials can help to ascribe causal consequences, thought by Snow, Rochford, Worden, and Benford (1986) to be one of the goals of framing analysis. The PEW survey that included references to the Abu Ghraib visual materials is such an 
example (May, 2004), with respondents clearly influenced by the images and evaluating the arch of the war negatively because of them. Experimental models to evaluate the effects of images on publics with differing interests and stakes in a war will be crucial to an understanding of how the lack of propositional syntax in visual communication affects publics. Future research could also target the effect of grisly photography as it relates to war vs. natural disaster to assess whether the impact of this type of photography is related to qualitative aspects of the photography or to values associated with who or what is responsible for the represented tragedy or catastrophe. 


\section{References}

Abdul-Ahad, G., Alford, K., Anderson, T., \& Leistner, R. (2005). Unembedded: Four independent photojournalists on the war in Iraq. White River Junction, VT: Chelsea Green.

Allan, S., \& Zelizer, B. (2003). Rules of engagement: Journalism and war. In S. Allan \& B. Zelizer (Eds.), Reporting war: Journalism in wartime (pp. 3-21). Oxfordshire, UK: Routledge.

American Psychological Association. (2009). Publication manual of the American Psychological Association (6th ed.). Washington, DC: Author.

Andsager, J. L. (2000). How interest groups attempt to shape public opinion with competing news frames. Journalism \& Mass Communication Quarterly, 77(3), 577-592.

Baudrillard, J. (2012). The Gulf War did not take place. (P. Patton, Trans.). Sydney, AU: Power Publications. (Original work published 1991).

Bennett, W. L., \& Iyengar, S. (2008). A new era of minimal effects? The changing foundations of political communication. Journal of Communication, 58, 707-731. doi:10.1111/j.1460-2466.2008.00410.x

Bock, A., Isermann, H., \& Kneiper, T. (2011). Quantitative content analysis of the visual. In E. Margolis \& L. Pauwels (Eds.), The Sage handbook of visual research methods (pp. 265-282). Los Angeles, CA: Sage.

Boorstin, D. (1992). The image: A guide to pseudo-events in America. New York, NY: Vintage.

Borah, P. (2009). The visual framing of the Indian Ocean tsunami and hurricane Katrina. Newspaper Research Journal, 30(1), 50-57.

Carpenter, S. (2007). U.S. elite and non-elite newspapers' portrayal of the Iraq war: A comparison of frames and source use. Journalism and Mass Communication Quarterly, 84(4), 761-776.

Carragee, K. M., \& Roefs, W. (2004). The neglect of power in recent framing research. Journal of Communication, 54(2), 214-233. 
CBS News. (2005). World War II Casualties. Retrieved from: http://www.cbsnews.com/elements/2005/05/06/in_depth_world/frameset693544.s html

Chong, D., \& Duncan, J. N. (2007). Framing theory. Annual Review of Political Science, 10, 103-26. doi:10/1146/annurev.polisci.10.072805.103054

Chong, D., \& Druckman, J. N. (2011). Strategies of counter-framing. Retrieved from: http://papers.ssrn.com/sol3/papers.cfm?abstract_id=1912083

Coleman, C., Hartley, H., \& Kennamer, J. D. (2006). Examining claimsmakers' frames in news coverage of direct-to-consumer advertising. Journalism and Mass Communication Quarterly, 83(3), 549-564.

Conetta, C. (2003). Iraqi combatant and noncombatant fatalities in the 2003 conflict (Research Monograph No. 8). Retrieved from Project on Defense Alternatives website: http://www.comw.org/pda/fulltext/0310rm8.pdf

Conetta, C. (2005). Vicious circle: The dynamics of occupation and resistance in Iraq Part one. Patterns of popular discontent (Research Monograph No. 10). Retrieved from Project on Defense Alternatives website http://www.comw.org/pda/fulltext/0505rm10.pdf

Cook, F., Tyler, T., Goetz, E., Gordon, M., Protess, D., Lef, D., \& Molotch, H. (1983). Media and agenda setting effect on the public, interest group leaders, policy markers, and policy. Public Opinion Quarterly, 47, 6-35.

Creative Research Systems. (2012). Sample size calculator. Retrieved from http://www.surveysystem.com/sscalc.htm

Culler, J. (1997). Literary theory: A very short introduction. Oxford, UK: Oxford University Press.

Dake, D. (2005). Aesthetics theory. In K. Smith \& S. Moriarty (Eds.), Handbook of visual communication: Theory, methods and media (p. 11). Mahwah, NJ: Erlbaum.

D’Angelo, P. (2002). News framing as a multiparadigmatic research program: A response to Entman. Journal of Communication, 52(4), 870-888.

Entman, R. (1993). Framing: Toward clarification of a fractured paradigm. Journal of Communication, 43(4), 51-58. 
Fahmy, S., \& Johnson, T. (2005). "How we performed": Embedded journalists' attitudes and perceptions towards covering the Iraq war. Journalism \& Mass Communication Quarterly, 82(2), 301-317.

Fahmy, S. (2007). They took it down: Exploring determinants of visual reporting in the toppling of the Saddam statue in national and international newspapers. Mass Communication and Society, 10(2), 143-170.

Fahmy, S., \& Kim, D. (2008). Picturing the Iraq war: Constructing the image of war in the British and US Press. International Communication Gazette, 70(6), 443-462. doi:10.177/1748048508096142

Field, A. (2009). Discovering statistics using SPSS (3rd ed.). London, UK: Sage.

Foucault, M. (1988). Practicing criticism. In L. Kritzman (Ed.), Foucault, politics, philosophy, culture (pp. 152-156). New York, NY: Routledge. (Original work published 1981).

Freelon, D. (2012). ReCal: Reliability calculator for the masses. Retrieved from: http://dfreelon.org/utils/recalfront/

Frosh, P. (2001). The public eye and the citizen-voyeur: Photography as a performance of power. Social Semiotics, 11(1), 1470-1219. doi:10.1080/10350330120010957

Gamson, W., Croteau, D., Hoynes, W., \& Sasson, T. (1992). Media images and the social construction of reality. Annual Review Social, 18, 373-393.

Gamson, W., \& Modigliani, A. (1989). Media discourse and public opinion on nuclear power: A constructionist approach. American Journalist Society, 95(1), 1-37.

Gardner, T. N. (2008). War as a mediated narrative: The sextet of war rhetoric. In T. Conroy \& J. Hanson (Eds.), Constructing America's war culture: Iraq, media, and images at home (pp. 107-125). Lanham, MD: Lexington Books.

Gowing, N. (2003). Journalists and war: The troubling new tensions post 9/11. In D. K. Thussu \& D. Freedman (Eds.), War and the media (pp. 231-240). London, UK: Sage.

Griffin, M., \& Lee, J. (1995). Picturing the Gulf War: Constructing an image of war in Time, Newsweek, and U.S. News and World Report. Journalism and Mass Communication Quarterly, 72(4), 813-825. 
Griffin, M. (2004). Picturing America's "war on terrorism" in Afghanistan and Iraq. Journalism, 5(4), 381-402. doi:10.1177/1464884904044201

Griffin, M. (2010). Media images of war. Media, War \& Conflict, 3(1), 7-41. doi:10.1177/1/1750635210356813

Hall, S. (1974). Media power: The double bind. Journal of Communication, 24(4), 19-26.

Hallin, D. C. (1986). The “uncensored war:” The media and Vietnam. Berkeley, CA: University of California Press.

Hallin, D. C., \& Gitlin, T. (1993). Agon and ritual: The Gulf War as popular culture and as television drama. Political Communication, 10, 411-424.

Hirschman, C., Preston, S., \& Loi, V. M (1995). Vietnamese casualties during the American war: A new estimate. Population and Development Review, 21(4), 783812. Retrieved from: http://www.jstor.org/stable/2137774

Hoyt, M., \& Palattella, J. (2007). Reporting Iraq: An oral history of the war by the journalists who covered it. Hoboken, NJ: Melville House Publishing.

Huff Post Media. (2011). The biggest news magazines of 2010 by circulation. Audit Bureau of Circulation (2010). Retrieved 11.06.2011 from: http://www.huffingtonpost.com/2010/08/12/the-biggest-newsmagazine_n_680468.html\#s126026\&title=4_The_New

Iraq Body Count. (2012). Civilian deaths by violence. Retrieved from Iraq Body Count: http://www.iraqbodycount.org/database/

Iyengar, S. (1991). Is anyone responsible? How television frames political issues. Chicago, IL: University of Chicago Press.

Kaplan, F. (2007). Who disbanded the Iraqi army? And why was nobody held accountable. Slate. Retrieved 06.18.2012 from: http://www.slate.com/articles/news_and_politics/war_stories/2007/09/who_ disbanded_the_iraqi_army.html

Keith, S., Schwalbe, C. B., \& Silcock, B. W. (2010). Comparing war images across media platforms: Methodological challenges for content analysis. Media, War \& Conflict, 3, 87-98. doi:10.1177/175063521353676 
King, C., \& Lester, P. L. (2005). Photographic coverage during the Persian Gulf and Iraqi wars in three U. S. newspapers. Journalism \& Mass Communication Quarterly, 82(1), 623-637.

Kobré, K. (2008). Photojournalism: The professionals' approach (6th ed.). Amsterdam, Netherlands: Focal Press.

Krippendorff, K. (2004). Content analysis: An introduction to its methodology (2nd ed.). Thousand Oaks, CA: Sage.

Kuypers, J. \& Cooper, S. (2005). A comparative framing analysis of embedded and behind the lines reporting on the 2003 Iraq war. Qualitative Research Reports in Communication, 6(1), 1-10.

Lakoff, G. (1996). Moral politics: How liberals and conservatives think. Chicago, IL: University of Chicago Press.

Leland, A., \& Oboroceanu, M-J. (2010). American war and military operations casualties: Lists and statistics. Congressional Research Service: Report for congress. Retrieved from: http://www.fas.org/sgp/crs/natsec/RL32492.pdf

Lewis, S., \& Reese, S. D. (2009). What is the war on terror?: Framing through the eyes of journalists. Journalism and Mass Communication Quarterly, 86(1), 85-102.

Lombard, M., Snyder-Duch, J., \& Campanella Bracken, C. (2010). Practical resources for assessing and reporting intercoder reliability in content analysis projects. Retrieved from: http://astro.temple.edu/ lombard/reliability/

Major, L. H., \& Perlmutter, D. (2005). The fall of a pseudo icon: The toppling of Saddam Hussein's statue as image management. Visual Communication Quarterly, 12(12), 38-45. doi:10.1080/15551393.2005.9687441.

McGirk, T. (2006, March 27). One morning in Haditha. Time, 167, 34-36.

McGreal, C. (Feb. 13, 2012). Obama's proposed budget trims little from Pentagon spending. The Guardian. U.S. Edition Retrieved from: http://www.guardian.co.uk/world/2012/feb/13/obama-budget-cuts-pentagonspending

McQuail, D. (2010). McQuail's mass communication theory. Los Angeles, CA: Sage. 
Mintz, A., \& Redd, S. (2004). Framing effects in international relations, Synthese, 135, 193-213.

Moeller, S. D. (1989). Shooting war: Photography and the American experience of combat. New York, NY: Basic Books.

Molotch, H., \& Lester, M. (1975). Accidental news: The great oil spill as local occurrence and national event. American Journal of Sociology, 81(2), 235-260.

Neuendorf, K. A. (2002). The content analysis guidebook. Thousand Oaks, CA: Sage.

Neuman, W. R., Just, M. R., \& Crigler, A. N. (1992). Common knowledge: News and the construction of political meaning. Chicago, IL: University of Chicago Press.

Newton, J. H. (2001). The burden of visual truth: The role of photojournalism in mediating reality. Mahwah, NJ: Lawrence Erlbaum.

Nöth, W. (2011). Visual semiotics: Key features and an application to picture ads. In E. Margolis \& L. Pauwels (Eds.), The Sage handbook of visual research methods (pp. 298-316). Los Angeles, CA: Sage.

Olk, B., \& Kappas, A. (2011). Eye tracking as a tool for visual research. (In E. Margolis \& L. Pauwels (Eds.), The Sage handbook of visual research methods (pp. 433451). Los Angeles, CA: Sage.

Ott, B., Aoki, E., \& Dickinson, G. (2011). Ways of (not) seeing guns: Presence and absence at the Cody Firearms Museum. Communication and Critical/Cultural Studies, 8(3), 215-239. doi:10.1080/14791420.2011.594068.

Pan, Z., \& Kosicki, G. (2001). Framing as a strategic action in public deliberation. In S. Reese, O. Gandy, Jr., \& A. Grant (Eds.), Framing public life: Perspectives on media and our understanding of the social world (pp. 35-66). Mahwah, NJ: Lawrence Erlbaum.

Pan, Z., Ostman, R. E., Moy, P., \& Reynolds, P. (1994). News media exposure and its learning effects during the Persian Gulf War. Journalism Quarterly, 71(1), 7-19.

Pennebaker, J.W., Chung, C.K., Ireland, M., Gonzales, A., \& Booth, R.J. (2007). The development and psychometric properties of LIWC2007. [Software manual]. Austin, TX (www.liwc.net) 
Perlmutter, D. (1992). The vision of war in high school social science textbooks. Communication, 13, 143-160.

Perlmutter, D. (1998). Photojournalism and foreign policy: Icons of outrage in international crises. Westport, CT: Praeger.

PEW Research Center. (May, 2004). Iraq prisoner scandal hits home, but most reject troop pullout. Retrieved from: http://www.people-press.org/2004/05/12/iraqprison-scandal-hits-home-but-most-reject-troop-pullout/1/

PEW Research Center's Project for Journalism Excellence. (March 15, 2005). 2005 Annual report: Newspaper public attitudes. Retrieved from: http://www.journalism.org/node/1417

PEW Research Center. (July, 2005). Republicans uncertain on Rove resignation. Retrieved from: http://www.people-press.org/2005/07/19/republicans-uncertainon-rove-resignation/

PEW Research Center. (December, 2007). Iraq portrait: How the press has covered events on the ground. Retrieved from: http://pewresearch.org/pubs/665/iraqportrait-how-the-press-has-covered-events- on-the-ground

Pfau, M., Haigh, M., Gettle, M., Donnelly, M., Scott, G., Warr, D., \& Wittenberg, E. (2005). Embedding journalists in military combat units: Impact on newspaper story frames and tone. Journalism \& Mass Communication Quarterly, 81(1), 7488 .

Price, V., Tewksbury, D., \& Powers, E. (1997). Switching trains of thought: The impact of news frames on readers' cognitive responses. Communication Research, 24(5), 481-506.

Reese, S. D., \& Lewis, S. C. (2009). Framing the "War on Terror": The internalization of policy in the U.S. Press, Journalism, 10(6), 777-797. doi: $10.1177 / 1464884909344480$

Riffe, D., Lacy, S., \& Fico, F. (2005). Analyzing media messages: Using quantitative content analysis in research. New York, NY: Routledge.

Rose, G. (2006). Visual methodologies: An introduction to the interpretation of visual methodologies. London, UK: Sage. 
Scheufele, B. (2004). Framing effects approach: A theoretical and methodological critique. Communications, 29, 401-428.

Shoemaker, P. J., \& Reese, S. D. (1996). Mediating the message: Theories of influences on mass media content. White Plains, NY: Vintage Books.

Smith, K. (2005). Perception and the Newspaper Page: A critical analysis. In S. Moriarty, G. Barbatsis, \& K. Kenney (Eds.). Handbook of visual communication: Theory, methods and media (pp. 81-95). Mahwah, NJ: Erlbaum.

Smith, K., Moriarty, S., Barbatsis, G., \& Kenney, K. (2005). Handbook of visual communication: Theory, methods and media. Mahwah, NJ: Erlbaum.

Snow, D., Rochford, E. B., Worden, S., \& Benford, R. (1986). Frame alignment processes, micromobilization, and movement participation. American Sociological Review, 51, 464-481.

Sontag, S. (1973). On photography. New York, NY: Picador.

Sontag, S. (2002, December). Looking at war: Photography's view of devastation and death. The New Yorker. Retrieved from: http://www.newyorker.com/archive/2002/12/09/021209crat_atlarge

Sontag, S. (2003). Regarding the pain of others. New York, NY: Picador.

Tankard, J. W. (2001). The empirical approach to the study of media framing. In S. Reese, O. Gandy, Jr., \& A. Grant (Eds.), Framing public life: Perspectives on media and our understanding of the social world (pp. 95-106). Mahwah, NJ: Lawrence Erlbaum.

Tannen, D. (1993). Framing in discourse. New York, NY: Oxford University Press.

Tee, E. (2011). Tim Page: "Every war picture becomes an anti-war picture." CNN International. Retrieved from http://www.cnngo.com/singapore/life/tim-pageevery-good-war-picture-becomes-anti-war-picture-712463

Thussu, D. K. (2003). Live TV and bloodless deaths: War, infotainment and 24/7 news. In D. K. Thussu \& D. Freedman (Eds.), War and the media (pp. 117-132). London, UK: Sage.

Thompson, J. (1990). Ideology and modern culture: Critical social theory in the era of mass communication. Stanford, CA: Stanford University Press. 
Tuchman, G. (1978). Making news: A study in the construction of reality. New York, NY: Free Press.

Tversky, A., \& Kahneman, D. (1981). The framing of decisions and the psychology of choice. Science, 221(4481), 453-458.

Urbaniak, G. C., \& Pious, S. (2008). Research randomizer: Social Psychology Network. Retrieved from: http://www.randomizer.org/form.htm

U. S. Department of Defense. (2003). Public Affairs guidance (PAG) on embedding media during possible future operations/deployments in the U.S. central commands (Centcom) area of responsibility (AOR). Retrieved from: http://www.defense.gov/news/feb2003/d20030228pag.pdf

U.S. Department of Defense. (2012). Operation Iraqi freedom (OIF) U.S. casualty status fatalities as of: May 4, 2012, 10 a.m. EDT. Retrieved from: http://www.defense.gov/news/casualty.pdf

Wagner, J. (2011). Visual studies and empirical social inquiry. In E. Margolis \& L. Pauwels (Eds.), The Sage handbook of visual research methods (pp. 49-69). Los Angeles, CA: Sage.

Wanta, W., \& Fahmy, S. (2005). What photojournalists think others think: The visual coverage of the 9/11 attacks \& the Afghan war. Conference Paper: International Communication Association Annual Meeting. New York, NY.

Weber, C. (2003). The media, the "war on terrorism" and the circulation of nonknowledge. In D. K. Thussu \& D. Freedman (Eds.), War and the media (pp. 191-199). London, UK: Sage.

Zelizer, B. (2004). When war is reduced to a photograph. In S. Allan \& B. Zelizer (Eds.), Reporting war: Journalism in wartime (pp. 115-135). Oxfordshire, UK: Routledge.

Zelizer, B. (2010). About to die: How news images move the public. New York, NY: Oxford University Press. 


\section{Appendix A: Coding Categories}

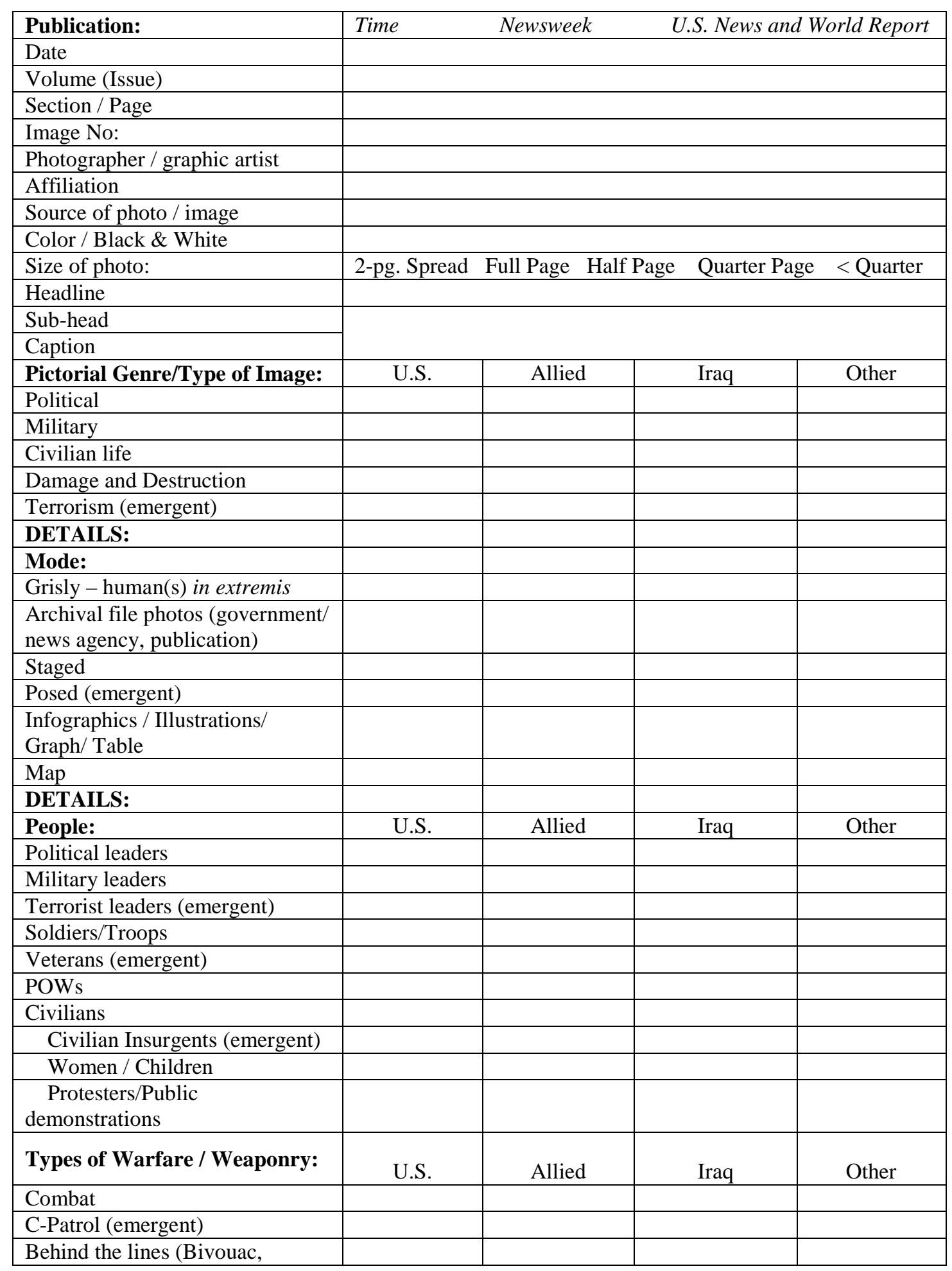




\begin{tabular}{|l|l|l|l|l|}
\hline practice) & & & \\
\hline "Cataloging the Arsenal" & & & \\
$\begin{array}{l}\text { Jets/helicopters/ } \\
\text { Humvees/Tanks/Naval vessels, } \\
\text { missiles }\end{array}$ & & & & \\
\hline Drones & & & & \\
\hline Casualties: & U.S. & Allied & Iraq & Other \\
\hline Political wounded (emergent) & & & & \\
\hline Political dead (emergent) & & & & \\
\hline Military wounded & & & & \\
\hline Military dead & & & & \\
\hline Civilian wounded & & & & \\
\hline Civilian dead & & & & \\
\hline Terrorist wounded (emergent) & & & & \\
\hline Terrorist dead (emergent) & & & & \\
\hline $\begin{array}{l}\text { Ceremonial (funerals, dress } \\
\text { uniform) }\end{array}$ & & & & \\
\hline \multicolumn{1}{|c|}{ Coffins } & & & & \\
\hline Destruction: & U.S. & Allied & Iraq & \\
\hline Infrastructure & & & & \\
\hline Oil and energy & & & & \\
\hline Ecological subjects & & & & \\
\hline Misc. Emergent Categories: & U.S. & & & \\
\hline Political Misconduct & & & & \\
\hline Military Misconduct & & & & \\
\hline Political - Guantanamo & & & & \\
\hline
\end{tabular}




\section{Appendix B: Codebook}

\section{Coding Protocols}

Coding Unit

The coding unit is one photograph

Context Unit

Name of publication (Time, Newsweek, U.S. News and World Report)

\section{Categories}

\section{The primary researcher will complete the information below:}

Date Published

Date of the magazine edition, usually on the front cover. Format: Month.Day.Year $\mathrm{xx} / \mathrm{xx} / \mathrm{xx}$

Volume/ (Issue) The newsmagazine Volume and Issue numbers will be noted.

Page No.

The newsmagazine page number on which the image appears.

Image No.

Each photograph/image will be assigned a number before coders come into contact with the coding document.

Photographer $\quad$ Name of the photographer (if listed)

Affiliation Name of the wire services, staff photographer or media corp. Please note if this information is not available with NA.

Source of Photo Name of the source of the photo. Same as above unless noted as archival or image from different source such as Getty Images, US Government./Military, Defense Contractor (Raytheon, McDonnell Douglas), etc.

Color Black \& White

Note whether a photograph is in color or black and white with the designation $\mathrm{C}$ or $\mathrm{B} / \mathrm{W}$.

Size of Photo

The dimensions of the photograph as follows:

2-pg. spread / full / half / quarter / < quarter

Headline

Note the exact wording in the headline of the article. 
Subheading Note the exact wording in the subhead of the article.

Caption Note the exact wording of the caption accompanying the image.

Coders: $\quad$ Please code a genre and as many details per photo as seem appropriate.

If there is a photograph that you find particularly interesting, please feel free to note your impressions somewhere on the coding sheet.

Type of Image (Pictorial Genre)

Genre Codes: $\quad$ Each photograph or image will usually have a focus that allows it to be categorized as a certain genre.

One of the genre codes can usually be assigned to that photograph. For example: A photograph that shows President Bush on a battleship would only be coded as "political leader" and not additionally for the battleship or the troops that might be watching the speech. It is clear from the centrality of President Bush's placement, that he is the subject of the photograph.

If an image is "political" and also a mode code "archival" image, please check both of those codes.

Detail Codes Each photograph or image will also have details that should be noted. See codes below: mode, people, cataloging the arsenal, casualties, and destruction/damage. 


\section{Genre Codes}

Political

Military

Wartime Civilian

Life
A type of image whose focus is on political issues dealing with the war and also political leaders. For example: indicted political players, or political leaders meeting dignitaries, giving a speech, getting in a car or out of a helicopter, attending a meeting, etc. Please differentiate between whether those pictured are: U.S., Allied, or Iraqi political leaders and the name of the leader (if known).

Leaders that are not allied leaders, such as Gerhard Schröder of Germany, or Jacques Chirac of France, should be listed under "Other." If they are all in the same picture together, then list everyone that is in the photograph.

There might be some questions regarding whether to code Colin Powell as military or political. In this case, during the War in Iraq, Colin Powell was a political appointee and therefore should be coded as political.

Likewise, Donald Rumsfeld, although he was Secretary of Defense and oversaw the Pentagon, was a political appointee and therefore should be coded as a political leader.

A type of photograph that centers on military activity.

This code also include leaders such as generals in the field or behind the scenes. Please differentiate between U.S., Allied, and Iraqi, or Other military leaders. Fill in a name if known or available.

Chairman of the Joint Chief of Staff and other such officers, although they are political appointees, are advisors because they have risen through the ranks of the military. Such advisors should be coded as military.

A type of photo that documents everyday life in Iraq or in America or its Allies' home countries. For example, people going to work, school, church or mosque, et cetera. 
This should NOT include images of civilians being detained or questioned by troops (which should be coded as military). While this questioning or searching someone's home does "happen" during wartime, it is not a daily occurrence for the civilian population. I am more interested in documenting whether photographs of people going to work/school or carrying on with their lives are reflected in the corpus of photographs.

Protesters should not be included in this group.

Damage and

Destruction

Terrorism
A type of image whose focus is the destruction of infrastructure: buildings, mosques, resources (oil/water/food), bridges, et cetera.

A type of photograph that centers on terrorist activity and/or leaders as identified by the media. This category should not include civilian insurgents in Iraq despite their use of terrorist tactics.

\section{Detail Codes}

In addition to a genre code there will be details in the photograph that will be subcategories of the genre.

\section{Mode}

Grisly

A type of image that shows human(s) in extremis: distressed, wounded, or dead soldiers or civilians. Again, please differentiate between U.S., Allied, or Iraqi soldiers or civilians and if a face is visible or a name published.

Archival File Photos A type of image used to illustrate something in the article, but does not necessarily depict action on the ground in Iraq. It could be from a previous war, or be of training going on in the US from a different war. The main point is that the photo was not taken close to the time it was published.

Posed:

A type of image that is posed as in portraiture. A designation as posed should not carry any negative connotation. Images of this sort could occur in any genre. Politicians and military leaders might be posed for a portrait for the cover of a magazine and 
Staged:

Infographic, Illustration

Map

A type of image that shows the territory in which the war is taking place, or the relationship between different groups, such as Sunnis, Shi'ites, Kurds, et cetera.

\section{People}

Political Leaders

Political leaders of the U.S., Iraq, or Allied countries (see here: http://en.wikipedia.org/wiki/Multi-National_Force_-_Iraq

Military Leaders

Persons identifiable as a military leader through recognition, caption, or text. Please write down the name of the military leader.

Terrorist Leaders Usually internationally active individuals that use tactics of terror, such as suicide bombings to attain political aims (This definition is used in full recognition of the difficulty and ambiguity of this term). Typically it is used to designate individuals whose political aims are not allied with a particular state, but are more ideological in nature. 
Soldiers/Troops An individual or group of soldier(s) or pilot(s) is pictured. Typically even a single soldier can be referred to in the plural as "troops."

POWs

Combatants that have been detained, shown captured, whether on the battlefield or detained somewhere else. If they are detained somewhere else, key words used might be "extraordinary rendition" or simply "rendition." Again, please differentiate between U.S., Allied, or Iraqi combatants.

Civilians Any person pictured and not connected to the military. Again, please differentiate between U.S., Allied, Iraqi, or Other civilians.

Civilian Insurgents Iraqi civilians (Sunni and/or Shi'ite, aka Shia) that used guerilla tactics to fight against the change in power structure after the democratic elections. Often these tactics target other Iraqi civilians, civilian police, or U.S. armed forces.

Veterans

U.S. veterans from former or current wars that are pictured regarding veteran benefits, future plans, healing, adjusting to civilian life, honoring other soldiers, running for political office, et cetera.

Protesters Images that show civilians protesting against the war from any country. Please indicate from which county.

Women and/or Any photograph in which women and/or children are the main Children focus of the image. Again, please differentiate between U.S., Allied, or Iraqi women and/or children.

\section{Types of Warfare and Weaponry}

Combat

A type of image that shows soldiers in direct active combat with the enemy.

It should not include practicing behind the lines, which sometimes can look like active combat. Again, please differentiate between U.S., Allied (which ally), Iraqi, or Other combatants. 
C-Patrol

Behind the lines

Weaponry/Arsenal

Jets/ Helicopters

Humvees/Tanks

Naval Vessels

Missiles/ IEDs/

Electronic

explosive devices

Drones

\section{Casualties}

Political Wounded Photographs that include political individuals injured in the performance of their duties. Please differentiate between U.S., Allied, Iraqi, or Other politicians.

Political Dead

Military Wounded

A designation as C-patrol should include soldiers on patrol, advancing in the theater of operations, searching residences, or individuals.

Again, please differentiate between U.S., Allied (which ally), or Iraqi combatants.

A type of image that documents soldiers behind the lines, relaxing, exercising, training for combat, playing sports, et cetera.

This category is meant to keep track of images that seem to list or "promote" the extensive firepower of the U.S. military. It is NOT meant to include every instance in photographs or images that include a tank or airplane.

Graphic images/drawings, photographs or diagrams in which the subject of the image is jets, airplanes, helicopters, humvees tanks, naval vessels, missiles, IEDs, EEDs, et cetera.

Graphic images/drawings, photographs or diagrams in which the subject of the image is drones used to deliver missiles, bombs or surveillance technology.

Photographs that include political individuals who were assassinated or died in the performance of their duties or because of their political role. Please differentiate between U.S., Allied, Iraqi, or Other individuals.

Photographs that include soldiers injured on the battlefield or recovering in a hospital. If in a hospital, please indicate where the 
hospital is located and please differentiate between U.S., Allied, Iraqi, or Other soldiers.

Military Dead Photographs that include dead soldiers in the field, in a morgue, in a hospital, or represented by a funeral, casket, or symbolic representations such as family photographs, et cetera. Please note in the space provided whether the face is visible or covered and whether the body is exposed (naked) or not. Please differentiate between U.S., Allies, Iraqi, or insurgent, or Other dead.

Civilian Wounded Photographs that include injured civilians. Civilians are usually referred to as "collateral damage," civilians, or some indication that the subject of the photograph is not a member of military personnel. The exception to this designation will be civilian insurgents. Please note whether the pictured wounded are civilians and/or civilian insurgents.

Civilian Dead

Photographs that include dead civilians in a hospital, morgue, at a funeral, or on the street. Please note in the space provided whether the face is visible or covered and whether the body is exposed (naked) or not. This detail code will include civilian insurgents usually designated as such in the caption. Please make a note that those pictured are insurgents.

Terrorist wounded Photographs that include injured terrorists, or those identified as terrorists by the media.

Terrorist dead Photographs that include dead terrorists, or those identified as terrorists by the media. This will include representative photographs. Please note in the space provided whether the face is visible or covered.

Ceremonial A type of photo that documents ceremonies such as military honors, funerals, in Iraq or in America or its Allies' home countries.

Also include the implied dead such as pictures of people grieving or pictures of coffins/graves. Please note that death is implied and how. Please differentiate between U.S., Allied, Iraqi civilians, or other (specify). 
From approximately 2004-2007, an Iraqi insurgency against coalition forces took place. Iraqis that collaborated with the U.S., such as police, were a prominent target, leading to large numbers of Iraqi civilian deaths.

\section{Destruction and Damage}

War Damage Images that show the destruction of government buildings and hospitals; cultural landmarks such as museums and mosques, destruction of neighborhoods and interruptions of activities of daily living such as going to school or work.

Oil and Energy Images that show the destruction of oil fields, reserves, et cetera.

Ecological Subjects Images that show the destruction of agriculture, water, environment, and/or animals.

\section{Emergent Categories}

If, while coding, you notice a category or a detail that you believe needs to be added to the code sheet, please contact me via email and we can discuss it with all coders and come to a consensus about what code to use for those types of images/details. Sometimes there will be details that can simply be added to the codes already assigned by adding it to the code area already supplied.

\section{Coding Decisions}

Some of the photographs will include elements that suggest two genres. For instance, you might be coding a photograph that has 3 soldiers driving in a tank. You might wonder if you should code for both of those categories. The answer is NO. Very likely the main focal point of the photograph is the soldiers. You would then code it as "military" and would not code it for the vehicle. However, there might be a photograph of an aircraft carrier taken from a distance with troops lined up in formation on the deck. The prominence of the aircraft carrier and the relative diminutive nature of the troops should lead you to code the photograph as "naval vessel." If however, you judge that the reason the photograph is taken from a distance is to show the size of a battalion, then it would be coded for troops. Sometimes the caption will indicate how the photograph should be read.

If, while coding, two genres seem relevant to a coding unit, please make your best decision and clarify why you feel that decision outweighs coding in another genre. Make 
a note of your second choice of genre. If continual questions arise, please contact me so that coding instructions can be clarified, or additional training and examples can be given.

\section{Coding Questions}

Coding questions or the application of a new emergent code will be resolved by finding consensus between all coders. If the questions are the result of instructions regarding the coding or categories, the codebook will be revised and further training provided. 


\section{Appendix C: Tables}

Table 3

Intercoder Agreement per Category Using Cohen's Kappa

\begin{tabular}{lcccc}
\hline Category & Total Agreement & Coder $\mathbf{1 ~ \& ~ 3}$ & Coder 1 \& 2 & Coder 2 \& 3 \\
\hline & & & & \\
Genre: & & & & \\
Political-U.S. & 0.975 & 1.000 & 0.962 & 1.000 \\
Political-Allied & 0.333 & 0.000 & 1.000 & 0.000 \\
Political-Iraq & 0.822 & 0.826 & 0.850 & 0.774 \\
Political-Other & 0.775 & 0.663 & 1.000 & 0.663 \\
Military-U.S. & 0.847 & 0.902 & 0.845 & 0.793 \\
Military-Allied & 1.000 & 1.000 & 1.000 & 1.000 \\
Military-Iraq & 0.363 & 0.387 & 0.387 & 0.315 \\
Civilians-U.S. & 0.534 & 0.558 & 0.658 & 0.387 \\
Civilians-Iraq & 0.785 & 0.762 & 0.854 & 0.738 \\
Terrorism-Iraq & 0.130 & 0.000 & 0.391 & 0.000 \\
Terrorism-Other & 0.827 & 1.000 & 0.741 & 0.741 \\
Destruction-Iraq & 0.923 & 0.884 & 1.000 & 0.884 \\
Destruction-Other & 1.000 & 1.000 & 1.000 & 1.000 \\
$\quad$ Genre Subtotal & $\mathbf{0 . 7 2 0}$ & $\mathbf{0 . 6 9 0}$ & $\mathbf{0 . 8 2 0}$ & $\mathbf{0 . 6 4 0}$ \\
& & & & \\
Mode: & & & & \\
Archival-U.S. & 0.779 & 0.799 & 0.673 & 1.000 \\
Archival-Iraq & 0.164 & 0.000 & 0.493 & 0.000 \\
Info-graphics-U.S. & 0.826 & 0.741 & 0.853 & 0.884 \\
Info-graphics-Iraq & 0.749 & 0.741 & 0.653 & 0.853 \\
Map-Iraq & 0.815 & 0.741 & 0.853 & 0.853 \\
\multicolumn{1}{c}{ Mode Subtotal } & $\mathbf{0 . 6 7 0}$ & $\mathbf{0 . 6 0 0}$ & $\mathbf{0 . 7 1 0}$ & $\mathbf{0 . 7 2 0}$ \\
& & & & \\
People: & & & & \\
Political leader-U.S. & 1.000 & 1.000 & 1.000 & 1.000 \\
Political leader-Iraq & 0.815 & 0.865 & 0.847 & 0.731 \\
Political leader-Other & 0.662 & 0.493 & 1.000 & 0.493 \\
Military leader-U.S. & 1.000 & 1.000 & 1.000 & 1.000 \\
Terrorist-Other & 0.775 & 0.663 & 1.000 & 0.663 \\
Soldiers/Troops-U.S. & 0.905 & 1.000 & 0.976 & 0.856 \\
Soldiers/Troops-Allied & 1.000 & 1.000 & 1.000 & 1.000 \\
Soldiers/Troops-Iraq & 0.707 & 0.560 & 0.560 \\
Soldiers/Troops-Other & 1.000 & 0.000 & 1.000 & 1.000 \\
Combat-U.S. & 0.827 & 0.904 & 0.741 & 0.741 \\
C-Patrol-U.S. & 0.713 & 0.582 & 0.653 \\
C-Patrol-Iraq & 0.769 & 0.658 & 0.853 & 0.796 \\
Grisly-U.S. & 0.660 & 0.490 & 0.491 \\
Grisly-Iraq & 0.975 & 0.962 & 1.000 \\
Behind-the-Lines-U.S. & 0.775 & 0.663 & 1.000 \\
& & &
\end{tabular}


Table 3

Intercoder Agreement per Category using Cohen's Kappa (continued)

\begin{tabular}{|c|c|c|c|c|}
\hline Category & Average Agreement & Coder $1 \& 3$ & Coder $1 \& 2$ & Coder $2 \& 3$ \\
\hline \multicolumn{5}{|l|}{ People: } \\
\hline Behind-the-Lines-Allied & 1.000 & 1.000 & 1.000 & 1.000 \\
\hline Veterans-U.S. & 1.000 & 1.000 & 1.000 & 1.000 \\
\hline P.O.W.-Iraq & 0.936 & 0.904 & 0.904 & 1.000 \\
\hline Civilian life - Iraq & 0.850 & 0.780 & 0.890 & 0.879 \\
\hline Civilian life-Other & 0.775 & 0.663 & 1.000 & 0.663 \\
\hline Insurgents-Iraq & 0.826 & 0.884 & 0.853 & 0.741 \\
\hline Protesters-Iraq & 1.000 & 1.000 & 1.000 & 1.000 \\
\hline Protesters-Other & 1.000 & 1.000 & 1.000 & 1.000 \\
\hline Women \& Children-U.S. & 0.864 & 0.796 & 1.000 & 0.796 \\
\hline Women \& Children-Iraq & 0.884 & 0.960 & 0.826 & 0.865 \\
\hline People Subtotal & 0.870 & 0.880 & 0.890 & 0.830 \\
\hline \multicolumn{5}{|l|}{ Arsenal: } \\
\hline Cataloging the Arsenal-U.S. & 0.902 & 0.853 & 0.853 & 1.000 \\
\hline Drones-U.S. & 1.000 & 1.000 & 1.000 & 1.000 \\
\hline Arsenal Subtotal & 0.950 & 0.930 & 0.930 & 1.000 \\
\hline \multicolumn{5}{|l|}{ Casualties: } \\
\hline Political Dead-Iraq & 1.000 & 1.000 & 1.000 & 1.000 \\
\hline Military Wounded-U.S. & 0.826 & 0.884 & 0.741 & 0.853 \\
\hline Military Dead-U.S. & 0.936 & 1.000 & 0.904 & 0.904 \\
\hline Military Dead-Iraq & 1.000 & 1.000 & 1.000 & 1.000 \\
\hline Civilian Wounded-Iraq & 0.902 & 0.853 & 1.000 & 0.853 \\
\hline Civilian Wounded-Other & 0.333 & 0.000 & 0.000 & 1.000 \\
\hline Civilian Dead-Iraq & 0.776 & 0.790 & 0.884 & 0.653 \\
\hline Civilian Dead-Other & 1.000 & 1.000 & 1.000 & 1.000 \\
\hline Ceremonial-U.S. & 0.864 & 1.000 & 0.796 & 0.796 \\
\hline Coffins-U.S. & 1.000 & 1.000 & 1.000 & 1.000 \\
\hline Coffins-Iraq & 0.333 & 0.000 & 1.000 & 0.000 \\
\hline Casualty Subtotal & 0.820 & 0.780 & 0.850 & 0.820 \\
\hline \multicolumn{5}{|l|}{ Damage \& Destruction: } \\
\hline Destruction-U.S. & 1.000 & 1.000 & 1.000 & 1.000 \\
\hline Destruction-Iraq & 1.000 & 1.000 & 1.000 & 1.000 \\
\hline Destruction-Other & 1.000 & 1.000 & 1.000 & 1.000 \\
\hline Damage Subtotal & 1.000 & 1.000 & 1.000 & 1.000 \\
\hline \multicolumn{5}{|l|}{ Emergent Categories } \\
\hline Military Misconduct-U.S. & 0.940 & 0.910 & 1.000 & 0.910 \\
\hline Emergent Subtotal & 0.940 & 0.910 & 1.000 & 0.910 \\
\hline Total Reliability & 0.856 & 0.830 & 0.890 & 0.850 \\
\hline
\end{tabular}


Table 4

Statistical Significance of Iraq War Categorical Relationships

\begin{tabular}{llll}
\hline Category & $\mathrm{n}=356$ & $\mathrm{df}=1$ & Chi Square $^{*}$ \\
\hline
\end{tabular}

U.S. Political Leader / U.S. Military $\quad .783$

U.S. Political Leader / U.S. Military Leaders $\quad .536$

\begin{tabular}{ll} 
U.S. Political Leader / U.S. Troops & .378 \\
\hline
\end{tabular}

U.S. Political Leader / U.S. Behind the lines troops $\quad .137$

U.S. Political Leader / U.S Combat $\quad .378$

U.S. Political Leader / U.S. Combat Patrol

U.S. Political Leader / U.S. Military Wounded $\quad .277$

U.S. Political Leader / U.S. Military Dead $\quad .313$

U.S. Political Leader / U.S. Veteran $\quad .783$

U.S. Political Leader / U.S. Military Misconduct $\quad .294$

U.S. Political Leader / U.S. Armaments $\quad .313$

$\begin{array}{ll}\text { U.S. Political Misconduct / U.S. Military } & .879\end{array}$

U.S. Political Misconduct / U.S. Military Leaders $\quad .733$

U.S. Political Misconduct / U.S. Troops $\quad .627$

U.S. Political Misconduct / U.S. Behind the Lines Troops $\quad .412$

U.S. Political Misconduct / U.S. Combat $\quad .627$

U.S. Political Misconduct / U.S. Combat Patrol $\quad .345$

U.S. Political Misconduct / U.S. Military Wounded $\quad .549$

U.S. Political Misconduct / U.S. Military Dead $\quad .578$

U.S. Political Misconduct / U.S. Veteran $\quad .879$

U.S. Political Misconduct / U.S. Military Misconduct $\quad .563$

U.S. Political Misconduct / U.S. Armaments $\quad .578$

U.S. Protesters / U.S. Military $\quad .915$

U.S. Protesters / U.S. Military Leaders $\quad .810$

U.S. Protesters / U.S. Troops $\quad .732$

U.S. Protesters / U.S. Behind the Lines Troops $\quad .564$

U.S. Protesters / U.S. Combat $\quad .732$

U.S. Protesters / U.S. Combat Patrol $\quad .507$

U.S. Protesters / U.S. Military Wounded

U.S. Protesters / U.S. Military Dead $\quad .695$

U.S. Protesters / U.S. Veteran $\quad .915$

U.S. Protesters / U.S. Military Misconduct $\quad .684$

U.S. Protesters / U.S. Armaments $\quad .695$

U.S. Political Guantanamo / U.S. Military $\quad .896$

U.S. Political Guantanamo / U.S. Military Leaders $\quad .786$

\footnotetext{
${ }^{*}$ Note. All calculations based on $\mathrm{n}=356$ and $\mathrm{df}=1$. All Chi Square calculations are not significant (n.s.) unless marked with an asterisk $(*)$ indicating values $<.05$, thus significant.
} 
Table 4

Statistical Significance of Iraq War Categorical Relationships

U.S. Political Guantanamo / U.S. Behind the Lines Troops

\begin{tabular}{lr} 
U.S. Political Dead / U.S. Military & .958 \\
\hline
\end{tabular}

U.S. Political Dead / U.S. Military Leaders $\quad .905$

U.S. Political Dead / U.S. Troops $\quad .865$

U.S. Political Dead / U.S. Behind the lines troops $r .774$

U.S. Political Dead / U.S. Combat $\quad .865$

$\begin{array}{lr}\text { U.S. Political Dead / U.S. Combat Patrol } & .741\end{array}$

U.S. Political Dead / U.S. Military Wounded $\quad .834$

U.S. Political Dead / U.S. Military Dead $\quad .845$

$\begin{array}{lr}\text { U.S. Political Dead / U.S. Veterans } & .958\end{array}$

U.S. Political Dead / U.S. Military Misconduct $\quad .839$

$\begin{array}{lr}\text { U.S. Political Dead / U.S. Armaments } & .845\end{array}$

$\begin{array}{lr}\text { U.S. Political Leader / Iraq Political } & .354\end{array}$

U.S. Political Leader / Iraq Political Leader $\quad .218$

\begin{tabular}{lr} 
U.S. Political Leader / Iraq Protesters & .697 \\
\hline .783
\end{tabular}

U.S. Political Leader / Iraq Political Dead $\quad .783$

$\begin{array}{lr}\text { U.S. Political Leader / Iraq Political Misconduct } & .580\end{array}$

$\begin{array}{lr}\text { U.S. Political Misconduct / Iraq Political } & .609\end{array}$

U.S. Political Misconduct / Iraq Political Leader $\quad .497$

U.S. Political Misconduct / Iraq Protesters $\quad .830$

U.S. Political Misconduct / Iraq Political Dead $\quad .879$

$\begin{array}{lr}\text { U.S. Political Misconduct / Iraq Political Misconduct } & .760\end{array}$

$\begin{array}{lr}\text { U.S. Protesters / Iraq Political } & .719\end{array}$

U.S. Protesters / Iraq Political Leader $\quad .633$

U.S. Protesters / Iraq Protesters $r$

U.S. Protesters / Iraq Political Dead $\quad .915$

$\begin{array}{lr}\text { U.S. Protesters / Iraq Political Misconduct } & .830\end{array}$ 
Table 4

Statistical Significance of Iraq War Categorical Relationships

Category

$n=356$

$\mathrm{df}=1$

Chi Square*

U.S. Political Guantanamo / Iraq Political

U.S. Political Guantanamo / Iraq Political Leader

U.S. Political Guantanamo / Iraq Protesters

.853

U.S. Political Guantanamo / Iraq Political Dead

.897

U.S. Political Guantanamo / Iraq Political Misconduct

U.S. Political Dead / Iraq Political

U.S. Political Dead / Iraq Political Leader

U.S. Political Dead / Iraq Protesters

U.S. Political Dead / Iraq Political Dead

U.S. Political Dead / Iraq Political Misconduct

Allied Political Leader / Iraq Political

Allied Political Leader / Iraq Political Leader

Allied Political Leader / Iraq Protesters

Allied Political Leader / Iraq Political Dead

Allied Political Leader / Iraq Political Misconduct

Allied Protesters / Iraq Political

Allied Protesters / Iraq Political Leader

Allied Protesters / Iraq Protesters

Allied Protesters / Iraq Political Dead

Allied Protesters / Iraq Political Misconduct

U.S. Military / Iraq Military

U.S. Military / Iraq Troops

U.S. Military / Iraq Patrol

U.S. Military / Iraq Insurgents

U.S. Military / Iraq POW

U.S. Military / Iraq Arsenal

U.S. Military / Iraq Military Misconduct

U.S. Military Leader / Iraq Military

U.S. Military Leader / Iraq Troops

U.S. Military Leader / Iraq Patrol

U.S. Military Leader / Iraq Insurgents

U.S. Military Leader / Iraq POW

U.S. Military Leader / Iraq Arsenal 
Table 4

Statistical Significance of Iraq War Categorical Relationships

U.S. Behind the Lines / Iraq Military

U.S. Behind the Lines / Iraq Troops

U.S. Behind the Lines / Iraq Patrol

U.S. Behind the Lines / Iraq Insurgents

U.S. Behind the Lines / Iraq POW

U.S. Behind the Lines / Iraq Arsenal

U.S. Behind the Lines / Iraq Military Misconduct

U.S. Combat / Iraq Military

U.S. Combat / Iraq Troops

U.S. Combat / Iraq Patrol

U.S. Combat / Iraq Insurgents

U.S. Combat / Iraq POW

U.S. Patrol / Iraq Military

U.S. Patrol / Iraq Troops

U.S. Patrol / Iraq Patrol

U.S. Patrol / Iraq Insurgents

U.S. Military Wounded / Iraq Military 
Table 4

Statistical Significance of Iraq War Categorical Relationships

U.S. Military Misconduct / Iraq Military

U.S. Military Misconduct / Iraq Troops

U.S. Military Misconduct / Iraq Patrol

U.S. Military Misconduct / Iraq Insurgents

U.S. Military Misconduct / Iraq POW

.839

U.S. Military Misconduct / Iraq Arsenal

U.S. Military Misconduct / Iraq Military Misconduct

U.S. Armaments / Iraq Military

U.S. Armaments / Iraq Troops

U.S. Armaments / Iraq Patrol

U.S. Armaments / Iraq Insurgents

U.S. Armaments / Iraq POW

.845

U.S. Armaments / Iraq Arsenal

U.S. Armaments / Iraq Military Misconduct

Allied Patrol / Iraq Military

.958

Allied Patrol / Iraq Troops

.940

Allied Patrol / Iraq Patrol

.958

Allied Patrol / Iraq Insurgents

.852

Allied Patrol / Iraq POW

.958

Allied Patrol / Iraq Arsenal

Allied Patrol / Iraq Military Misconduct

Allied Behind the Lines / Iraq Military

Allied Behind the Lines / Iraq Troops

Allied Behind the Lines / Iraq Patrol

Allied Behind the Lines / Iraq Insurgents

Allied Behind the Lines / Iraq POW

Allied Behind the Lines / Iraq Arsenal

Iraq Military / Iraq Civilians

Iraq Military / Iraq Civilian Wounded

Iraq Military / Iraq Civilian Dead

Iraq Troops / Iraq Civilians

Iraq Troops / Iraq Civilian Dead

Iraq Patrol / Iraq Civilians 
Table 4

Statistical Significance of Iraq War Categorical Relationships

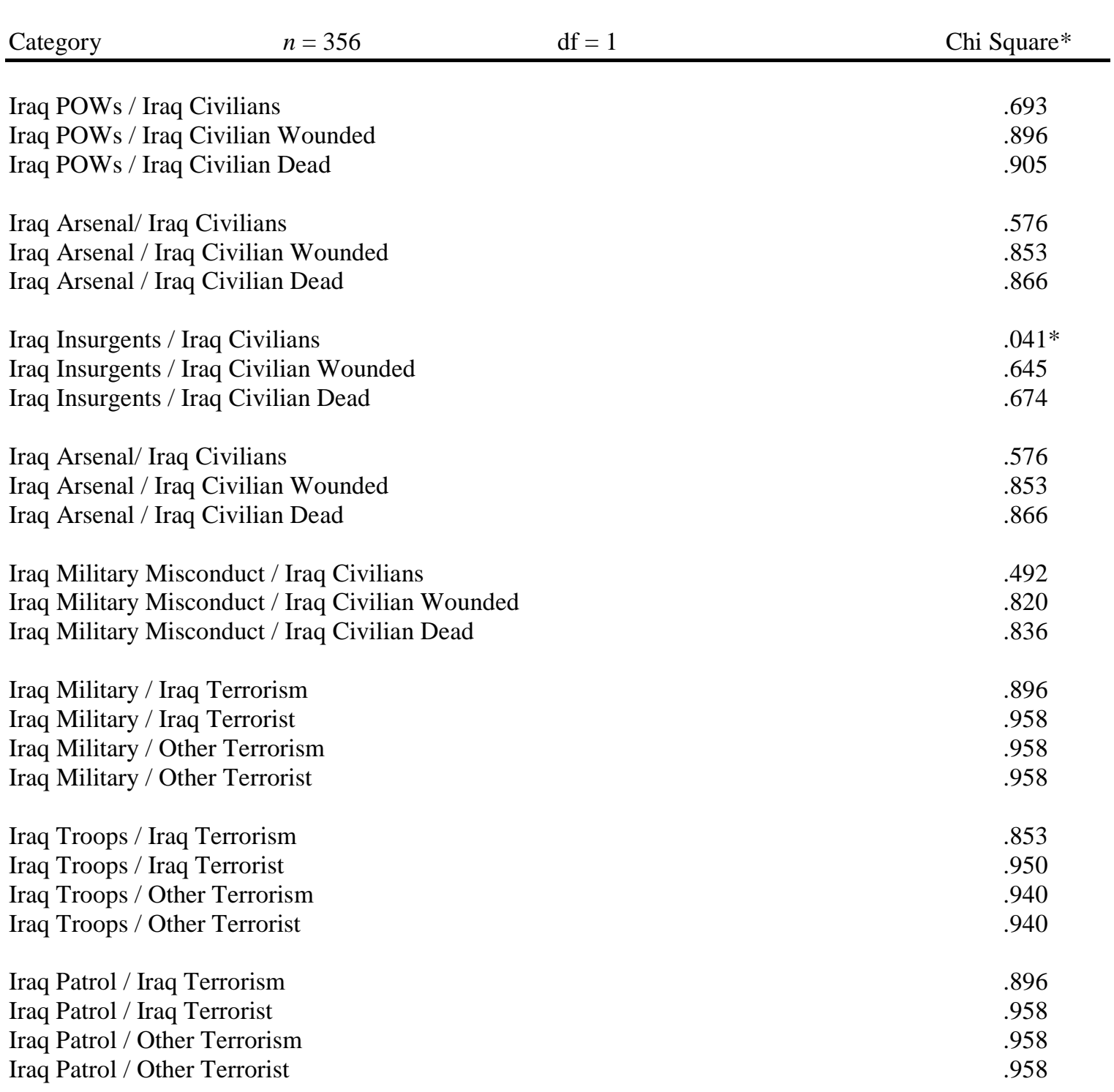


Table 4

Statistical Significance of Iraq War Categorical Relationships

Category

Iraq Insurgents / Iraq Terrorism

Iraq Insurgents / Iraq Terrorist

Iraq Insurgents / Other Terrorism

Iraq Insurgents / Other Terrorist

Iraq POWs / Iraq Terrorism

Iraq POWs / Iraq Terrorist

Iraq POWs / Other Terrorism

Iraq POWs / Other Terrorist

Iraq Arsenal / Iraq Terrorism

Iraq Arsenal / Iraq Terrorist

Iraq Arsenal / Other Terrorism

Iraq Arsenal / Other Terrorist

Iraq Military Misconduct / Iraq Terrorism

Iraq Military Misconduct / Iraq Terrorist

Iraq Military Misconduct / Other Terrorism

Iraq Military Misconduct / Other Terrorist

Destruction U.S. / Destruction Iraq

Destruction U.S. / Destruction Oil

Destruction Other / Destruction Iraq

Destruction Other / Destruction Oil

U.S. Military Misconduct / U.S. Military

U.S. Military Misconduct / U.S. Military Leader

U.S. Military Misconduct / U.S. Troops

U.S. Military Misconduct / U.S. Behind the Lines

U.S. Military Misconduct / U.S. Combat

U.S. Military Misconduct / U.S. Patrol

U.S. Military Misconduct / U.S. Military Wounded

U.S. Military Misconduct / U.S. Military Dead

U.S. Military Misconduct / U.S. Armaments $\mathrm{df}=1$

Chi Square*

.645

.852

.000

.852

.896

.958

.958

.958

.853

.940

.940

.940

.820

.926

.926

.926

.725

.926

.684

.915

.839

.649

.516

.274

.516

.207

.423

.457

.457 
Table 5

High Frequency Categories in Gulf War Pictures in Newsmagazines ${ }^{2}$

\begin{tabular}{lrr}
\hline Category / Genre & Images & Percent \\
\hline Arsenal (U.S., Allied) & 249 & $23 \%$ \\
Troops (Noncombat-U.S., Allied) & 158 & $14 \%$ \\
Political Leaders (U.S.: Bush) & 80 & $7 \%$ \\
Military Leaders (U.S.) & 59 & $5 \%$ \\
Political Leaders (Iraq: Hussein) & 47 & $4 \%$ \\
Arsenal (Iraq) & 40 & $4 \%$ \\
Combat (All nations) & 38 & $3 \%$ \\
Destruction (Iraq) & 37 & $3 \%$ \\
Media (U.S.) & 36 & $3 \%$ \\
Civilian life (U.S.) & 36 & $3 \%$ \\
POWs (U.S.-Allied) & 32 & $3 \%$ \\
Historical Photos & 31 & $3 \%$
\end{tabular}

2 Table from Griffin and Lee's study published in 1995. 
Table 6

Low Frequency Categories in Gulf War Pictures in Newsmagazines ${ }^{3}$

\begin{tabular}{|c|c|c|}
\hline Category / Genre & Images & Percent \\
\hline Military Casualties & 27 & $2 \%$ \\
\hline Damage and Destruction (Saudi Arabia, Kuwait) & 27 & $2 \%$ \\
\hline Prisoners of War (Iraqi) & 22 & $2 \%$ \\
\hline Political Leaders (Arab world, excluding Iraq) & 19 & $2 \%$ \\
\hline Public Demonstrations (U.S.) & 19 & $2 \%$ \\
\hline War Time Civilian Life (Kuwait) & 19 & $2 \%$ \\
\hline Oil and Energy & 15 & $1 \%$ \\
\hline Public Demonstrations (Arab) & 14 & $1 \%$ \\
\hline Political Leaders (Soviet, Iranian, Chinese, U.N.) & 13 & $1 \%$ \\
\hline Civilian Casualties (Iraqi) & 13 & $1 \%$ \\
\hline Ecological Subjects & 12 & $1 \%$ \\
\hline Palestinian Leaders, Activists, Protesters & 10 & $1 \%$ \\
\hline War Time Civilian Life (Iraqi) & 8 & $1 \%$ \\
\hline War Inflicted Damage and Destruction (Israel) & 7 & $.6 \%$ \\
\hline Civilian Casualties (Saudi, Kuwaiti, Israel) & 6 & $.5 \%$ \\
\hline Military Casualties (Iraqi) & 6 & $.5 \%$ \\
\hline Troops (Iraqi) & 5 & $<.5 \%$ \\
\hline Wartime Civilian Life (Israel and Occupied Territory) & 5 & $<.5 \%$ \\
\hline Iranian Activists or Protesters & 4 & $<.5 \%$ \\
\hline Wartime Civilian Life (Saudi Arabia) & 2 & $<.5 \%$ \\
\hline Public Demonstrations (Other Allied) & 1 & $<.5 \%$ \\
\hline Military Casualties (Saudi, Egyptian, British, French) & 1 & $<.5 \%$ \\
\hline Military Leaders (Iraqi) & 0 & $0 \%$ \\
\hline Other & 7 & $.6 \%$ \\
\hline
\end{tabular}

3 Table from Griffin and Lee's study published in 1995. 